DIW BERLIN

Discussion Papers

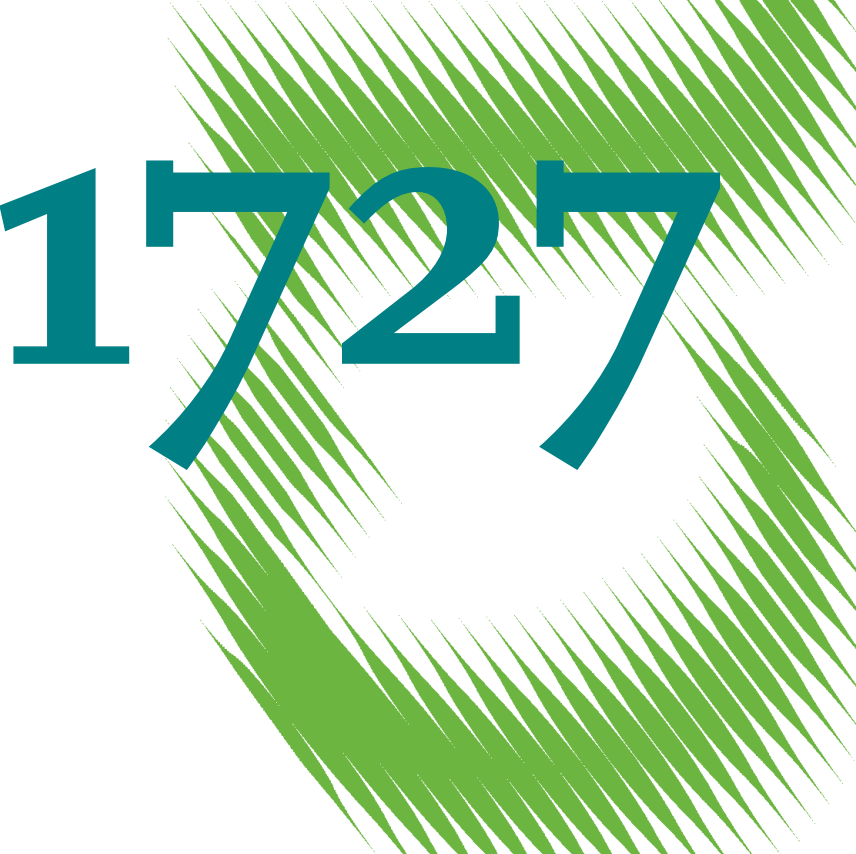

Measuring Stick-Style Housing Policies: A Multi-country Longitudinal Database of Governmental Regulations 
Opinions expressed in this paper are those of the author(s) and do not necessarily reflect views of the institute.

IMPRESSUM

(C) DIW Berlin, 2018

DIW Berlin

German Institute for Economic Research

Mohrenstr. 58

10117 Berlin

Tel. +49 (30) $89789-0$

Fax +49 (30) $89789-200$

http://www.diw.de

ISSN electronic edition 1619-4535

Papers can be downloaded free of charge from the DIW Berlin website:

http://www.diw.de/discussionpapers

Discussion Papers of DIW Berlin are indexed in RePEc and SSRN:

http://ideas.repec.org/s/diw/diwwpp.html

http://www.ssrn.com/link/DIW-Berlin-German-Inst-Econ-Res.html 


\title{
Measuring stick-style housing policies: \\ A multi-country longitudinal database of governmental regulations ${ }^{\text {th }}$
}

\author{
Konstantin A. Kholodilin ${ }^{\mathrm{a}, \mathrm{b}}$ \\ ${ }^{a}$ DIW Berlin, Mohrenstraße 58, 10117, Berlin, Germany \\ ${ }^{b}$ NRU HSE, Kantemirovskaya ul., 3, korp. 1, lit. A, 194100, St. Petersburg, Russia
}

\begin{abstract}
This paper introduces a new international longitudinal database of governmental housing policies. The regulations are measured using binary variables based on a thorough analysis of the real-time country-specific legislation. Three major restrictive policies are considered: rent control, protection from restriction, and housing rationing. The database covers 47 countries and states between 1910 and 2018. This allows comparisons of regulation stringency across both time and space. The analysis reveals a surge of all restrictive policies in the first half of the 20th century. However, following World War II, the evolution of policies diverged: while rent control became more flexible or was phased out, tenure security stabilized at a high level or even increased, while housing rationing became used less frequently. An application of dynamic multivariate longitudinal clustering permits dividing the sample in two groups. One cluster comprises countries with more flexible rent control, stronger tenure security, and more housing rationing. It mostly includes European continental countries. Another cluster unifies countries with a more rigid rent control, weaker tenant protection, and rarely used housing rationing.
\end{abstract}

Keywords: regulation indices, rent control, tenure security, housing rationing. JEL codes: C43, O18, R38.

\footnotetext{
This study is partly supported by Luxembourg University. This paper is written as a part of the "HOUSREG-Housing Regulation in Europe" research project supported by Luxembourg University. We thank Espen Andersen, Philip Ando, Andrés Blanco Blanco, Emily Dix, Christian Enzer, Christoph Enzler, Hildur Gróa Gunnarsdóttir, Kari Gyllander, Alejandro Jacobo Ostapchuk, Jakob Juul-Sandberg, Annika Klintefelt, Sebastian Kohl, Julien Licheron, Mette Lindbjerg Jørgensen, Dimitrios Moschos, Peter Nägele, Mounira Nouri, Maja Pindstrup, Yulia Prozorova, Kua Hui Shan, Dmitriy Shevyakov, and Jón Rúnar Sveinsson for their kind help in finding the statistical data and legal acts. We also are grateful for comments by the participants of the workshop of the Macroeconomic department of the DIW Berlin and the seminar of the Department of Quantitative Methods for Economics and Business at the Universidad de Murcia, which took place on February 12 and March 1, 2018, respectively, where some results of this study were presented.
} 



\section{Contents}

1 Introduction 1

2 Housing policy 2

2.1 Stimulating tools of housing policy . . . . . . . . . . . . . . . . . 3

2.2 Restrictive tools of housing policy . . . . . . . . . . . . . . . . . . . 4

2.3 Other policies affecting housing market . . . . . . . . . . . . . . . . 10

3 Approaches to measuring housing policy 11

3.1 Existing approaches . . . . . . . . . . . . . . . . . . . 11

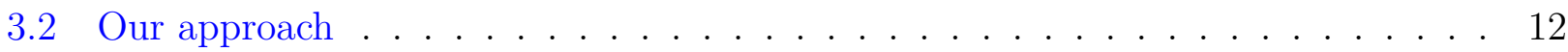

4 Descriptive analysis of housing policy indices $\quad 15$

4.1 Worldwide and continent-specific perspectives . . . . . . . . . . . . . . . 15

4.2 Dynamic multivariate cluster analysis . . . . . . . . . . . . . . . . . . 18

4.3 Robustness check . . . . . . . . . . . . . . . . . . . 18

5 Concluding remarks $\quad 19$

$\begin{array}{lr}\text { Literature } & 20\end{array}$

$\begin{array}{lr}\text { Appendix } & 26\end{array}$ 


\section{List of Tables}

1 Literature on measurement of housing regulations . . . . . . . . . . . . 26

2 Country-specific studies on housing regulations . . . . . . . . . . . . . . 26

3 List of countries, for which regulation indices are constructed . . . . . . . . . . 28

4 Rent control . . . . . . . . . . . . . . . . . . . . . 29

5 Tenure security . . . . . . . . . . . . . . . . . . . . . . . . . . . . 29

6 Housing rationing . . . . . . . . . . . . . . . . . . 30

7 List of legal acts used in the analysis . . . . . . . . . . . . . . . . . 30

8 Composition of clusters . . . . . . . . . . . . . . . . . . 64

9 Correlation between our and alternative indices . . . . . . . . . . . . . . 64

\section{List of Figures}

1 Existence of rent control . . . . . . . . . . . . . . . . . . 65

2 Housing policy tools . . . . . . . . . . . . . . . . 66

$3 \quad$ Number of legal acts regulating housing market by country . . . . . . . . . . 67

4 Countries covered by this study . . . . . . . . . . . . . . . . . . 68

5 Evolution of distribution of the housing regulations intensity . . . . . . . . . 69

6 Rent control intensity by continents . . . . . . . . . . . . . . . . . 70

7 Generations of rent control by continent . . . . . . . . . . . . . . 71

8 Tenure security intensity by continents . . . . . . . . . . . . . . . . . 72

9 Housing rationing intensity by continents . . . . . . . . . . . . . . 73

10 Cluster-based trajectories of housing regulation intensity . . . . . . . . . . . 74

11 Alternative housing policy indices . . . . . . . . . . . . . . . 75 


\section{Introduction}

Housing is one of the most important aspects of the human life. It is also one of the heavily regulated sectors. Since World War I, in most countries, the government actively intervenes in the housing market trying to correct the actually existing or imaginary market failures. For example, as seen in Figure 1, virtually all countries had or still have rent controls. Currently, the re-introduction of rent control is discussed in some countries (e.g., Hong Kong, ${ }^{1}$ Malta, ${ }^{2}$ and the $\mathrm{USA}^{3}$ ). Thus, that housing market regulations played an important role, is not just historical fact, it remains present reality.

While, in order to achieve its goals, the government uses various combinations of carrots and sticks, here we concentrate only on stick policies. In particular, we examine the three restrictive housing market regulations of rent control, protection of tenants from eviction, and housing rationing. Being ubiquitous and often used at a large scale, these policies can affect various aspects of the housing market and of the whole economy. These can influence housing prices and rents, the choice between the rental and own housing, residential construction, accumulation of wealth, as well as residential mobility. Indirectly, they can contribute to the buildup of speculative price bubbles and unemployment persistence. The assessment of their effects can be largely facilitated by the creation of the indices quantifying the degree of stringency of such governmental interventions. Therefore, the purpose of this study is to develop a multi-country, multi-period, database of housing market regulations. The corresponding restrictive housing market policies are approximated by a set of indices based on a thorough analysis of all the relevant legislation issued in 47 countries (at the national or state level) between 1910 and 2018. This is a unique data set in terms of its spatio-temporal coverage and the scope of regulations it considers.

This study has several important advantages. First, it covers a very long period of time, which is important, given long-lasting effects of governmental regulations upon markets, especially housing markets where a very durable good is traded. Second, it uses a wide panel of countries from all the continents and takes advantage of a large variety of socio-economic and

\footnotetext{
${ }^{1}$ Choi (2017).

${ }^{2}$ Personal communication of Kurt Xerri on February 21, 2018.

${ }^{3}$ Axel-Lute (2017).
} 
cultural conditions as well as historical paths. In a causal regression analysis, panel data allow accounting for unobservable country-specific effects and, thus, alleviating the possible omitted variable bias.

Three words of caution should be issued. First, this study focuses mainly on national level regulations. In the case of federal, like Canada, Mexico, and the USA, where provinces and states play an important role in determining housing policy, regional regulations are also taken

into account. However, municipal policies are not measured here. Second, apart from being written in an undecipherable juridical jargon, the legal acts are very complex due to numerous exceptions, procedural details, and cross-references. Hence, any attempt to map them into a set of measurable variables implies that a balance must be struck between the simplicity of the mapping (coding) and the feasibility of the whole task. In other words, the coding should be not oversimplified, while allowing regulation indices to be built within weeks instead of years. Third, the regulation indices introduced here measure what is written in the legal acts, not their enforcement. In order to account for the effectiveness of the legislation in each country, institutional knowledge of experienced practitioners is needed. Even if we gain access to such knowledge by interviewing practitioners, it will be limited to, at most the last 30 years of their working life; thus, it is not possible to gauge the degree that laws were enforced in more distant past.

The paper is organized as follows. The next section describes the tools of housing policy in both narrow and wide senses. In section 3, the existing approaches to measuring housing market regulation indices are discussed and our approach to the regulation index construction is explained. In section 4, an exploratory analysis of our regulation indices is carried out. The evolution of the three restrictive policies worldwide and at the continent level is investigated. Moreover, the countries are categorized by clusters and the cluster-specific dynamics are examined. Finally, section 5 concludes the study.

\section{Housing policy}

Housing policy, in a wide sense, can be defined as the set of all measures applied by a government in order to affect housing market performance. The main purpose of such interventions is to provide people with affordable housing that simultaneously must satisfy certain 
quality standards. Apart from this, the government can pursue additional purposes: political stability, competitiveness of the domestic economy, and even stimulation of industrialization. For instance, during the interwar period, housing rents in Germany were restricted in order to moderate the workers' wage increase requests and to make, as a result, domestic products less expensive. In the 1920s, the Brazilian authorities sought to increase investments in manufacturing by discouraging real estate investments, which were highly profitable at that time. Eventually, through rent control, authorities managed to reduce this profitability, thus making investments in the manufacturing sector relatively more profitable (Bonduki 1994, p. 717).

Governments can take advantage of a large variety of tools in order to regulate housing markets; see Figure 2 for a schematic representation of housing policies. The instruments of housing policy, in a narrow sense, can be classified as either stimulating or restrictive. Stimulating housing policies come in two forms: object aid, which helps with residential (social) construction, and subject aid, which assists the tenants through housing allowances. The restrictive measures encompass rent control, protection of tenants from eviction, and housing rationing. Each of these tools is examined in more detail below.

\subsection{Stimulating tools of housing policy}

Stimulation of residential construction. The main purpose of this type of housing policy is to expand the supply of housing, in particular cheap homes. The rising supply should make housing more affordable. Other purposes are also pursued. It is, for example, a creation of a strong class of owners who are resistant against the communist propaganda, like in West Germany during the Cold War. Especially in aging societies, the purpose of simulating policies is often the accumulation of wealth to provide for old age. Support of families, improvement of housing conditions, and fostering the economy through construction industry, among others, are also the goals of stimulating housing policy, see Haas (2018). The policy of stimulating residential construction includes the following instruments:

- provision of state aid in form of construction subsidies and low or zero interest loans;

- provision of the state credit guarantees;

- reduction of the taxes and fees (particularly, land stamp duty); and 
- provision of building land at lower prices or in form of a long-term leasing.

Using such instruments, the state intends to foster residential building and provide in the first place the low-income households with an affordable housing. This housing - sometimes called social housing - can be both rental and owner-occupied. Sometimes (for example, in Spain in the 1940-1970s) the state builds the rental housing that is later to be purchased by the tenants afterward. In Iceland in the 1930-1970s, social workers' houses were predominantly built as owner-occupied ones; see Sveinsson (2004). The rent in social housing is subject to restrictions and is typically set at the level of the construction and operation costs plus a moderate markup representing a "fair profit" for the landlord. Admittance as a tenant in social housing requires proving that you have a low enough income. However, once moved in, tenant income is practically never tested. As a result, households with increased income keep occupying social housing, even though they are formally no longer eligible for it. For this reason, many low-income persons cannot gain access to social housing. The problem is that both verifying the income levels of households living in social housing and carrying out evictions are too costly. By decreasing its efficiency, this is one of the main disadvantages of social rental housing.

Housing allowances. These are state subsidies paid to low-income households or, sometimes, directly to their landlords (for example, in the USA, where this aid is known as housing vouchers). The idea is to cover a part of the housing costs of such households in order to permit them to live in appropriate conditions. This policy can be considered to be an alternative or a complement to social housing policy. In this case, the means testing can be conducted on a continuous basis, with housing allowances adjusted in accordance with the changing income of the household. It is also a more flexible form of aid, since it allows the households to choose the dwelling where they would like to live more freely. A big disadvantage of such a policy is its inflationary effect: especially in the housing market, with its rigid short-run supply, an increase in demand will immediately lead to rising rents and prices.

\subsection{Restrictive tools of housing policy}

Protection of tenants from eviction. The purpose of this restrictive policy is to reduce eviction risks for the tenants. Prior to World War I, in most countries the corresponding 
legislation was very liberal. The relations between landlord and tenants were regulated mainly by their rental contract. The contracts could have a definite or indefinite duration. If the contract duration was definite, then after it was over, the landlord could evict the tenant without any formalities. During the contract term, the eviction could normally happen only if the tenant violated certain conditions indicated in the contract or in the civil code. One such eviction reason could be a delayed payment of rent.

At that time, contracts, as a rule, were short term, typically up to one year. Under normal conditions, this did not cause too many problems for the tenants. However, in the extraordinary situations, such as wars, revolutions, natural catastrophes, etc., which led to an acute housing shortage, a loss of housing due to eviction could result in a homelessness. Therefore, when faced with such situations, almost everywhere policy makers started introducing the following limitations to make the eviction of tenants more difficult:

- automatic prolongation of the existing contracts upon their expiration, sometimes indefinitely, sometimes for a short period, which was, however, steadily extended in each new legal act;

- prohibition for the landlords to break rental contracts, except for a more or less clearly identified set of reasons: e.g., non-payment of rent; urgent need of the landlord or his relatives to move into the dwelling occupied by the tenant; negligent treatment of the housing by the tenant; his unacceptable behavior with respect to other tenants or the owner; etc.

Among all housing policy instruments, the protection of tenants from eviction turned out to be the most durable. During the first decades after its introduction, it was considered an emergency measure called into existence by extreme circumstances. However, it later became strongly rooted in legislation and in people's mind. In part, it is related to the fact that it does not require any direct manipulation of market prices, unlike rent control policy. An important advantage of this policy is that it makes the rental relation more stable. Its pitfall is that it makes it more difficult to evict bad-faith tenants, thereby decreasing the attractiveness of investments in the housing sector. Therefore, for example, in Germany with its strong eviction protection, a tenant-occupied dwelling offered for sale is worth substantially less than 
an identical vacant dwelling; see Kholodilin et al. (2017).

Rent control. The main purpose of this policy is the protection of tenants from rental increases. When housing becomes scarce, rents start growing because, in the short run, which can last several years, it is impossible to extend housing supply quickly. As rent is one of the most important components of household expenditures (in different countries, the share of the housing expenses varies around 15-30\%), its increases strongly affect the purchasing power of the population.

Like many other instruments of the modern housing policy, rent control originated during World War I. ${ }^{4}$ By the beginning of the war, the vast majority of urban populations in Europe and North America were tenants. Mass mobilization converted them into a powerful force, meaning that the authorities had to respect their interests. Therefore, in order to avoid social turmoil, governments froze prices for basic consumption goods and services, including housing rents. Initially, this policy was thought to serve as an interim emergency measure, which could be removed as soon as the housing market returned to normality. ${ }^{5}$ Nevertheless, once put in place, rent control was prolonged many times, thus remaining in effect for many decades.

Rent control includes:

- rules regulating the setting of rent in newly concluded rental contracts (either for the very first time after the dwelling was completed or after the previous contract was over);

- rules regulating updating rent within the existing rental contracts;

- exceptions, which specify either housing not subject to the regulations or the segments of the housing market subject to stricter controls.

Researchers distinguish between first- and second-generation rent controls; see, for example, Arnott (2003). First-generation rent control implies a rent freeze, when the rent is fixed at some basic level. There are different ways of determining basic rent: 1) rent for this or similar dwellings at some date; typically, prior to some crucial event (e.g., a war) or at the date of

\footnotetext{
${ }^{4}$ Willis (1950) finds numerous examples of such policies in the more remote past. However, rent control did not have systematic and mass character that it acquired in the 20th century.

${ }^{5}$ In many countries, the legal acts stipulated that rent control should disappear 1-2 years after enactment or several months after the war ended.
} 
enactment of the corresponding legal act (e.g., in Germany, Poland, and Spain after WWI as well as on the territory of the former Russian Empire during WWI and Russian Civil War ${ }^{6}$ ); 2) certain percentage of the taxable (book) value of the dwelling (for instance, in Chile and Portugal); 3) absolute value (for example, in Italy and the USSR); or 4) value calculated by the local authorities depending on the structural and locational characteristics of the dwelling (e.g., in the USSR). ${ }^{7}$ Only governments could change the basic rent from time to time. It could not only be raised in order to cover at least a part of the growing expenses of the landlords, but also decreased in reaction to political or economic crises. The basic rent was reduced, for instance, in Chile in 1925 in reaction to a tenants strike, ${ }^{8}$ in Italy in 1927 and 1934, in Germany in 1931 as a result of the Great Depression, as well as in Poland in 1935. First-generation rent controls emerged during World War I and remained in force as late as the 1970s, when they started being replaced with second-generation rent controls; however, rent freezes are still used in some countries, especially developing ones.

Second-generation rent control implies a more or less free setting of rent when new contracts are concluded, but imposition of upper bounds on its growth rate within the existing contracts. The upper bound of rent growth can be the rate of increase of the consumer prices during the preceding year (e.g., in Colombia, Czech Republic, France, Italy, Poland, and Spain), mortgage interest rate (in Switzerland), or an index of government bonds (in Brazil). Sometimes, even under second-generation rent controls, the rent in the newly concluded contracts can be subject to limitations. For example, since 2015, in areas with an acute housing shortage in Germany, new rent cannot exceed the average market rent for similar dwellings in the same neighborhood by more than $10 \%$.

Rent control has both pros and cons. On the positive side, it makes dwellings more affordable for sitting tenants and exerts some anti-inflationary impact. The list of its pitfalls is longer. First, in case of a positive demand shock on the housing market, rent control slows the transition to the new equilibrium, as shown in Brueckner (2011), p. 141-143. Second, rent control causes the inefficient allocation of housing when sitting tenants stay put, even if their housing needs

\footnotetext{
${ }^{6}$ For an analysis of rent control acts in the former Russian Empire between 1918 and 1922 see Kholodilin (2017a).

${ }^{7}$ For an insightful discussion of the advantages and disadvantages of these methods see Willis (1949).

${ }^{8}$ Hidalgo Dattwyler (2003), p. 396.
} 
no longer match the quality and quantity of their present dwelling. Therefore, frequently there are large dwellings in inner cities that are occupied by older individuals who rent them cheaply, while big families occupy small, crowded dwellings and pay astronomical rents. Third, since it is impossible to legally raise rents, landlords look for workarounds. One widespread practice is, for instance, to force tenants to buy furniture left by the landlord or previous tenant for exorbitant prices. In some countries (for example, in Portugal prior to World War II), rent can be charged in a foreign currency and, being frozen nominally, can grow at the pace of devaluation of the domestic currency. Fourth, for the same reason, landlords can make repairs less frequently in an attempt to restore their rate of return by cutting their expenses. Fifth, keeping the rents artificially low also diminishes the incentives to invest in housing construction, as its rate of return decreases, given the constant rents against the background of other (consumer) prices rising almost without a limit. As a result, investors stop investing either into the housing sector in general, thus, accentuating the housing shortage, or, specifically, in the rental housing segment, which is replaced with owner-occupied housing. A conversion of dwellings into nonresidential premises (e.g., medical practices or lawyer offices) can also happen. Sixth, the wrongly shaped incentives can lead to paradoxical reactions. For example, in Chile in 1925, the owners of unhealthy dwellings were ordered to reduce the rent by $50 \%$ and freeze it at that level. As a result, some tenants started consciously degrading their dwellings in order to achieve an unhealthy state in order to obtain rent reductions! Finally, the prohibitions to freely increase rent not only reduce the revenue of the landlords, they also reduce tax revenues for the government.

Housing rationing. When there is an acute housing shortage, the government can impose measures like compulsory disposal of the housing in order to use fully the available housing stock. These measures include:

- registration of both dwellings and tenants in order to create a register of the available and becoming vacant dwellings as well as the creation of a waiting list for potential tenants;

- preservation of housing by banning the demolition of it or conversion of its use to nonresidential purposes (for example, as office space or holiday dwellings for tourists);

- redistribution of housing by putting new tenants into unused or underutilized housing; 
- setting the maximum housing consumption norms (for instance, the maximum floor area or number of rooms per person);

- mobility restrictions meaning the creation of obstacles to move into areas with an especially acute housing shortage, while facilitating migration to other areas;

- nationalization of private housing by transferring it into state property.

As shown, the rationing of housing implies that the government intends to manipulate both its supply and demand. The supply is protected or, to some extent, increased through a mobilization of the available premises (including non-residential ones that are appropriate for lodging) for their use as housing. At the same time, demand is reduced by limiting the freedom of mobility freedom and by setting low norms of housing consumption.

In its most extensive form, housing rationing was extensively employed in centrally planned economies, such as Czechoslovakia, Poland, and the USSR. However, it was also used in market economies, for example, in Germany, Italy, Luxemburg, Spain, Switzerland, and even the USA. Most frequently, such measures are used in extraordinary circumstances, when the housing stock is destroyed (e.g., due to the bombardments, earthquakes, or hurricanes) and cannot be quickly restored. After the market has stabilized, these measures are typically abrogated. Nevertheless, even during peaceful times, housing rationing can still be applied. One example is the interdiction against using dwellings for non-residential purposes or holiday dwellings (e.g., recent restrictions on the letting apartments through Airbnb ${ }^{9}$ ). In North America, prohibitions to demolish or convert rental residential properties into condominiums are also quite widespread. Such policies diminish the attractiveness of the housing sector for investors by increasing their risks. Hence, it can be expected that it will negatively affect housing supply.

The housing policy instruments described here are not usually applied individually, but rather in various combinations. Combined their effects are sometimes offset and sometimes mutually strengthen. For example, a simultaneous application of eviction and rent controls can substantially reduce incentives to increase the housing supply. Therefore, in order to compensate for this, the government can use housing rationing, which counteracts the reductions in

\footnotetext{
${ }^{9}$ For example, Lee (2016).
} 
housing supply to some extent. It can also apply measures that stimulate residential building, thus extending the housing stock through new construction.

\subsection{Other policies affecting housing market}

The above list is far from exhaustive. The decisions of economic agents concerning construction, as well as the choice between own and rented housing, are also affected by many other governmental regulations, including, for example, city planning, environmental, tax policies, and banking regulations.

City planning imposes constraints on the spatial distribution and density of housing construction. As shown in Hilber and Vermeulen (2016), land use regulation can reduce the price elasticity of housing supply. As a result, there will be lower supply at higher prices. Environmental policies that impose stricter requirements on newly built housing (obligatory use of solar batteries, heat insulation, and so on), can cause construction cost increases, thus increasing house prices and reducing the number of dwelling completions. Through tax policy, the state sets land stamp duty, taxes for the use and inheritance of housing, and provides tax reductions, for instance, by subtracting mortgage interest. In this way, it changes the relative cost of both own and rented housing, thus affecting the choice of a particular tenure form by making it more or less attractive from a financial point of view. In many countries, tax policy is biased toward homeownership. For example, in the Netherlands and the USA, interest payments are subtracted from taxable income; thus, making the purchase of own housing using borrowed money very attractive. This can lead to the emergence of speculative price bubbles in real estate markets; see Figari et al. (2017). As an offsetting measure, taxation of imputed

rent can be used. However, this instrument is rarely used: for example, it is primarily found in The Netherlands, where it applies to all dwellings, and Greece, where it only applies to large dwellings. The banking regulation can generally restrict the supply of mortgage loans, in some cases to specific individuals based on their income and debt. After the Great Recession of 20082009, many countries introduced macroprudential regulations in order to avoid the buildup of speculative house price bubbles by limiting the mortgage loans provision. The opponents of this policy argue that it leads to a widening of the gap between the rich and poor, since the latter have a lower purchasing capacity and, hence, are subject to the restraints imposed on the mortgage crediting to a larger extent. 
Finally, it should be noted that legal acts often do not work, remaining ineffective, if not defunct, in practice. Firstly, laws that are very inconvenient for market participants tend to be avoided through various loopholes. The imagination of many people, who are motivated to find loopholes, is much richer than that of the handful of the lawmakers attempting to close these loopholes. Secondly, in order to make the laws effective, mechanisms to uncover violations of the laws are needed. The state is unable to provide each dwelling or building with a policeman who enforces compliance with the law. Most frequently, it is an interested party, i.e., tenants, who report violations of the law. However, they are not always willing to do so, because, even if they win the process, they still remain tenants of the landlord with whom the relationship is then strained. Thirdly, law enforcement is inhibited by ignorance of the laws by the people. For instance, Franco Ubeda (2016), based on a survey of lawyers, landlords, and tenants in Ecuador's capital Quito, showed that only 1\% of landlords and tenants are aware of the legislation regulating rental housing market. Similarly, in Bogotá (Colombia) only 10.4\% of low-income tenants are informed about the tenant protection (CENAC 2007) and in several Zambian cities about $30 \%$ of the respondents "had some idea about the existence of some rent controls" (Nzonzo 2005, p. 28).

\section{Approaches to measuring housing policy}

\subsection{Existing approaches}

In order to assess the impact of governmental regulations, they must be measured. There is some literature on measurement of regulations; see Table 1 for an overview. The majority of studies assess the stringency of housing policies for a single period of time. The cross-sectional dimension varies between 4 (Miletić 2016) and 126 countries (Global Property Guide). The degree of regulation is measured for various points of time: the stringency of rent control by Malpezzi and Ball (1993) for 1991, a procedural formalism index by Djankov et al. (2003) for 2000, a rent control index by Andrews et al. (2011) for 2009, and landlord and tenant law and practice of the Global Property Guide (GPG) for 2017. Kholodilin (2017b) is the first study in which indices depicting the evolution of governmental regulations over time are constructed, while Weber (2017) is the first researcher to develop a panel of indices encompassing 18 countries between 1973 and 2016 . 
Most studies approximate the intensity of restrictions imposed on the rent. Five out of the seven studies also account for the tenure security, that is, protection of tenants from eviction. Housing rationing is only included in analyses by two researchers: Miletić (2016) and Kholodilin (2017b). Finally, two studies - Malpezzi and Ball (1993) and Djankov et al. (2003) — attempt to quantify the enforcement of regulations.

\subsection{Our approach}

In our approach, the quantification of legal acts is carried out in several steps. This section describes the whole algorithm. Its purpose is to make the approach used here as transparent and replicable as possible. The first step consists of exploring the literature that summarizes governmental housing market regulations in the country of interest. In a few select cases, a nice and systematic description of the evolution of such legislation exists. The main sources of such information are the Tenlaw project at the Universität Bremen ${ }^{10}$ for the 28 European Union member states plus Japan, Norway, Serbia, Switzerland, and Turkey; the "Tenancy Law and Procedure in the EU" project of the European University Institute in Florence ${ }^{11}$ for 13 EU member states plus Switzerland; International Labour Office (1924) for the origins of housing policies in 17 European countries (Austria, Belgium, Czechoslovakia, Denmark, Finland, France, Germany, Great Britain, Hungary, Italy, Netherlands, Norway, Poland, Russia, Sweden, Switzerland, and Yugoslavia); historical and legal studies; as well as preambles of legal acts or parliamentary discussions of law drafts that provide justification of regulations (e.g., Belgium, Portugal, and Romania).

In the second step, a list of relevant legal acts is compiled and the search for their original (not revised) texts is conducted. Since we are interested in the evolution of the housing legislation, we need the "real-time" texts, as formulated at the moment of their enactment. Most frequently, such texts are found in government, or official, gazettes. Fortunately, many of these gazettes are digitized and available as online archives. Hence, it is relatively easy to search for the necessary information. In other cases, laws can be obtained free of charge by contacting the national parliaments (e.g., as is the case for Denmark, Iceland, and Norway). Still other

\footnotetext{
${ }^{10}$ http://www.tenlaw.uni-bremen.de/.

${ }^{11}$ https://www.eui.eu/DepartmentsAndCentres/Law/ResearchAndTeaching/ResearchThemes/ ProjectTenancyLaw.
} 
countries charge fees for providing the relevant laws (for example, Bulgaria, Singapore, and Sweden). As in some cases we were unable to locate laws as published in an official gazette, we use drafts of the laws from parliamentary proceedings (e.g., Belgium and Switzerland). In the worst case, answers to questions submitted remotely are not forthcoming (some African, Asian, as well as Latin American and Caribbean countries) or one must visit a library in the country of interest. Overall, the amount of legal texts collected in this study is quite impressive, as seen in Figure 3, which shows the number of laws examined for each country in the sample. This number varies dramatically from just two laws in Angola to more than 100 legal acts in the Czech Republic.

In the third step, the compiled legal acts are summarized. The relevant provisions are identified and recorded. In particular, the following fields are captured: area of application, rent control, tenant protection, housing rationing, and bodies responsible for conflict settling and regulation of the housing sphere. Language barrier is an important challenge at this stage. In many cases, knowledge of the foreign languages (English, French, German, Italian, and Spanish), Russian being his mother tongue, permits the author of the study to understand the legal texts. In other cases, native speakers help decipher these texts (e.g., those in Greek). Otherwise, the author takes advantage of machine translation (e.g., the internet service of Google Translator) in order to translate the texts written in the languages he or his colleagues do not speak. Although the quality of modern machine translations is relatively high, there is still a room for mistakes.

In the fourth step, the textual summaries of legal acts are mapped into numeric values. Here, we rely upon the approach of Weber (2017) to code rent laws and tenure security and Kholodilin (2017b) to code housing rationing. Based on a set of questions contained in Tables 4-6, binary variables are constructed that equal one, if regulation is more stringent, and zero, otherwise:

$$
I_{j t}^{k}= \begin{cases}1, & \text { if restriction } j \text { of type } k \text { is present in period } t \\ 0, & \text { otherwise }\end{cases}
$$

Below, the coding is described in more detail.

Rent control. In his dissertation, Weber (2017) defines six binary variables: "Real rent freeze" (the rents are not allowed to grow faster than inflation), "Nominal rent freeze" (the rents 
are frozen in nominal terms), "Rent level control" (some government body, arbitration council, or court fixes the rent level at the beginning of new contracts), "Intertenancy decontrol" (if the rent control ceases with a change of tenant), "Other specific rent decontrol" (certain types of dwellings or settlements are no longer subject to the rent control), and "Specific rent recontrol" (certain types of dwellings or settlements are subject to more stringent controls). We added a seventh variable "Subletting", which is equal to one, if rents for sublet premises are subject to rent control.

Tenure security. The corresponding four binary variables are defined in Table 5. The binary variables "Eviction protection during term or period" and "Eviction protection at the end of term or period" take the value one, if, in order to evict a tenant during the contract term or at the end of it, the landlord is required to present justified reasons. The "Minimum duration" variable equals one, if the contract duration must be at least two years, while the "Short-term tenancies" variable is 1 , if letting dwellings for a period of less than one year is prohibited.

Housing rationing. This policy is approximated with eight binary variables, see Table 6 . "Registration of housing" equals one, if landlords are obliged to register vacant, or all available, premises. The binary variable "Protection of housing" is one, if it is prohibited to use dwellings for non-residential purposes, merge or demolish them, or to convert rental dwellings into condominiums. The variable "Creation of housing space" equals one, if the state prescribes the use of all available space for housing purposes, e.g., through the reconstruction or conversion of non-residential premises or through the subdivision of big dwellings into smaller ones. The dummy variable "Requisition" equals one, if requisition with subsequent compulsory letting of the vacant dwellings is conducted. "Restriction of freedom to move" is one, if residential mobility is restricted: for example, if access to areas with an acute housing shortage is closed to all persons, who are neither "indispensable" for these areas nor residing there on a permanent basis. "Conservation of social composition" is one, if a balanced social composition of population in particular urban areas is protected through interdiction to upgrade the dwellings to a state considered being above the standard level. The variable "Housing consumption norms" equals one, if restrictions on the amount of housing that might be used by tenants are imposed. The dummy "Nationalization of housing" takes the value one, if the state nationalizes housing stock, and zero, if no nationalization or privatization occurs. Unlike requisition, nationalization 
means the loss of property rights for the owner and no compensation for property taken.

For each regulation type, $k$, a composite index is computed as a simple average of binary variables:

$$
I_{t}^{k}=\frac{1}{N_{k}} \sum_{j=1}^{N_{k}} I_{j t}^{k}
$$

where $k=\{$ Rent laws, Tenure security, Housing rationing $\}$.

The binary and composite indices are constructed for a large panel of countries, see Table 3 and Figure 4. The choice of countries is dictated by the availability of legal acts. The best coverage exists for Europe and Latin America. In Africa, only a few former French and Portuguese colonies, since it was relatively easy to locate the historical legal acts for them. For North American countries, coding is complicated by the fact that housing regulations there are created at the regional level, including not only states or provinces, but also cities.

Finally, an even more general index can be constructed (rental market regulation index):

$$
\mathrm{RMRI}=\frac{I_{t}^{\text {Rent laws }}+I_{t}^{\text {Tenure security }}}{2}
$$

which simultaneously accounts for both rent control and protection from eviction.

\section{Descriptive analysis of housing policy indices}

\subsection{Worldwide and continent-specific perspectives}

We start by examining the worldwide distribution of housing market regulations over time. Figure 5 shows the evolution of the distribution of regulation intensity around the world between 1910 and 2018. Values close to the center of the distribution are darker. The green curve depicts the worldwide average, while the red curve corresponds to the median. While governmental intervention into the housing market intensified during and after World War I in many countries, the absolute peak of regulation was during World War II. During that period, both the number of regulating countries (as reflected in the median regulation stringency) and country-specific regulation intensities strongly increased. This is true for all types of regulations. The postwar evolution was, however, different. Whereas rent control embarked on a slow but steady downward decline in regulation intensity, tenure security stabilized at a relatively high level around the world, with some countries even strengthening tenant protection further. The 
stringency of housing rationing also declined. To a large extent, this can be explained by the diminishing number of countries taking advantage of this policy, as the worldwide median is equal to zero starting from the second half of the 1960s.

Rent control. The first group of policies considered here are rent laws, or rent control. As pointed out in section 2, two generations of rent control can be distinguished: while firstgeneration rent control implies a freeze of nominal rate, second-generation control permits automatic percentage rent increases related to the rate of inflation, vacancy, and other forms of decontrol. This classification was used in our research for identifying dummy variables. ${ }^{12}$ The intensity of rent control by continents (as measured by an average of rent law binary indices) is shown in Figure 6. In all the cases, the intensity increases up to a peak and then stabilizes or decreases. The peaks take place at different times: in Europe, North America, and Oceania the highest rent control intensity is attained in the 1940s, in Latin America and Caribbean (LAC) it is achieved in the 1950s, while in Africa and Asia it is observed in the 1970s. Moreover, Europe and Oceania experienced higher than the world average intensity in the first half of the 20th century, LAC between 1950 and 1980 and then again from the late 1990s, Africa between 1960s and now, whereas Asia between 1980 and 2000s. Thus, Europe was the first to introduce rent control and to relax it, while Africa and LAC lag behind other continents. This is especially true for Africa, where rent control still has a very high intensity. This is related to the transition from first-generation rent control to either second-generation rent control or its complete removal. The evolution of two generations of rent control is shown Figure 7, where the shares of countries having either first- or second-generation controls are displayed by continent. The sum of the shares of first- and second-generation rent controls is not always equal to 1 , for some countries lift all restrictions on rent setting. Europe was the first to introduce the more flexible second generation of rent control in the early 1970s. In the early 1990s, the number of European countries with second-generation rent control exceeded that of the countries with first-generation rent control. To some extent, this was helped by the transition of former socialist countries to market economies. In the late 1970s, secondgeneration rent control was introduced in LAC, in the late 1990s in Asia, and only in the

\footnotetext{
${ }^{12}$ Alternative classifications also exist. For example, Lind (2001) distinguishes between five main types of rent control.
} 
2010s in Africa. Oceania did not have second-generation rent control and went directly to a free market, while in Africa and LAC there are still more countries with first-generation rent control than those with the second generation.

Tenure security. Another group of laws is tenure security laws. The composite tenure security index averaged by continents is displayed in Figure 8. Unlike rent control, which tends to decrease since the second half of the 20th century, tenure security displays an almost monotonic upward trend globally, stabilizing at a high level at the turn of the 21st century. Only in North America and Oceania does its intensity diminish after World War II. At the end of our sample period, tenure security is the highest in Europe and the lowest in Oceania. In Asia, it is substantially lower than the worldwide average, while in Africa and LAC it almost coincides with this average.

Housing rationing. The third group includes laws regarding housing rationing. Although this policy attracted little attention in the literature, it appears to be quite widely used: out of the 47 countries/provinces in our sample, 36 (i.e., almost 77\%) used or still use it. The intensity of housing rationing by continent over 100 years is shown in Figure 9. The measures of forceful redistribution of housing and tenants are almost omnipresent across the world. Only North America appears to have escaped such a policy at a large scale. It is known, though, that some US cities, e.g., Santa Monica (California) employed such forms of housing rationing as obligatory registration of vacant housing and prohibition to use dwellings to non-residential purposes; see Keating (1983). The continent that most actively took advantage of housing rationing is Europe. The two periods of the most extensive use of such policies coincide with the World Wars and the subsequent aftermath. Nevertheless, with the passage of time, European countries, although markedly reducing the application of housing rationing, did not dismantle them completely. Even new forms of housing rationing were introduced, such as protection of social composition areas in Germany; see Kholodilin (2017b). Latin America and Caribbean had similar, but somewhat lower, intensity of housing rationing as Europe. Africa and Asia had some episodes in their history (1950s and 2010s), when their intensity of housing rationing exceeded the worldwide average. Oceania only used such policies in the 1950s. 


\subsection{Dynamic multivariate cluster analysis}

Classification of the countries into more or less homogeneous groups can improve our understanding of regulations. Here, the clusters of countries are defined using the function $\mathrm{kml} 3 \mathrm{~d}$ of the $R$ package $\mathrm{kml}$ developed by Genolini et al. (2015). This is a clustering technique based on a non-parametric $k$-means algorithm for determining joint trajectories of the multivariate longitudinal data. In other words, $k$ clusters are identified based on the joint evolution of several regulation indices across time and countries. The technique uses Hartigan and Wong (1979) version of the $k$-means with Euclidean distance to measure the similarity of the country-specific regulation index trajectories and Caliński and Harabasz (1974) criterion to determine the optimal $k$ as default settings. Figure 10 displays the trajectories of the two clusters obtained for the three regulation indices jointly: rent control, tenure security, and housing rationing. In the cluster $A$, rent control was introduced later — at the beginning of World War II- and was liberalized also later than in the cluster $B$ countries. Cluster $A$ is also characterized by a lower tenure security and a much lower intensity of housing rationing policy. The composition of the clusters seems to be unrelated to a continent or legal origin, although in cluster $B$ the majority of countries are from the European continent; see Table 8. Thus, it can be treated as a continental regime of housing market regulations. The apparent heterogeneity of the clusters can be related to their low number. Different criteria are rather discordant about the "optimal" $k$ : the default Caliński-Harabasz and Ray-Turi choose $k=2$, Davies-Bouldin $k=4$, while Caliński-Harabasz 2 and 3 opt for $k=6$.

\subsection{Robustness check}

In this section, we compare our regulation indices with the alternative ones discussed in section 3. Figure 11 displays the maps of the alternative housing market regulation indices: stringency of rent control of Malpezzi and Ball (1993) for 1991, procedural formalism index of Djankov et al. (2003) for 2000, rent control index of Andrews et al. (2011) for 2009, landlord and tenant law and practice of the Global Property Guide (GPG) for 2017. While Djankov et al. (2003) and GPG indices cover various continents more or less uniformly; Malpezzi and Ball (1993) index is more representative of Europe, Latin and North America, but insufficiently covers Africa and Asia; and Andrews et al. (2011) index focuses only on the rich OECD countries. A general feature of all these indices is a low coverage of African countries. Table 9 
reports correlations between these and our indices as well as the corresponding $p$-values and number of observations. In order to compute the correlations, cross-sections of our indices for corresponding years are extracted. The correlations are statistically significant for two alternative indices: Malpezzi and Ball (1993) and GPG. The correlation between our rent laws index and stringency of rent control is negative. At first glance, it might appear surprising, since both indices increase in the intensity of government intervention. However, Malpezzi and Ball (1993) overall index measures not only stringency of rent control, but also that of tenure security. In addition, it accounts for the enforcement of legal acts, while our indices do not. Hence, the negative sign of correlation can result from the fact that by the early 1990s the intensity of rent control decreased, whereas tenure security increased worldwide. In fact, the correlation between Malpezzi and Ball (1993) index and our tenure security index is positive, albeit insignificant. The correlation between Malpezzi and Ball (1993) index and RMRI is not significant, which can be explained by the low number of observations on which this correlation is based. GPG index is negatively and significantly correlated with our rent laws and RMRI indices. The negative correlation is due to the fact that GPG index takes five integer values between -2 (strongly pro-tenant) and 2 (strongly pro-landlord).

\section{Concluding remarks}

In this study, a new multi-country long-term database of housing market regulations is introduced. The database covers about 50 countries over the period between 1910 and 2018. The indices are built using a comprehensive analysis of the real-time country-specific regulations. It includes regulation indices concerning such policies as rent control, protection of tenants from eviction (tenure security), and housing rationing. The coding approach that is mapping legal texts into a set of measurable values (indices) strikes the balance between the oversimplification and feasibility of the legal analysis.

Using multivariate longitudinal cluster analysis, the countries in our sample are classified in two groups: cluster $A$ with currently stronger rent laws, but weaker tenure security and cluster $B$ (continental Europe) that earlier switched to second-generation rent control, thus, currently restricting rents to a lesser degree, but with stronger protection from arbitrary evictions for tenants. 
Robustness checks show that, although our results do not agree with those of Malpezzi and Ball (1993) due to a different composition of the indices, the correlation between our rent control index and the index of Global Property Guide is statistically significant. This implies a certain concordance between our and alternative indices measuring governmental regulations of the housing market worldwide.

The database of the housing market regulations could serve as a good basis for both the exploratory and causal analyses. For example, the indices presented here can be used as explanatory variables for house prices and rents, homeownership rates, residential mobility, housing construction, etc. The database can be easily extended to include new countries (for example, from Africa, Asia, North America, and Oceania) and new indicators (e.g., stimulation of residential construction, housing allowances, and land-use regulations).

\section{Literature}

Andrews, D., A. Caldera Sánchez, and Å. Johansson (2011). Housing markets and structural policies in OECD countries. OECD Economic Department Working Papers (836).

Arnott, R. (2003). Tenancy rent control. Swedish Economic Policy Review 10(1), 89-134.

Attia, S. E. (2016). Rent control dilemma comeback in Egypt's governance: A hedonic approach. British University in Egypt Working Paper 979.

Axel-Lute, M. (2017). Could rent control come back? https://shelterforce.org/2017/12/21/could-rent-control-come-back/.

Ballesteros, M. M. (2001). Benefits (and losses) from rent control in the Philippines: An empirical study of Metro Manila. PIDS Discussion Paper Series no. 2001-23.

Ballesteros, M. M., T. P. Ramos, and J. E. Magtibay (2016). Rent control in the Philippines: An update. PIDS Discussion Paper Series no. 2016-40.

Bettendorf, L. and E. Buyst (1997). Rent control and virtual prices: A case study for interwar Belgium. The Journal of Economic History 57(3), 654-673. 
Bonduki, N. G. (1994). Origens da habitação social no Brasil. Análise social XXIX(127), $711-732$.

Bradbrook, A. J. (1977). The future of domestic rent control in Hong Kong.

Brueckner, J. K. (2011). Lectures on urban economics. Cambridge: MIT Press.

Caliński, T. and J. Harabasz (1974). A dendrite method for cluster analysis. Communications in Statistics — Theory and Methods 3(1), 1-27.

CENAC (2007). Caracterización del mercado de arrendamientos urbanos para el segmento de la población de bajos ingresos. Trabajo realizado para MAVDT-UN HÁBITAT-First Initiative. Bogotá: CENAC (Centro de Estudios de la Construcción y el Desarrollo Urbano y Regional).

Chembo, D. (2014). The rental regulation and protection of residential tenants in Tanzania. A Dissertation in Partial Fulfillment of the Requirements for the Award of the Degree of Master of Laws at St. Augustine University of Tanzania.

Cheung, S. N. (1975). Roofs or stars: the stated intents and actual effects of a rents ordinance. Economic Inquiry 13(1), 1-21.

Choi, A. (2017). Information note: Tenancy control in selected places. Hong Kong Research Office Legislative Council Secretariat IN16/16-17.

Collins, T. L. (2016). An introduction to the New York City rent guidelines board and the rent stabilization system. New York City Rent Guidelines Board.

Croizé, J.-C. (2009). Politique et Configuration du Logement en France (1900-1980). Vol. II et III.

de Peña Mulet, R. (1992). Breve recuento sobre la legislación de vivienda en Cuba. Universidad de Oriente, Santiago de Cuba.

Dey, P. D. and S. Dev (2006). Rent control laws in India. A critical analysis. National Institute of Urban Affairs. 
Dillon, T. (1982). Estimating the effects of the removal of rent controls in Alberta. Canada Mortgage and Housing.

Djankov, S., R. La Porta, F. López de Silanes, and A. Shleifer (2003). Courts: The Lex Mundi project. The Quarterly Journal of Economics 118(2), 453-517.

Figari, F., A. Paulus, H. Sutherland, P. Tsakloglou, G. Verbist, and F. Zantomio (2017). Removing homeownership bias in taxation: The distributional effects of including net imputed rent in taxable income. Fiscal Studies 38(4), 525-557.

Franco Ubeda, E. D. (2016). Las relaciones de carácter legal entre propietarios y arrendatarios, y su comportamiento al margen de la ley, provocando perdidas económicas y detrimento de la propiedad. Universidad Laica Vicente Rocafuerte de Guayaquil.

Genolini, C., X. Alacoque, M. Sentenac, C. Arnaud, et al. (2015). kml and kml3d: R packages to cluster longitudinal data. Journal of Statistical Software 65(4), 1-34.

Haas, H. (2018). Paradigms of home ownership promotion: The changing role of economists in the knowledge production for housing politics in Germany.

Hartigan, J. A. and M. A. Wong (1979). Algorithm AS 136: A k-means clustering algorithm. Journal of the Royal Statistical Society. Series C (Applied Statistics) 28(1), 100-108.

Henau, A. (1991). De belgische huishuren gedurende het interbellum. Workshop on Quantitative Economic History Research Paper 91.01 Katholieke Universiteit Leuven.

Hidalgo Dattwyler, R. (2003). Conflicto de alquileres y política de vivienda social en la década de 1920. El caso de Chile. Estudios Geográficos LXIV, 387-406.

Hilber, C. A. L. and W. Vermeulen (2016). The impact of supply constraints on house prices in England. Economic Journal 126(591), 358-405.

International Labour Office (1924). European housing problems since the war. Imprimeries réunies S.A.: Geneva.

International Labour Office (1925). The housing situation in the United States. Geneva. 
Jóhannsson, I. V. and J. R. Sveinsson (1986). Íslenska húsnæeðiskerfið - Rannsókn á stöðu og próun húsnœðismála. Reykjavík: Félagsvísindastofnun.

Keating, W. D. (1983). Rent control in California: Responding to the rental housing crisis. Institute of Governmental Studies, University of California, Berkeley.

Keating, W. D. (1987). Landlord self-regulation: New York City's rent stabilization system 1969-1985. Journal of Urban and Contemporary Law 31, 77.

Kholodilin, K. A. (2017a). Housing policy of non-Bolshevik governments during the Russian civil war. Higher School of Economics Working papers, WP BRP 151/HUM/2017.

Kholodilin, K. A. (2017b). Quantifying a century of state intervention in rental housing in Germany. Urban Research and Practice 10(3), 267-328.

Kholodilin, K. A. and M. G. Meerovich (2016). Housing policy in Soviet Russia and Germany between the two world wars: comparative analysis of two systems. Journal of Urban History.

Kholodilin, K. A., A. Mense, and C. Michelsen (2017). The market value of energy efficiency in buildings and the mode of tenure. Urban Studies 54(14), 3218-3238.

Kofner, S. (1997). Das Wohnraum-Mietrecht in Deutschland: Zeittafel zu seiner historischen Entwicklung, Teil I: 1896 bis 1945. Deutsche Wohnungswirtschaft 49, 321-332.

Kofner, S. (1999). Das Wohnraum-Mietrecht in Deutschland: Zeittafel zu seiner historischen Entwicklung, Teil II: 1946 bis 1998. Deutsche Wohnungswirtschaft 51(9), 275-289.

Lee, D. (2016). How Airbnb short-term rentals exacerbate Los Angeles's affordable housing crisis: Analysis and policy recommendations. Harvard Law and Policy Review 10, 229-253.

Lind, H. (2001). Rent regulation: A conceptual and comparative analysis. International Journal of Housing Policy 1(1), 41-57.

Malpezzi, S. and G. Ball (1993). Measuring the urban policy environment: an exploratory analysis using rent controls. Habitat International 17(2), 39-52. 
Malpezzi, S., A. G. Tipple, and K. G. Willis (1990). Costs and benefits of rent control: a case study in Kumasi, Ghana. Number 64. World Bank Publications.

Mark, M. (2013). Just ring twice: Law and society under the rent control regime in Israel, 1948-1954. Journal of Israeli History 32(1), 29-50.

Marmol Navas, E. A. (2001). Vacios legales que interrumpen el procedimiento en los juicios de inquilinato. Univesidad de El Salvador.

Miletić, A. R. (2016). Tenancy vs. ownership rights. housing rent control in Southeast and East-Central Europe, 1918-1928. Mesto a dejiny 5(1), 51-74.

Nägele, P. (2014). Das liechtensteinische Mietrecht unter besonderer Berücksichtigung des Mieterschutzes. Vaduz: Recht und Wirtschaft Verlaganstalt.

Nzonzo, M. T. (2005). A critical discussion and analysis of the relevance and efficacy of the rent act vis-à-vis the impact of other housing laws governing land tenure in Zambia. University of Zambia.

Pellejero, L. and R. Monaiser (2009). Las locaciones urbanas en Argentina. Una aproximación a la historia de su legislación. Universidad Nacional de La Pampa.

Polotto, M. R. (2012). Argumentación jurídica y trasfondo ideológico. análisis del debate legislativo sobre prórroga de alquileres en Argentina a principios del siglo XX. RechtsgeschichteLegal History (20), 309-327.

Priemus, H. (1983). Huurprijsbeheersing: omstreden instrument van volkshuisvestingsbeleid. Delft: Delftse Universitaire Pers.

Rohrbach, H. (2014). Die Entwicklung des schweizerischen Mietrechts von 1911 bis zur Gegenwart. Bundesamt für Wohnungswesen.

Soto Gil, V. (2013). Análisis del arrendamiento como alternativa en la política de vivienda de interés social en Colombia. Lecciones y reflexiones aprendidas a partir de la experiencia de Sudáfrica. Universidad Colegio Mayor de Nuestra Señora del Rosario. 
Sveinsson, J. R. (2004). The formation of urban homeownership in Iceland. Paper presented at the ENHR 2004 Conference "Housing: Growth and Regeneration", Cambridge, 2-6 July 2004.

Tabacu, A. (2006). Mijloace de protecţie juridică a chiriaşaului şi a proprietarului in contextul legilor cu caracter reparatoriu. Revista de Ştiinţe Juridice, 5.

Thibodeau, J.-C. (2001). Étude comparative de la législation sur le contrôle des loyers au Canada entre 1950 et 2000. Gouvernement du Québec.

Turnaturi, F. (2013). Locaciones urbanas. Universidad Abierta Interamericana.

Villatoro Illescas, G. D. (2009). La inobservancia del principio constitucional de igualdad en el contrato de arrendamiento de casa de habitación contenido en el decreto 1468 articulo 32 ley de inquilinato. Universidad de San Carlos de Guatemala.

Weber, J. P. (2017). The regulation of private tenancies - a multi-country analysis. Dissertation.

Willis, J. W. (1949). Rent control: The maximum rent date method. University of Pennsylvania Law Review 98, 654-684.

Willis, J. W. (1950). Short history of rent control laws. Cornell Law Quarterly 36(1), 54-94.

Wilson, W. (2017). A short history of rent control. House of Commons Briefing Paper no. 6747. 


\section{Appendix}

\section{Table 1: Literature on measurement of housing regulations}

\begin{tabular}{|c|c|c|c|c|c|c|}
\hline \multirow[t]{2}{*}{ Study } & \multirow[t]{2}{*}{ Period } & \multirow[t]{2}{*}{ Countries } & \multicolumn{4}{|c|}{ Regulation aspect } \\
\hline & & & $\begin{array}{l}\text { Rent con- } \\
\text { trol }\end{array}$ & $\begin{array}{l}\text { Tenure } \\
\text { security }\end{array}$ & $\begin{array}{l}\text { Housing } \\
\text { rationing }\end{array}$ & Enforcement \\
\hline $\begin{array}{l}\text { Malpezzi and Ball (1993): strin- } \\
\text { gency of rent control regimes }\end{array}$ & $\approx 1991$ & $\begin{array}{l}51 \text { market } \\
\text { economies }\end{array}$ & + & + & & + \\
\hline $\begin{array}{l}\text { Djankov et al. (2003): procedural } \\
\text { formalism (Lex Mundi Project) }\end{array}$ & 2000 & 109 & & + & & + \\
\hline $\begin{array}{l}\text { Andrews et al. (2011): rental market } \\
\text { regulations }\end{array}$ & 2009 & 30 & + & & & \\
\hline $\begin{array}{l}\text { Global Property Guide: landlord } \\
\text { and tenant law and practice }\end{array}$ & $\approx 2017$ & 116 & + & + & & \\
\hline $\begin{array}{l}\text { Miletić (2016): state involvement } \\
\text { with housing tenancy and housing } \\
\text { tenure }\end{array}$ & $1918-1928$ & 4 & + & & + & \\
\hline $\begin{array}{l}\text { Weber (2017): rental market regu- } \\
\text { lation }\end{array}$ & 1973-2016 & $\begin{array}{l}18 \text { advanced } \\
\text { economies }\end{array}$ & + & + & & \\
\hline $\begin{array}{l}\text { Weber (2017): rental market regu- } \\
\text { lation }\end{array}$ & $\approx 2016$ & 66 & + & + & & \\
\hline $\begin{array}{l}\text { Kholodilin (2017b): regulation in- } \\
\text { tensity }\end{array}$ & 1914-2015 & 1 (Germany) & + & + & + & \\
\hline
\end{tabular}

Table 2: Country-specific studies on housing regulations

\begin{tabular}{l|l}
\hline Country & Study and period under consideration \\
\hline Argentina & Pellejero and Monaiser (2009) 1921-2009, Polotto (2012) 1901-1950, Turnaturi (2013) 1921-2013 \\
Belgium & Henau (1991) 1914-1940, Bettendorf and Buyst (1997) 1929-1939 \\
Brazil & Bonduki (1994) 1930-1950 \\
Bulgaria & Miletić (2016) 1918-1928 \\
Canada & Thibodeau (2001) 1950-2000, Dillon (1982) 1940-1982 \\
Chile & Hidalgo Dattwyler (2003) 1921-1930 \\
Colombia & Soto Gil (2013) 1946-2013
\end{tabular}




\section{Table 2: Country-specific studies (continued)}

\begin{tabular}{|c|c|}
\hline Country & Study and period under consideration \\
\hline Cuba & de Peña Mulet (1992) 1902-1985 \\
\hline Egypt & Attia (2016) 1924-1996 \\
\hline El Salvador & Marmol Navas (2001) 1946-2001 \\
\hline France & Croizé (2009) 1900-1980 \\
\hline Germany & Kofner (1997) 1896-1945, Kofner (1999) 1946-1998, Kholodilin (2017b) 1914-2016 \\
\hline Ghana & Malpezzi et al. (1990) 1942-1989 \\
\hline Guatemala & Villatoro Illescas (2009) 1932-1992 \\
\hline Hong Kong & Cheung (1975) and Bradbrook (1977) 1921-1977, Choi (2017) 1921-2004 \\
\hline Iceland & Jóhannsson and Sveinsson (1986) 1939-1986 \\
\hline India & Dey and Dev (2006) 1918-2006 \\
\hline Israel & Mark (2013) 1948-1954 \\
\hline Liechtenstein & Nägele (2014) 1812-2014 \\
\hline Netherlands & Priemus (1983) 1916-1983 \\
\hline Philippines & Ballesteros (2001) 1946-2001, Ballesteros et al. (2016) 1971-2015 \\
\hline Romania & Tabacu (2006) 1919-2006 \\
\hline Russia & Kholodilin (2017a) 1917-1922, Kholodilin and Meerovich (2016) 1916-1939 \\
\hline Switzerland & Rohrbach (2014) 1911-2014 \\
\hline Tanzania & Chembo (2014) 1961-2015 \\
\hline UK & Wilson (2017) 1915-1989 \\
\hline USA & International Labour Office (1925) 1919-1925, Collins (2016) 1920-2016, Keating (1987) 1969-1985 \\
\hline Zambia & Nzonzo (2005) 1940-1994 \\
\hline
\end{tabular}


Table 3: List of countries, for which regulation indices are constructed

\begin{tabular}{l|l|l|l}
\hline Continent & Countries & $\begin{array}{c}\text { Sample } \\
\text { size }\end{array}$ & $\begin{array}{c}\text { Total } \\
\text { coun- } \\
\text { tries } \\
\text { (states) }\end{array}$ \\
& & 60 \\
\hline Africa & Angola, Madagascar, Mali, Morocco, Togo, Tunisia & 6 & 51 \\
\hline Asia & Cyprus, Macao, Philippines, Singapore & 4 & 53 \\
\hline Europe & Austria, Belgium, Czech Republic, France, Germany, Greece, Iceland, & 21 & \\
\hline LAC & Ireland, Italy, Liechtenstein, Luxembourg, Monaco, Norway, Poland, & & 52 \\
\hline North America & Portugal, Russia, San Marino, Slovakia, Spain, Switzerland, UK & & 5 \\
\hline World & Argentina, Bolivia, Brazil, Chile, Colombia, Mexico (Distrito Federal), & 11 & $5(60)$ \\
\hline
\end{tabular}




\section{Table 4: Rent control}

\begin{tabular}{l|l}
\hline Variable & Description \\
\hline Real rent freeze & $\begin{array}{l}\text { The dummy equals 1, if landlords may not increase rents } \\
\text { by more than the growth of official cost or price indices, } \\
\text { and 0, otherwise. } \\
1, \text { if rents are determined solely by the government or } \\
\text { another institution. } \\
1, \text { if landlords may not charge rents above a certain rent } \\
\text { level. } \\
1, \text { if rent control holds at the beginning and during the } \\
\text { tenancy. } \\
1, \text { if certain kind of dwellings are not de-controlled (new } \\
\text { constructions, vacant dwellings, or luxurious housing). } \\
\text { The dummy equals one if certain kind of dwellings fall } \\
\text { under a stricter rent regime. } \\
\text { Intertenancy decontrol } \\
\text { Other specific rent decontrictions are imposed on the rent from subletting } \\
\text { a part of or the whole apartment. }\end{array}$ \\
\hline
\end{tabular}

Table 5: Tenure security

\begin{tabular}{|c|c|}
\hline Variable & Description \\
\hline $\begin{array}{l}\text { Eviction protection during } \\
\text { term }\end{array}$ & $\begin{array}{l}\text { The dummy equals } 1 \text {, if only reasonable reasons leads to } \\
\text { a warranted eviction during the term or rent payment } \\
\text { period; and } 0 \text {, otherwise. }\end{array}$ \\
\hline $\begin{array}{l}\text { Eviction protection at the } \\
\text { end of term } \\
\text { Minimum duration }\end{array}$ & $\begin{array}{l}1 \text {, if only reasonable reasons leads to a warranted evic- } \\
\text { tion at the end of term or rent payment period. } \\
1 \text {, if a minimum duration period of }>2 \text { years is compul- } \\
\text { sory for every private tenancy. }\end{array}$ \\
\hline Short-term tenancies & $\begin{array}{l}1 \text {, if short-term tenancies that are tenancies } \leq 1 \text { year } \\
\text { are not allowed. }\end{array}$ \\
\hline
\end{tabular}




\section{Table 6: Housing rationing}

\begin{tabular}{|c|c|}
\hline Variable & Description \\
\hline Registration of housing & $\begin{array}{l}\text { The dummy equals } 1 \text {, if owners are forced to register } \\
\text { vacant or all available housing; and } 0 \text {, otherwise. }\end{array}$ \\
\hline Protection of housing & $\begin{array}{l}1 \text {, if such type of policy (prohibition to use dwellings for } \\
\text { non-residential purposes, merge, or demolish dwellings) } \\
\text { is conducted. }\end{array}$ \\
\hline Creation of housing & $\begin{array}{l}\text { 1, if such type of policy (subdivision of large dwellings } \\
\text { in smaller ones) is conducted. }\end{array}$ \\
\hline Requisition & $\begin{array}{l}\text { 1, if such type of policy (compulsory letting of the vacant } \\
\text { dwellings) is conducted. }\end{array}$ \\
\hline Mobility restriction & $\begin{array}{l}1 \text {, if such type of policy (prohibition to move into areas } \\
\text { with housing shortage) is conducted. }\end{array}$ \\
\hline $\begin{array}{l}\text { Conservation of social com- } \\
\text { position }\end{array}$ & $\begin{array}{l}1, \text { if areas are delimited, where above-the-standard-level } \\
\text { modernizations are prohibited. }\end{array}$ \\
\hline $\begin{array}{l}\text { Housing } \quad \text { consumption } \\
\text { norms }\end{array}$ & $\begin{array}{l}1 \text {, if restrictions on the maximum amount of housing } \\
\text { being used by tenants are imposed. }\end{array}$ \\
\hline Nationalization of housing & $\begin{array}{l}1 \text {, if state nationalizes housing stock, and } 0 \text {, if no na- } \\
\text { tionalization or privatization. }\end{array}$ \\
\hline
\end{tabular}

Table 7: List of legal acts used in the analysis

\begin{tabular}{|c|c|c|}
\hline $\begin{array}{l}\text { Date of legal } \\
\text { act (yyyy- } \\
\text { mm-dd) }\end{array}$ & $\begin{array}{l}\text { Enactment } \\
\text { or publica- } \\
\text { tion date } \\
\text { (yyyy-mm- } \\
\text { dd) }\end{array}$ & Title of legal act \\
\hline \multicolumn{3}{|r|}{ Angola (AO) } \\
\hline 1961-03-07 & 1961-03-07 & Decreto No. 43525 \\
\hline 2015-10-02 & 2015-12-31 & Lei $\mathrm{n} .^{\circ} 26 / 15$, de 23 de Outubro - Lei do Arrendamento Urbano \\
\hline \multicolumn{3}{|r|}{ Argentina (AR) } \\
\hline 1921-09-15 & 1921-09-19 & Ley 11156 Locación urbana. Modificación de los artículos 1504, 1507, 1509, 1583, 1604 y 1610 \\
\hline 1921-09-15 & 1921-09-19 & Ley 11157 Locación urbana: Congelación de alquileres; suspensión de desalojos en Capital Federal y en territorios nacionales \\
\hline 1923-10-01 & 1923-10-04 & Ley 11231 Locación Urbana: Prórroga de los contratos hasta el 30/09/24 \\
\hline 1924-12-02 & 1924-12-10 & Ley 11318 Locación urbana: prórroga de la ley 11231 hasta el 30 de setiembre de 1925 \\
\hline $1925-08-26$ & 1925-08-26 & Corte Suprema de Justicia de la Nación - Mango, Leonardo c/Traba, Ernesto - 26/8/1925 - Fallos: 144:220 \\
\hline 1939-09-01 & & Ley 12591 \\
\hline 1942-09-17 & 1942-09-23 & Ley 12771 reajuste de arrendamientos rurales \\
\hline 1943-06-29 & 1943-07-10 & $\begin{array}{l}\text { Decreto } 1580 / 43 \text { Establece rebaja de alquileres a partir del } 1 / 7 / 43 \text { para la Capital Federal y partidos circunvecinos de la } \\
\text { Provincia de Buenos Aires }\end{array}$ \\
\hline 1943-08-20 & 1943-09-16 & $\begin{array}{l}\text { Decreto } 5893 \text { de } 1943 \text { Amplía las disposiciones del decreto núm. } 1580 \text { (1), en lo que se refiere a los contratos de locación y } \\
\text { sublocación de piezas }\end{array}$ \\
\hline 1944-06-15 & 1944-06-24 & $\begin{array}{l}\text { Decreto } 15516 \text { de junio } 15 \text { de } 1944 \text { (A. de M.) fija normas sobre causas que motivan desalojos de inmuebles sujetos a locación } \\
\text { o sublocación or mejoras o reparaciones durante la vigencia del decreto núm. 1580/43 }\end{array}$ \\
\hline 1944-09-28 & 1944-10-14 & $\begin{array}{l}\text { Decreto } 26527 \text { de setiembre } 28 \text { de } 1944 \text { (A. de M.) establece excepciones al art. } 4 \text { del decreto núm. 1580 de 29/6/943 sobre } \\
\text { régimen de locación de inmuebles }\end{array}$ \\
\hline 1944-10-17 & $1944-10-27$ & $\begin{array}{l}\text { Decreto } 27736 \text { de octubre } 17 \text { de } 1944 \text { (A. de M.) declara que los convenios sobre precios y plazos de locación durante la } \\
\text { vigencia del decreto núm. } 1580 \text { (4), siempre que se ajusten a las disposiciones del Código civil son válidos y no contravienen } \\
\text { las prescripciones del art. } 12 \text { de dicho decreto }\end{array}$ \\
\hline 1944-12-06 & 1944-12-12 & Decreto 33059 de 1944 Sustiye el art. 4 del decreto núm. 1580/43 (1), referente al régimen de alquileres \\
\hline
\end{tabular}




\section{Table 7: List of legal acts (continued)}

\begin{tabular}{|c|c|c|}
\hline $\begin{array}{l}\text { Date of legal } \\
\text { act (yyyy- } \\
\text { mm-dd) }\end{array}$ & $\begin{array}{l}\text { Enactment } \\
\text { or publica- } \\
\text { tion date } \\
\text { (yyyy-mm- } \\
\text { dd) }\end{array}$ & Title of legal act \\
\hline $1945-11-21$ & 1945-11-23 & $\begin{array}{l}\text { Decreto } 29716 \text { de } 21 \text { de noviembre de } 1945 \text { (A. de M.) prorroga hasta el } 31 \text { de diciembre de } 1946 \text { el régimen establecido por } \\
\text { los decretos núms. } 1580 / 43 \text { y } 33059 / 44 \text { sobre locación de fincas urbanas }\end{array}$ \\
\hline 1946-09-20 & 1946-09-21 & Ley 12847 Suspende el trámite de los juicios pendientes de desalojo \\
\hline $1946-09-28$ & $1946-10-04$ & $\begin{array}{l}\text { Ley } 12862 \text { hace extensiva a todo el territorio de la República las disposiciones de la ley núm. } 12847 \text { sobre suspensión de } \\
\text { desalojos }\end{array}$ \\
\hline 1946-11-29 & 1946-11-29 & Ley 12886 prorroga las locaciones \\
\hline $1946-12-22$ & 1947-01-03 & Ley 12926 prorroga las disposiciones de las leyes núms. 12.847 y 12.862 sobre suspensión de desalojos \\
\hline 1947-06-27 & 1947-07-02 & Ley 12991 prorroga hasta el 31 de julio la vigencia de la ley sobre desalojos \\
\hline $1947-08-06$ & $1947-08-18$ & Ley 12998 suspende desalojos hasta el 30/06/49 y fija excepciones \\
\hline 1947-09-26 & 1947-10-01 & Ley 13026 prórroga de las locaciones comprendidas en el artículo 1 de la ley 12886 . \\
\hline 1948-08-19 & 1948-08-25 & Ley 13228 sustituye el inc. c del artículo 2 de la ley 12998 (desalojos) \\
\hline $1949-06-24$ & $1949-06-28$ & Ley 13525 prorroga hasta el 30/9/49 la vigencia de las leyes $12886,12998,13026,13228$ \\
\hline $1949-07-28$ & 1949-08-02 & Ley 13538 suspende todos los juicios de desalojo hasta el 30/09/49 \\
\hline 1949-09-29 & 1949-10-05 & Ley 13581 Régimen de emergencia de las locaciones urbanas \\
\hline $1950-05-19$ & $1950-05-20$ & Ley 13897 Cámaras Regionales Paritarias de Conciliación y Arbitraje Obligatorio \\
\hline 1950-07-07 & 1950-09-18 & Ley 13936 modifica la ley 13581 en lo que se refiere a desalojos \\
\hline 1951-09-05 & 1951-09-13 & Ley 14053 prorroga y modifica la ley 13581 de locaciones urbanas \\
\hline $1952-09-30$ & $1952-10-06$ & Ley 14178 modifica la ley 13.581 desalojo \\
\hline 1954-09-29 & 1954-10-13 & Ley 14356 Locación urbana: modificación y prórroga de la ley 13.581 \\
\hline 1955-09-30 & 1955-10-04 & Decreto-ley 160,30 septiembre 1955 prorroga la vigencia de la ley 13.581 y sus modificaciones sobre locaciones urbanas \\
\hline $1955-12-30$ & $1955-12-30$ & Decreto-ley 7588/55 Locación urbana: Modificación y prórroga de la ley 13.581 \\
\hline $1956-12-26$ & 1957-01-11 & Decreto-ley 23034/56 (Int.) prórroga del régimen de emergencia en matería de locación urbana \\
\hline $1957-02-28$ & 1957-03-08 & Decreto-ley 2186/57 Régimen de la locación urbana \\
\hline 1958-05-29 & 1958-05-30 & Ley 14438 paralización de juicios de desalojo \\
\hline 1958-11-15 & 1958-12-09 & Ley 14775 prórroga del régimen de locaciones y de la paralización de juicios de desalojo y lanzamientos \\
\hline 1959-06-30 & 1959-07-15 & Ley 14809 prórroga del régimen de locaciones y de la paralización de juicios de desalojo y lanzamientos \\
\hline 1959-07-31 & 1959-08-01 & Ley 14821 Régimen de locaciones urbanas \\
\hline 1960-08-31 & & Ley 15331 plazo para abonar la liquidación por capital, intereses y costas en los juicios por desalojo por falta de pago \\
\hline 1960-11-17 & 1960-12-06 & Ley 15775 Régimen de locación urbana \\
\hline 1964-09-29 & 1964-09-30 & Ley 16485 Locación urbana; ampliación de la prórroga del régimen de emergencia hasta el 31 de diciembre de 1964 \\
\hline $1964-12-30$ & 1965-01-11 & Ley 16654 Locación urbana; prórroga del régimen de emergencia hasta el 31 de julio de 1965 \\
\hline $1965-10-01$ & $1965-10-11$ & Ley 16739 régimen de locación urbana \\
\hline $1967-07-27$ & $1967-08-02$ & Ley 17368 Locación urbana; retorno al sistema del Código Civil en los nuevos contratos \\
\hline $1970-12-29$ & 1971-01-01 & Ley 18880 Locación urbana - régimen \\
\hline 1970-12-30 & 1970-12-30 & Ley 18901/70 Locación urbana - Plan de apoyo financiero para locatarios con incapacidad económica \\
\hline $1971-12-31$ & 1971-12-31 & $\begin{array}{l}\text { Ley } 19405 \text { Prórroga de contratos. Reducción de los porcentajes de aumentos. Sustitución de los artículos } 2 \text { y } 5 \text { de la ley } \\
18880\end{array}$ \\
\hline 1973-02-05 & $1973-02-12$ & Decreto 981/73 Vivienda - Registro de locatarios de menores recursos - Habilitación en el Ministerio de Bienestar Social \\
\hline $1973-12-21$ & $1974-01-21$ & Ley 20625 Locaciones urbanas - Régimen de emergencia \\
\hline 1976-06-29 & 1976-07-01 & Ley 21342 Normalización de locaciones urbanas. Régimen que reemplaza al instituído por la Ley 20.625 y sus prórrogas \\
\hline 1984-09-20 & 1984-12-16 & Ley 23091 Locaciones urbanas \\
\hline 1987-11-12 & 1987-12-03 & Ley 23542 Locaciones urbanas: Reducción porcentual \\
\hline 1989-09-29 & 1989-10-06 & $\begin{array}{l}\text { Ley } 23747 \text { Disposiciones para los locadores y locatarios comprendidos en la Ley } \mathrm{N}^{\circ} 23.091 \text { y en las normas del régimen general } \\
\text { aplicable a las locaciones urbanas cualquiera fuere su destino }\end{array}$ \\
\hline 1991-03-27 & 1991-04-01 & Ley 23928 Convertibilidad del Austral \\
\hline 1997-04-23 & 1997-05-14 & Ley 24808 Locaciones urbanas. Resolución anticipada. Modificación de la ley 23091 \\
\hline 2002-01-06 & 2002-01-06 & Ley 25561 Emergencia pública y reforma del sistema cambiario \\
\hline 2002-02-03 & 2002-02-04 & $\begin{array}{l}\text { Decreto 214/02 Decreto de Necesidad y Urgencia del Poder Ejecutivo Nacional ("Reordenamiento del Sistema Financiero. } \\
\text { Nuevas medidas económicas. Pesificación") }\end{array}$ \\
\hline 2014-12-01 & 2015-08-01 & Ley 26994 Código Civil y Comercial de la Nación \\
\hline \multicolumn{3}{|r|}{ Australia (AU) } \\
\hline $1915-12-29$ & 1916-01-01 & Fair Rents Act \\
\hline 1920-01-01 & 1920-01-01 & Fair Rents (Amendment) Act \\
\hline 1926-02-08 & 1926-02-08 & Fair Rents (Amendment) Act \\
\hline 1928-11-09 & 1928-11-09 & Fair Rents (Amendment) Bill \\
\hline
\end{tabular}




\section{Table 7: List of legal acts (continued)}

\begin{tabular}{|c|c|c|}
\hline $\begin{array}{l}\text { Date of legal } \\
\text { act (yyyy- } \\
\text { mm-dd) }\end{array}$ & $\begin{array}{l}\text { Enactment } \\
\text { or publica- } \\
\text { tion date } \\
\text { (yyyy-mm- } \\
\text { dd) }\end{array}$ & Title of legal act \\
\hline 1930-12-19 & $1930-12-19$ & The Landlord and Tenant Amendment (Distress Abolition) Act, 1930 \\
\hline 1931-08-14 & 1931-08-14 & Ejectments Postponement Act 1931 \\
\hline 1931-10-07 & 1931-10-07 & Reduction of Rent Act 1931 \\
\hline $1932-12-30$ & $1932-12-30$ & Landlord and Tenants (Amendment) Act 1932 \\
\hline $1939-12-20$ & $1939-12-20$ & Increase of rent (War restrictions) Act \\
\hline $1942-11-26$ & $1942-11-26$ & Landlord and Tenant Act 1942 \\
\hline $1946-12-14$ & 1947-01-01 & Defense (Transitional Provisions) Act 1946 \\
\hline $1948-08-16$ & 1948-08-16 & National Security (Landlord and Tenant) Regulations \\
\hline $1954-12-16$ & $1954-12-16$ & Landlord and Tenant Act Amendments 1954 \\
\hline 1956-01-01 & 1956-01-01 & Landlord and Tenant Act Amendments 1956 \\
\hline 1958-09-30 & $1958-09-30$ & Landlord and Tenant Act 1958 \\
\hline 1962-10-05 & 1962-10-05 & Excessive Rents Act 1962 \\
\hline $1964-12-16$ & 1964-12-16 & Landlord and Tenant Act Amendments 1964 \\
\hline $1968-12-13$ & $1968-12-13$ & Landlord and Tenant Act Amendments 1968 \\
\hline 1978-03-30 & $1978-03-30$ & Residential Tenancies Act 1978 \\
\hline $1985-11-06$ & 1986-01-01 & Landlord and Tenant Act Amendments 1985 \\
\hline 1988-01-21 & 1988-01-21 & Residential Tenancies Act 1987 \\
\hline 1998-01-14 & 1998-01-14 & Residential Tenancies Act 1997 \\
\hline $2010-06-17$ & 2010-06-17 & Residential Tenancies Act 2010 \\
\hline \multicolumn{3}{|r|}{ Austria (AT) } \\
\hline $1917-01-26$ & $1917-01-28$ & Verordnung des Gesamtministeriums vom 26. Jänner 1917 über den Schutz der Mieter \\
\hline 1918-01-20 & 1918-01-20 & $\begin{array}{l}\text { Verordnung des Justizministers und des Ministers für soziale Fürsorge im Einvernehmen mit den beteiligten Ministern vom } \\
\text { 20. Jänner } 1918 \text { über den Schutz der Mieter }\end{array}$ \\
\hline 1918-10-18 & $1918-10-23$ & $\begin{array}{l}\text { Verordnung des Ministers für soziale Fürsorge im Einvernehmen mit dem Minister des Innern vom } 18 . \text { Oktober } 1918 \text {, } \\
\text { betreffend die Einführung des Wohnungsnachweises }\end{array}$ \\
\hline 1918-10-26 & 1918-10-26 & $\begin{array}{l}\text { Verordnung des Justizministers und des Ministers für soziale Fürsorge im Einvernehmen mit den beteiligten Ministern vom } \\
\text { 26. Oktober } 1918 \text { über den Schutz der Mieter }\end{array}$ \\
\hline 1918-11-13 & 1918-11-18 & $\begin{array}{l}\text { Vollzugsanweisung des Deutschösterreichischen Staatrates vom 13. November 1918, betreffend Anforderung von Wohnungen } \\
\text { durch Gemeinden }\end{array}$ \\
\hline $1922-12-07$ & 1922-12-07 & Bundesgesetz vom 7. Dezember 1922 über die Miete von Wohnungen und Geschäftsräumlichkeiten (Mietengesetz) \\
\hline $1922-12-07$ & 1923-01-01 & Bundesgesetz vom 7. Dezember 1922, betreffend Wohnungsanforderung \\
\hline $1922-12-16$ & $1922-12-16$ & Verordnung der Bundesministerien für Justiz und für soziale Verwaltung vom 16. Dezember 1922 über die Mietkommissionen \\
\hline 1929-06-14 & 1929-06-14 & $\begin{array}{l}\text { Bundesgesetz vom } 14 . \text { Juni } 1929 \text {, betreffend die Förderung der Wohnbautätigkeit und Abänderung des Mietengesetzes } \\
\text { (Wohbauförderungs- und Mietengesetz) }\end{array}$ \\
\hline 1929-06-22 & 1929-07-04 & Bundesgesetz über die Miete von Wohnungen und Geschäftsräumlichkeiten (Mietengesetz) \\
\hline 1933-07-21 & 1933-07-21 & Verordnung des Bundesregierung vom 21. Juli 1933, womit das Mietengesetz abgeändert wird (Mietengesetznovelle 1933) \\
\hline $1938-02-25$ & $1938-02-25$ & Bundesgesetz über die Förderung der Errichtung von Wohnhäusern (WFE. 1938) \\
\hline 1938-06-04 & 1938-03-18 & Erste Verordnung des Reichsstatthalters (Österreichische Landesregierung) über die Mietzinsregelung im Lande Österreich \\
\hline 1938-08-31 & 1938-08-31 & 2. VO zur Ausführung der VO über Kündigungsschutz für Miet- und Pachträume \\
\hline $1938-12-15$ & 1938-12-15 & 4. VO über den Höchstbetrag für Reichsbürgschaften für den Kleinwohnungsbau \\
\hline $1939-04-20$ & 1939-04-20 & Verordnung zur Erleichterung der Wohnungsbeschaffung für kinderreiche Familien \\
\hline 1939-04-30 & 1939-04-30 & G über Mietverhältnisse mit Juden \\
\hline 1939-09-05 & 1939-09-05 & 3. VO zur Ausführung der VO über Kündigungsschutz für Miet- und Pachträume \\
\hline 1940-08-14 & 1940-08-14 & 5. VO zur Ausführung der VO über Kündigungsschutz für Miet- und Pachträume \\
\hline 1940-09-10 & 1940-09-10 & VO zur Änderung und Ergänzung des G über Mietverhältnisse mit Juden \\
\hline 1940-11-15 & 1940-11-15 & Erlaß zur Vorbereitung des deutschen Wohnungsbaues nach dem Kriege \\
\hline $1940-12-20$ & $1940-12-20$ & VO über den Höchstbetrag für Reichsbürgschaften auf dem Gebiete des Wohnungswesens, Siedlungswesens und Städtebaues \\
\hline 1941-01-15 & 1941-01-15 & G zur Änderung des Reichsmietengesetzes \\
\hline 1941-07-29 & 1941-07-29 & VO über das Verbot der Umwandlung von Wohnungen in Räume anderer Art \\
\hline $1942-08-14$ & $1942-08-14$ & VO über das Verbot der Zweckentfremdung von Wohnungen \\
\hline $1942-12-15$ & $1942-12-15$ & MieterschutzG \\
\hline 1943-02-27 & 1943-02-27 & VO zur Wohnraumlenkung \\
\hline 1943-06-21 & 1943-06-21 & VO zur Wohnraumversorgung der luftkriegsbetroffenen Bevölkerung \\
\hline $1945-08-22$ & 1945-09-01 & $\begin{array}{l}\text { Gesetz vom 22. August 1945, betreffend die Anforderung und Vergebung von Wohn- und Geschäftsräumen (Wohnungsan- } \\
\text { forderungsgesetz) }\end{array}$ \\
\hline
\end{tabular}




\section{Table 7: List of legal acts (continued)}

\begin{tabular}{|c|c|c|}
\hline $\begin{array}{l}\text { Date of legal } \\
\text { act (yyyy- } \\
\text { mm-dd) }\end{array}$ & $\begin{array}{l}\text { Enactment } \\
\text { or publica- } \\
\text { tion date } \\
\text { (yyyy-mm- } \\
\text { dd) }\end{array}$ & Title of legal act \\
\hline 1955-06-15 & 1955-06-30 & 101. Bundesgesetz: Verlängerung der Geltungsdauer des Wohnungsanforderungsgesetzes 1953 \\
\hline $1967-06-29$ & $1967-06-29$ & $\begin{array}{l}\text { Bundesgesetz vom 29. Juni } 1967 \text { über die Förderung der Errichtung von Klein- und Mittelwohnungen (Wohnbauförderungs- } \\
\text { gesetz 1968) }\end{array}$ \\
\hline 1967-06-30 & 1968-01-01 & 281. Bundesgesetz: Mietrechtsänderungsgesetz \\
\hline 1981-11-12 & 1982-01-01 & Bundesgesetz vom 12. November 1981 über das Mietrecht (Mietrechtsgesetz - MRG) \\
\hline $1993-11-26$ & 1993-12-01 & $\begin{array}{l}\text { 800. Bundesgesetz, mit dem das Wohnungsgemeinnützigkeitsgesetz, das Mietrechtsgesetz, das Wohnungseigentumsgesetz } \\
\text { 1975, das Heizkostenabrechnungsgesetz, das Bundes-Sonderwohnbaugesetz 1982, das Bundes-Sonderwohnbaugesetz 1983, das } \\
\text { Wohnbauförderungsgesetz } 1968 \text { und das Wohnbauförderungsgesetz } 1984 \text { geändert werden und mit dem ein Richtwertgesetz } \\
\text { (RichtWG) geschaffen wird (3. Wohnrechtsänderungsgesetz - 3. WÄG) }\end{array}$ \\
\hline \multicolumn{3}{|r|}{ Belgium (BE) } \\
\hline 1917-08-19 & 1917-08-19 & Arrêté-loi du 19 août 1917 \\
\hline 1918-12-10 & 1918-12-11 & Loi du 10 décembre 1918 sur les loyers \\
\hline 1919-04-30 & 1919-04-30 & Loi du 30 avril 1919 sur les loyers \\
\hline 1919-08-25 & 1919-08-27 & $\begin{array}{l}\text { Loi du } 28 \text { août } 1919 \text { en vue de prévenir la hausse exagérée des loyers et d'empêcher que les locataires soient contraints, sans } \\
\text { motifs graves, à déménager }\end{array}$ \\
\hline 1919-10-11 & 1919-10-11 & Loi du 11 octobre 1919 instituant une Société nationale des habitations et logements à bon marché \\
\hline 1920-04-21 & 1920-04-21 & Arrêté royale du 21 avril 1920 suspendant temporairement certaines actions et exécutions en matiére de bail [Royal Decree] \\
\hline 1920-08-14 & 1920-08-14 & Loi du 14 août 1920 modifiant et completant les lois des 30 avril et 25 août 1919 sur les loyers \\
\hline 1921-07-25 & 1921-07-25 & $\begin{array}{l}\text { Loi du } 25 \text { juillet } 1921 \text { portant revision de la loi du } 11 \text { octobre } 1919 \text { instituant une Société Nationale des habitations et } \\
\text { logements à bon marché }\end{array}$ \\
\hline 1922-06-15 & 1922-06-15 & Loi du 15 juin 1922 suspendant temporairement certaines actions et exécutions en matière de bail à loyer \\
\hline 1922-11-24 & 1922-11-25 & Loi du 24 novembre 1922 portant revision de la loi du 14 août 1920 sur les loyers \\
\hline $1923-02-23$ & $1923-02-23$ & Loi du 23 février 1923 portant revision de la loi du 14 août 1920 sur les loyers \\
\hline $1924-12-27$ & 1924-12-31 & Loi du 27 décembre 1924 prorogeant et modifiant la loi sur les loyers du 20 février 1923 \\
\hline $1925-12-31$ & 1926-01-01 & Loi du 31 décembre 1925 portant prorogation des lois coordonnées du 20 février 1923 et 27 décembre 1924 sur les loyers \\
\hline $1926-12-28$ & 1927-01-01 & Loi du 28 décembre 1926 portant revision de la législation exceptionnelle en matière de baux à loyer \\
\hline 1929-12-31 & 1930-01-01 & Loi prorogeant et modifiant certaines dispositions exceptionnelles en matière de baux à loyer \\
\hline $1931-12-28$ & 1932-01-01 & Loi du 28 décembre 1931 prorogeant certaines dispositions exceptionnelles en matière de baux à loyer \\
\hline $1932-12-30$ & & Loi du 30 décembre 1932 prorogeant certaines dispositions exceptionnelles en matière de baux à loyer \\
\hline 1933-08-03 & & Loi du 3 août 1933 prorogeant certaines dispositions exceptionnelles en matière de baux à loyer \\
\hline $1933-12-28$ & & Loi du 28 décembre 1933 prorogeant certaines dispositions exceptionnelles en matière de baux à loyer \\
\hline $1934-07-31$ & & Arrêté royale (arrêté-loi) du 31 juillet 1934 \\
\hline $1934-10-31$ & & Arrêté royale (arrêté-loi) du 31 octobre 1934 \\
\hline $1935-12-10$ & & Arrêté royale (arrêté-loi) du 10 décembre 1935 relative aux baux à loyer \\
\hline 1936-12-30 & 1936-12-30 & Loi du 30 décembre 1936 prorogeant certaines dispositions exceptionnelles en matière de baux à loyer \\
\hline 1938-03-11 & $1938-03-13$ & Loi du 11 mars 1938 portant certaines dispositions exceptionnelles en matière de baux à loyers \\
\hline $1940-03-22$ & $1940-03-22$ & Loi du 22 mars 1940 portant des dispositions exceptionnelles et temporaires en matière de baux à loyer \\
\hline $1940-08-20$ & & Arrêté du 20 août 1940 \\
\hline 1940-09-20 & 1940-09-20 & Arrêté des Secrétaires généraux des Départements de la Justice et des Finances du 20 septembre 1940 \\
\hline 1941-04-28 & 1941-04-28 & Arrêté du 28 avril 1941 \\
\hline $1942-11-18$ & 1942-11-18 & Arrêté du 18 novembre 1942 \\
\hline $1943-07-15$ & $1943-07-15$ & Arrêté du 15 juillet 1943 \\
\hline 1945-03-12 & $1945-03-15$ & $\begin{array}{l}\text { Arrêté-Loi du } 12 \text { mars } 1945 \text { portant des dispositions exceptionnelles et temporaires en matiere de baux à loyer et mettant } \\
\text { fin à la validité temporaire des arrêtes des } 20 \text { septembre } 1940,28 \text { avril } 1941,18 \text { novembre } 1942 \text { et } 15 \text { juillet } 1943\end{array}$ \\
\hline 1946-12-05 & 1946-12-08 & Arrêté-Loi du 5 décembre 1946 instituant un regime provisoire en ce qui concerne l'echeance de certains baux à loyer \\
\hline 1947-02-19 & 1947-02-19 & Arrêté-Loi du 19 février 1947 suspendant temporairement certaines actions et executions en matiere de baux à loyer \\
\hline $1947-05-14$ & 1947-05-14 & Loi du 12 mai 1947 suspendant temporairement certaines executions en matiere de baux à loyer \\
\hline $1947-05-31$ & $1947-05-31$ & $\begin{array}{l}\text { Loi du } 30 \text { mai } 1947 \text { portant interpretation de l'article 1er de la loi du } 12 \text { mai } 1947 \text { suspendant temporairement certaines } \\
\text { executions en matiere de baux à loyer }\end{array}$ \\
\hline $1947-06-27$ & 1947-06-28 & $\begin{array}{l}\text { Loi du } 27 \text { juin } 1947 \text { prorogeant la loi du } 12 \text { mai } 1947 \text { suspendant temporairement certaines executions en matiere de baux à } \\
\text { loyer }\end{array}$ \\
\hline 1947-08-01 & 1947-08-01 & Loi du 31 juillet 1947 portant des dispositions exceptionnelles en matiere de baux à loyer \\
\hline $1948-03-31$ & 1948-04-01 & Loi du 31 mars 1948 modifiant la loi du 31 juillet 1947, portant des dispositions exceptionnelles en matiere de baux à loyer \\
\hline 1948-06-28 & 1948-07-01 & $\begin{array}{l}\text { Loi du } 28 \text { juin } 1948 \text { prorogeant et modifiant les dispositions de l'article } 43 \text { des lois coordonnées des } 31 \text { juillet } 1947 \text { et } 31 \text { mars } \\
\text { 1948, portant des dispositions exceptionnelles en matiere de baux à loyer }\end{array}$ \\
\hline
\end{tabular}




\section{Table 7: List of legal acts (continued)}

\begin{tabular}{|c|c|c|}
\hline $\begin{array}{l}\text { Date of legal } \\
\text { act (yyyy- } \\
\text { mm-dd) }\end{array}$ & $\begin{array}{l}\text { Enactment } \\
\text { or publica- } \\
\text { tion date } \\
\text { (yyyy-mm- } \\
\text { dd) }\end{array}$ & Title of legal act \\
\hline 1948-08-24 & 1948-08-27 & $\begin{array}{l}\text { Loi du } 24 \text { août } 1948 \text { modifiant les lois coordonnées des } 31 \text { juillet } 1947 \text { et } 31 \text { mars } 1948 \text { portant les dispositions exceptionnelles } \\
\text { en matiere de baux à loyer }\end{array}$ \\
\hline 1948-12-31 & 1949-01-01 & Loi du 31 décembre 1948 modifiant les lois portant des dispositions exceptionnelles en matiere de baux à loyer \\
\hline 1949-05-31 & 1949-06-22 & Loi du 31 mai 1949 modifiant les lois portant des dispositions exceptionnelles en matiere de baux à loyer \\
\hline 1949-12-22 & 1949-12-31 & Loi du 22 décembre 1949 modifiant les lois portant des dispositions exceptionnelles en matiere de baux à loyer \\
\hline 1950-06-30 & 1950-07-01 & Loi du 30 juin 1950 modifiant les lois portant des dispositions exceptionnelles en matiere de baux à loyer \\
\hline $1950-12-20$ & 1951-01-01 & Loi du 20 décembre 1950 portant des dispositions exceptionnelles en matière de baux à loyer \\
\hline 1951-06-01 & 1951-06-08 & $\begin{array}{l}\text { Loi du } 1 \text { juin } 1951 \text { interpretant, completant et modifiant la loi du } 20 \text { décembre } 1950 \text { portant des dispositions exceptionnelles } \\
\text { en matière de baux à loyer }\end{array}$ \\
\hline 1951-12-21 & $1951-12-24$ & $\begin{array}{l}\text { Loi du } 21 \text { décembre } 1951 \text { modifiant la loi du } 20 \text { décembre } 1950 \text { portant des dispositions exceptionnelles en matière de baux } \\
\text { à loyer }\end{array}$ \\
\hline 1951-12-22 & $1951-12-26$ & $\begin{array}{l}\text { Loi du } 22 \text { décembre } 1951 \text { étendant le champ d'application de la législation portant des dispositions exceptionnelles en matière } \\
\text { de baux à loyer à certaines catégories de baux commerciaux, portant sur des immeubles à revenus modiques }\end{array}$ \\
\hline $1952-12-29$ & 1953-01-01 & $\begin{array}{l}\text { Loi du } 29 \text { décembre } 1952 \text { modifiant les lois coordonnees du } 10 \text { mars } 1952 \text { portant des dispositions exceptionnelles en matière } \\
\text { de baux à loyer }\end{array}$ \\
\hline 1953-07-15 & 1953-07-20 & $\begin{array}{l}\text { Loi du } 15 \text { juillet } 1953 \text { completant les lois coordonnées du } 10 \text { mars } 1952 \text { portant des dispositions exceptionnelles en matière } \\
\text { de baux à loyer, modifiées par la loi du } 29 \text { décembre } 1952\end{array}$ \\
\hline 1953-09-21 & & Lois coordonnées du 21 septembre 1953 portant des dispositions exceptionnelles en matière de baux à loyer \\
\hline $1953-12-28$ & 1954-01-01 & $\begin{array}{l}\text { Loi du } 28 \text { décembre } 1953 \text { modifiant les lois coordonnées du } 21 \text { septembre } 1953 \text { portant des dispositions exceptionnelles en } \\
\text { matière de baux à loyer }\end{array}$ \\
\hline 1955-06-30 & 1955-07-01 & $\begin{array}{l}\text { Loi du } 30 \text { juin } 1955 \text { amenageant, en faveur des locataires de condition modeste, le retour au droit commun en matière de } \\
\text { baux à loyer }\end{array}$ \\
\hline 1964-01-29 & 1964-02-08 & Loi du 29 janvier 1964 tendant à protéger les loyers des habitations modestes \\
\hline $1966-12-28$ & 1967-01-01 & $\begin{array}{l}\text { Loi du } 28 \text { décembre } 1966 \text { modifiant et prorogeant la loi du } 29 \text { janvier } 1964 \text { tendant à protéger les loyers des habitations } \\
\text { modestes }\end{array}$ \\
\hline 1967-06-12 & $1967-06-15$ & Loi du 12 juin 1967 portant des dispositions exceptionnelles en matiere de baux à loyer \\
\hline $1967-12-22$ & 1968-01-01 & $\begin{array}{l}\text { Loi du } 22 \text { décembre } 1967 \text { prorogeant la loi du } 12 \text { juin } 1967 \text { portant des dispositions exceptionnelles en matière de baux à } \\
\text { loyer }\end{array}$ \\
\hline 1968-12-24 & 1969-01-01 & $\begin{array}{l}\text { Loi du } 24 \text { décembre } 1968 \text { prorogeant la loi du } 12 \text { juin } 1967 \text { portant des dispositions exceptionnelles en matière de baux à } \\
\text { loyer, prorogée par la loi du } 22 \text { décembre } 1967\end{array}$ \\
\hline 1975-04-10 & 1974-12-01 & Loi du 10 avril 1975 relative aux loyers des immeubles d'habitation \\
\hline 1976-03-30 & 1976-04-11 & Loi du 30 mars 1976 relative au mesures de redressement économique \\
\hline 1976-12-24 & 1976-12-24 & Loi du 24 décembre 1976 relative au mantien de l'emploi, du pouvoir d'achat et de la compétitivité de l'économie \\
\hline 1977-12-27 & 1978-01-01 & Loi du 27 décembre 1977 réglant pour 1978 les baux et autres conventions concédant la jouissance d'un immeuble \\
\hline 1978-11-13 & 1979-01-01 & Loi du 13 novembre 1978 réglant temporairement les baux et autres conventions concédant la jouissance d'un immeuble \\
\hline $1979-12-24$ & 1977-01-07 & Loi du 24 décembre 1979 portant des mesures urgentes de gestion budgétaire \\
\hline $1980-12-23$ & 1981-01-01 & Loi du 23 décembre 1980 réglant temporairement les baux et autres conventions concédant la jouissance d'un immeuble \\
\hline $1981-12-24$ & 1982-01-01 & Loi du 24 décembre 1981 réglant temporairement les baux et autres conventions concédant la jouissance d'un immeuble \\
\hline $1982-12-30$ & 1983-01-01 & Loi du 30 décembre 1982 réglant temporairement les baux et autres conventions concédant la jouissance d'un immeuble \\
\hline 1983-12-29 & 1984-01-01 & Loi du 29 décembre 1983 relative aux contrats de louage de biens immeubles \\
\hline 1985-01-22 & 1985-01-01 & Loi du 22 janvier 1985 de redressement contenant des dispositions sociales \\
\hline 1991-02-20 & 1991-02-28 & Loi du 20 février 1991 modifiant et complétant les dispositions du Code civil relatives aux baux à loyer \\
\hline 1991-03-01 & 1991-03-02 & $\begin{array}{l}\text { Loi du } 1 \text { mars } 1991 \text { modifiant la loi du } 20 \text { février } 1991 \text { modifiant et complétant les dispositions du Code civil relatives aux } \\
\text { baux à loyer }\end{array}$ \\
\hline $1995-12-01$ & 1995-12-05 & Loi du 1 décembre 1995 relative à la prorogation de certains baux à loyer \\
\hline 2007-04-26 & 2007-06-05 & Loi du 26 avril 2007 portant des dispositions en matière de baux à loyer \\
\hline 2009-06-18 & 2009-08-07 & $\begin{array}{l}\text { Loi du } 18 \text { juin } 2009 \text { complétant la loi sur les baux à loyer en ce qui concerne l'imputation au preneur des frais d'intervention } \\
\text { d'un tiers }\end{array}$ \\
\hline \multicolumn{3}{|r|}{ Bolivia (Plurinational State of) $(\mathrm{BO})$} \\
\hline 1930-05-09 & 1930-05-01 & $\begin{array}{l}\text { Decreto Supremo 09-05-1930, Inquilinato - prescribe las condiciones del contrato de alquiler de predios urbanos, de higiene } \\
\text { y salubridad de las viviendas. }\end{array}$ \\
\hline $1932-10-27$ & $1932-10-27$ & Ley de 27 de octubre de 1932 \\
\hline 1933-01-24 & 1933-01-24 & $\begin{array}{l}24 \text { de enero de } 1933 \text { movilización militar, reglamenta las leyes relativas a los funcionarios movilizados, moratoria de pago de } \\
\text { alquileres, exención de derechos notariales en favor de los reservistas, etc. }\end{array}$ \\
\hline 1934-10-18 & $1934-10-27$ & Ley del 18 de octubre de $1934-2$ - Moratoria de alquileres se establece a favor de los conscriptos \\
\hline
\end{tabular}




\section{Table 7: List of legal acts (continued)}

\begin{tabular}{|c|c|c|}
\hline $\begin{array}{l}\text { Date of legal } \\
\text { act (yyyy- } \\
\text { mm-dd) }\end{array}$ & $\begin{array}{l}\text { Enactment } \\
\text { or publica- } \\
\text { tion date } \\
\text { (yyyy-mm- } \\
\text { dd) }\end{array}$ & Title of legal act \\
\hline 1939-05-24 & 1939-05-24 & Decreto supremo del 24 de Mayo de 1939 Consejos de vivienda \\
\hline 1941-03-15 & 1941-03-15 & Ley de 15 de marzo de 1941 \\
\hline 1941-03-17 & 1941-03-17 & $\begin{array}{l}\text { Decreto supremo del } 17 \text { de marzo de } 1941 \text { - juicios de desahucio.- de acuerdo con el el artículo } 2^{\circ} \text { de la ley de } 15 \text { de marzo, } \\
\text { conocerán de estos juicios únicamente los jueces instructores }\end{array}$ \\
\hline 1945-01-03 & 1945-01-01 & Ley de rebaja de alquileres, 3 de enero de 1945 \\
\hline 1956-10-11 & 1956-10-11 & Ley de 11 de octubre de 1956 \\
\hline 1959-12-11 & 1959-12-11 & Ley del Inquilinato, 11 de diciembre de 1959 \\
\hline 1973-04-17 & 1973-04-17 & $\begin{array}{l}\text { Decreto Supremo No } 10820 \text { del } 17 \text { de Abril de } 1973 \text { - Suprímense las Comisarías de Vivienda dependientes de las Alcaldías } \\
\text { de las capitales de Departamento de la República }\end{array}$ \\
\hline 1982-02-05 & 1982-02-05 & $\begin{array}{l}\text { Decreto Ley No } 18844 \text { del } 5 \text { de Febrero de } 1982 \text { - En tanto se proceda a la revalorización de los valores catastrales actuales, } \\
\text { por la Dirección de Catastro Urbano, quedan congelados los cánones de alquiler }\end{array}$ \\
\hline 2017-06-19 & 2017-06-19 & $\begin{array}{l}\text { Ley } 959 \text { de } 19 \text { junio } 2017 \text {, promueve la implementación de programas y proyectos de vivienda social, destinados preferente- } \\
\text { mente a familias de escasos recursos y grupos menos favorecidos, a través de la transferencia de terrenos y la utilización de } \\
\text { recursos del Impuesto Directo a los Hidrocarburos - IDH }\end{array}$ \\
\hline \multicolumn{3}{|r|}{ Canada, Ontario (CA-ON) } \\
\hline 1940-09-11 & 1940-09-21 & Order \\
\hline 1940-09-24 & 1940-10-01 & Order nr. 7 respecting maximum rentals \\
\hline 1941-11-21 & 1941-11-01 & $\begin{array}{l}\text { Regulations respecting leasehold rights and obligations in time of war / Règlements sur la tenure par bail en temps de guerre } \\
\text { (Wartime Leasehold Regulations) }\end{array}$ \\
\hline 1944-08-15 & 1945-01-18 & National Housing Act \\
\hline \multirow[t]{6}{*}{$1945-12-18$} & 1946-01-01 & $\begin{array}{l}\text { An Act to confer certain transitional powers upon the Governor in Council during the National Emergency arising out of } \\
\text { the War (National Emergency Transitional Powers Act, 1945) }\end{array}$ \\
\hline & 1947-03-01 & Order no. 686 respecting maximum rentals and termination of leases for housing accommodation and shared accommodation \\
\hline & 1947-04-07 & Order no. 707 respecting maximum rentals and termination of leases for housing accommodation and shared accommodation \\
\hline & 1947-10-24 & Order no. 771 respecting maximum rentals and termination of leases for housing accommodation and shared accommodation \\
\hline & $1948-02-23$ & Order no. 779 respecting maximum rentals and termination of leases for housing accommodation and shared accommodation \\
\hline & 1948-05-07 & Order no. 782 respecting maximum rentals and termination of leases for housing accommodation and shared accommodation \\
\hline 1948-10-20 & 1948-10-22 & Order no. 791 respecting maximum rentals and termination of leases for housing accommodation and shared accommodation \\
\hline 1949-11-10 & 1949-12-15 & Order no. 813 respecting maximum rentals and termination of leases for selfcontained dwellings and lodgings \\
\hline 1951-04-05 & 1951-04-05 & An Act to provide for the Regulation of Leaseholds (Leasehold Regulations Act, 1951) \\
\hline 1951-04-30 & 1951-04-30 & Apr. 30, 1951 lapse of Continuation of Transitional Measures Act, 1947 (11 Geo. VI, ch. 16) \\
\hline \multirow[t]{2}{*}{ 1953-04-02 } & 1953-04-02 & An act respecting Rent Control (Rent Control Act, 1953) \\
\hline & 1954-03-02 & Repeal of Rent Control Act, 1953 \\
\hline $1975-07-29$ & $1975-12-18$ & An Act to provide for the Review of Rents in respect of Residential Premises (Residential Premises Rent Review Act, 1975) \\
\hline $1975-12-15$ & 1975-12-15 & $\begin{array}{l}\text { An Act to provide for the restraint of profit margins, prices, dividends and compensation in Canada (Anti-Inflation Act of } \\
1975 \text { / Loi anti-inflation) }\end{array}$ \\
\hline 1979-06-22 & 1979-12-01 & The Residential Tenancies Act \\
\hline 1984-05-17 & 1984-05-17 & City of Toronto Act, 1984 [Provincial regulation] \\
\hline 1986-07-10 & 1986-07-10 & Act respecting the Protection of Rental Housing (Rental Housing Protection Act, 1986 - 1998) \\
\hline 1986-12-04 & 1985-08-01 & Residential Rent Regulation Act \\
\hline 1989-09-05 & 1990-01-01 & Planning Act \\
\hline 1992-08-10 & 1993-01-01 & Rent Control Act \\
\hline 1998-01-01 & 1998-06-17 & Tenant Protection Act \\
\hline 2006-06-22 & 2007-01-31 & Residential Tenancies Act, 2006 \\
\hline 2011-09-27 & 2011-09-27 & Chapter 667 Residential rental property demolition and conversion control \\
\hline 2017-05-18 & 2017-05-30 & An Act to amend the Residential Tenancies Act, 2006 (Rental Fairness Act, 2017) \\
\hline \multicolumn{3}{|r|}{ Canada, Quebec (CA-QC) } \\
\hline 1940-09-11 & 1940-10-01 & Extension of the power of the Wartime Prices and Trade Board to control rentals and housing accommodation. \\
\hline 1940-09-24 & 1940-10-01 & Order nr. 7 respecting maximum rentals \\
\hline $1941-11-21$ & 1941-11-01 & $\begin{array}{l}\text { Regulations respecting leasehold rights and obligations in time of war / Règlements sur la tenure par bail en temps de guerre } \\
\text { (Wartime Leasehold Regulations) }\end{array}$ \\
\hline 1944-08-15 & $1945-01-18$ & National Housing Act \\
\hline $1945-12-18$ & 1946-01-01 & $\begin{array}{l}\text { An Act to confer certain transitional powers upon the Governor in Council during the National Emergency arising out of the } \\
\text { War (National Emergency Transitional Powers Act, 1945; Loi de } 1945 \text { sur les pouvoirs transitoires résultant de circonstances } \\
\text { critiques nationales) }\end{array}$ \\
\hline
\end{tabular}




\section{Table 7: List of legal acts (continued)}

\begin{tabular}{|c|c|c|}
\hline $\begin{array}{l}\text { Date of legal } \\
\text { act (yyyy- } \\
\text { mm-dd) }\end{array}$ & $\begin{array}{l}\text { Enactment } \\
\text { or publica- } \\
\text { tion date } \\
\text { (yyyy-mm- } \\
\text { dd) }\end{array}$ & Title of legal act \\
\hline 1951-03-07 & 1951-03-07 & Loi concernant la Régie des loyers \\
\hline 1951-12-04 & 1951-12-04 & $\begin{array}{l}\text { Loi pour favoriser la conciliation entre locataires et propriétaires [Act to amend the "Act respecting the regulation of rentals" } \\
\text { Act to promote conciliation between lessees and property-owners] }\end{array}$ \\
\hline 1957-12-12 & 1957-12-12 & Loi modifiant la Loi pour favoriser la conciliation entre locataires et propriétaires \\
\hline 1958-12-18 & 1958-12-18 & Loi prolongeant d'une année l'application de la Loi pour favoriser la conciliation entre locataires et propriétaires \\
\hline 1962-02-14 & 1962-02-14 & Loi prolongeant et modifiant la Loi pour favoriser la conciliation entre locataires et propriétaires \\
\hline 1963-02-28 & 1963-02-28 & Loi prolongeant et modifiant la Loi pour favoriser la conciliation entre locataires et propriétaires \\
\hline 1966-03-15 & 1966-03-15 & Loi prolongeant et modifiant la Loi pour favoriser la conciliation entre locataires et propriétaires \\
\hline 1967-02-03 & 1967-02-03 & Loi prolongeant la Loi pour favoriser la conciliation entre locataires et propriétaires \\
\hline 1967-02-09 & 1967-02-09 & 1966 Loi prolongeant certains baux à l'occasion de l'Expo 67 \\
\hline 1973-02-28 & 1973-02-28 & Loi pour empêcher les hausses abusives de loyer en 1973 \\
\hline $1973-12-22$ & $1973-12-22$ & Loi prolongeant et modifiant la Loi pour favoriser la conciliation entre locataires et propriétaires \\
\hline $1975-12-15$ & $1975-12-15$ & $\begin{array}{l}\text { An Act to provide for the restraint of profit margins, prices, dividends and compensation in Canada (Anti-Inflation Act of } \\
1975 \text { / Loi anti-inflation) }\end{array}$ \\
\hline 1975-12-19 & 1975-12-19 & Loi prolongeant et modifiant la Loi pour favoriser la conciliation entre locataires et propriétaires \\
\hline $1977-12-22$ & & $\begin{array}{l}\text { Loi modifiant la loi pour favoriser la conciliation entre locataires et propriétaires, le Code civil et d'autres dispositions } \\
\text { législatives }\end{array}$ \\
\hline 1979-11-07 & 1980-10-01 & $\begin{array}{l}\text { Loi instituant la Régie du logement et modifiant le Code civil et d'autres dispositions législatives (Loi sur la Régie du } \\
\text { logement) }\end{array}$ \\
\hline 1987-12-16 & $1987-12-17$ & Loi modifiant la Loi sur la Régie du logement et le Code civil \\
\hline & & Chile (CL) \\
\hline $1906-02-20$ & 1906-02-20 & Ley 1838 \\
\hline 1925-02-19 & 1925-02-19 & Decreto Ley N.o 261 , sobre alquileres de habitaciones \\
\hline 1925-03-09 & 1925-05-01 & Decreto Ley 308 \\
\hline $1927-12-31$ & 1928-01-05 & Decreto con fuerza de ley 2100 \\
\hline 1931-03-12 & 1931-04-08 & Decreto con fuerza de ley número 33 \\
\hline 1932-08-30 & 1932-08-31 & Decreto Ley 520 \\
\hline 1941-03-04 & 1941-03-19 & Ley 6844 \\
\hline 1954-09-16 & 1954-09-25 & Ley 11622 \\
\hline 1975-04-09 & 1975-04-01 & Decreto Ley 964 \\
\hline 1982-01-07 & 1982-01-29 & Ley 18101 \\
\hline \multicolumn{3}{|r|}{ China, Macao Special Administrative Region (MO) } \\
\hline 1940-03-09 & 1940-03-09 & $\begin{array}{l}\text { Diploma Legislativo n. }{ }^{\circ} 652 \text {, de } 9 \text { de Março de } 1940 \text {, Regulando o arrendamento de prédios rústicos e actualizando algumas } \\
\text { disposições da legislação fiscal desta colónia }\end{array}$ \\
\hline 1940-05-18 & 1940-05-18 & $\begin{array}{l}\text { Diploma Legislativo n. }{ }^{\circ} 669 \text {, Substituindo várias disposições do diploma legislativo n. }{ }^{\circ} 652 \text {, que regula o arrendamento de } \\
\text { prédios urbanos e actualiza algumas disposições da legislação fiscal }\end{array}$ \\
\hline $1942-10-17$ & 1942-10-17 & Diploma Legislativo n. ${ }^{\circ} 783$, Arrendamento de prédios urbanos \\
\hline 1948-06-11 & 1948-06-11 & Decreto n. ${ }^{\circ} 36909$ \\
\hline $1949-12-12$ & $1949-12-12$ & Decreto $n .^{\circ} 37647$ \\
\hline 1961-03-07 & 1961-03-07 & $\begin{array}{l}\text { Decreto No. } 43525 \text { regula o arrendamento dos prédios urbanos do ultramar, sem prejuízo das disposições do Código Civil, } \\
\text { quer gerais, quer próprias do contrato de locação, que o não contrariem }\end{array}$ \\
\hline 1980-08-25 & 1980-08-25 & Lei n. ${ }^{\circ} 13 / 80 / M$, Habitação económica \\
\hline 1995-08-14 & 1996-01-01 & Lei n. ${ }^{\circ} 12 / 95 / \mathrm{M}$, Regime do Arrendamento Urbano \\
\hline \multicolumn{3}{|r|}{ Colombia $(\mathrm{CO})$} \\
\hline 1946-03-17 & 1946-03-17 & Decreto número 888 de 1946 \\
\hline 1956-09-26 & 1956-09-26 & Decreto número 1070 de 1956 \\
\hline 1977-01-14 & 1977-01-18 & Decreto número 63 de 1976 \\
\hline $1977-12-20$ & 1978-01-01 & Decreto número 2923 de 1977 \\
\hline $1978-12-22$ & 1979-01-01 & Decreto número 2813 de 1978 \\
\hline $1985-06-18$ & $1985-06-18$ & Ley 56 de 1985 \\
\hline 2003-07-10 & $2003-07-10$ & Ley 820 de 2003 \\
\hline \multicolumn{3}{|r|}{ Cyprus (CY) } \\
\hline 1954-03-03 & 1954-03-03 & $\begin{array}{l}\text { Chapter } 86 \text { of the Laws: A Law to amend and consolidate the Law controlling and relating to rent and matters incidental } \\
\text { thereto }\end{array}$ \\
\hline
\end{tabular}




\section{Table 7: List of legal acts (continued)}

\begin{tabular}{|c|c|c|}
\hline $\begin{array}{l}\text { Date of legal } \\
\text { act (yyyy- } \\
\text { mm-dd) }\end{array}$ & $\begin{array}{l}\text { Enactment } \\
\text { or publica- } \\
\text { tion date } \\
\text { (yyyy-mm- } \\
\text { dd) }\end{array}$ & Title of legal act \\
\hline 1962-03-22 & $1962-03-22$ & 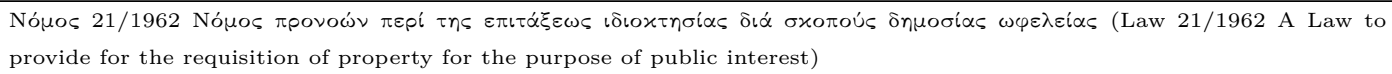 \\
\hline 1966-08-01 & 1966-08-01 & 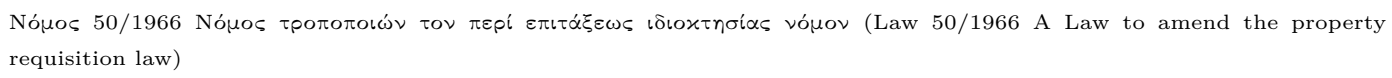 \\
\hline 1968-01-29 & 1968-01-29 & 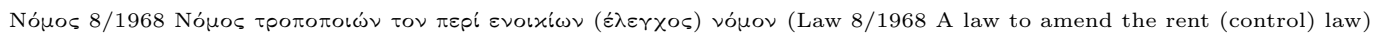 \\
\hline $1975-07-11$ & $1975-07-11$ & 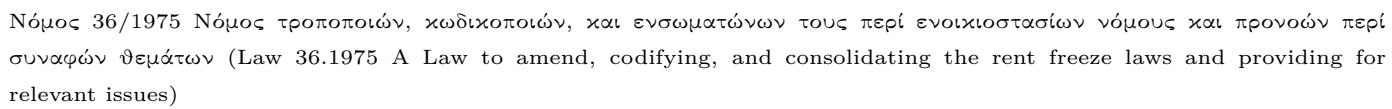 \\
\hline 1975-11-14 & $1975-11-14$ & 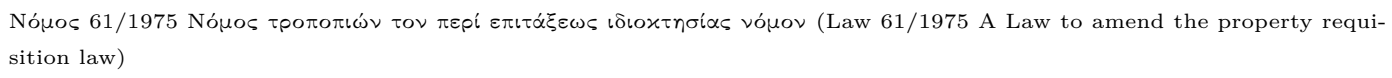 \\
\hline $1976-02-13$ & $1976-02-13$ & 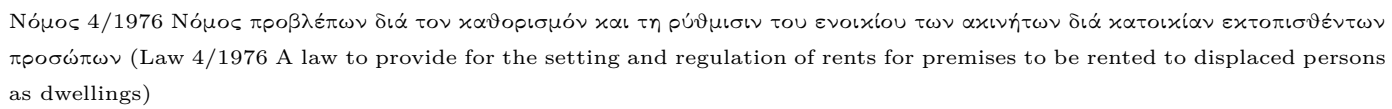 \\
\hline $1977-05-27$ & 1977-04-01 & 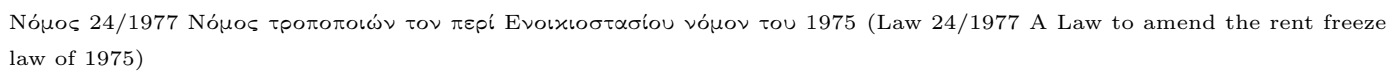 \\
\hline $1978-10-27$ & $1978-10-27$ & 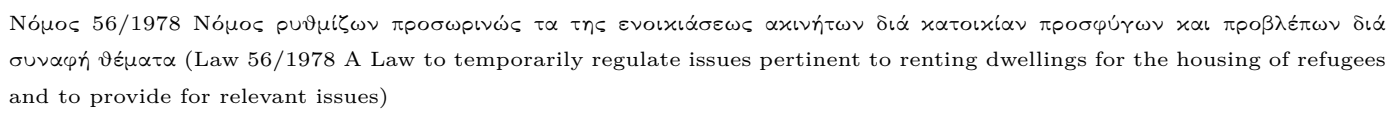 \\
\hline $1980-02-15$ & $1980-02-15$ & 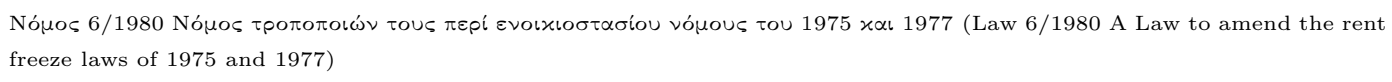 \\
\hline 1983-04-22 & $1983-04-22$ & 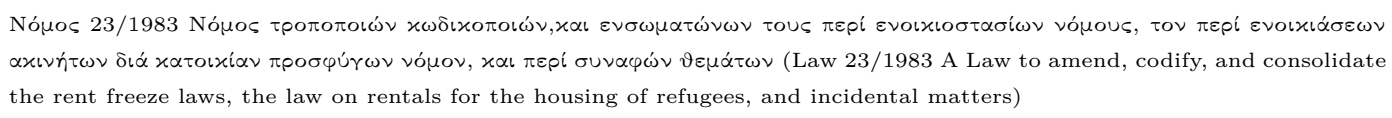 \\
\hline $1983-07-22$ & $1983-07-22$ & 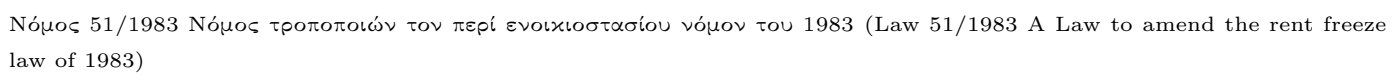 \\
\hline 1984-04-19 & 1984-04-19 & 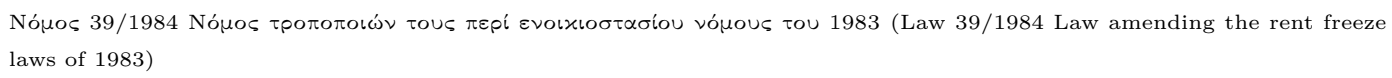 \\
\hline 1986-04-25 & $1986-04-25$ & 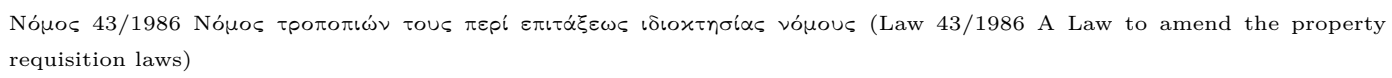 \\
\hline $1986-06-13$ & 1986-06-13 & 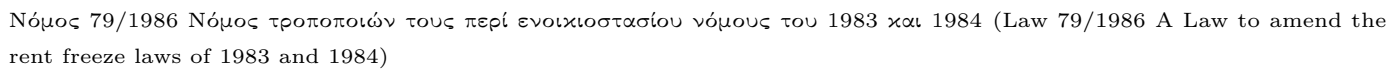 \\
\hline 1986-07-04 & 1986-07-04 & 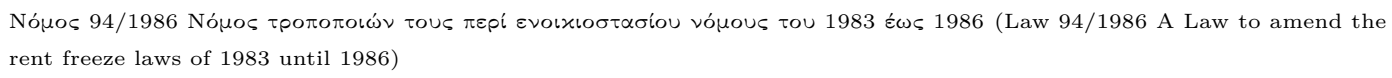 \\
\hline $1988-07-22$ & $1988-07-22$ & 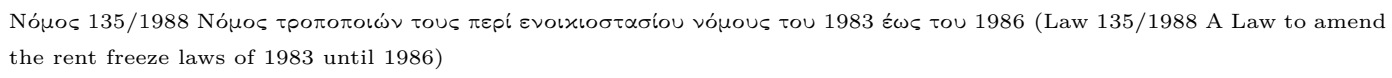 \\
\hline 1989-04-14 & 1989-01-01 & 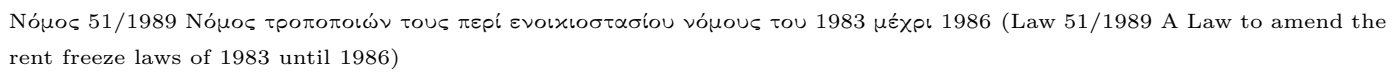 \\
\hline 1991-04-10 & 1991-04-10 & 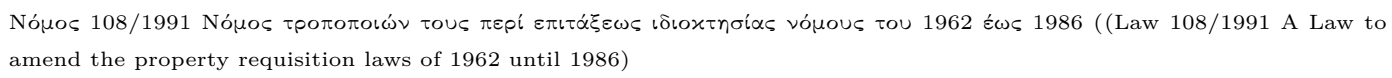 \\
\hline $1991-04-26$ & 1991-04-26 & 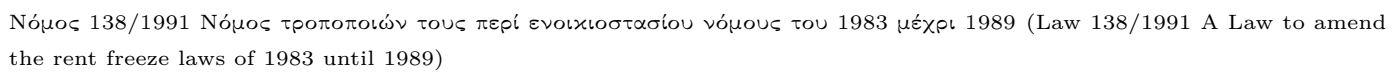 \\
\hline 1992-07-24 & $1992-07-24$ & 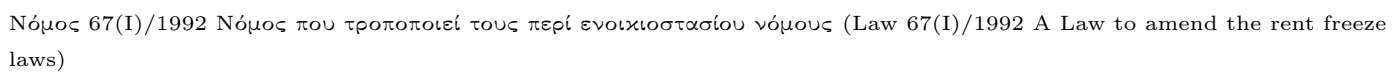 \\
\hline $1992-12-18$ & $1992-12-18$ & 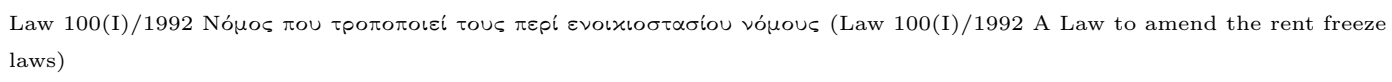 \\
\hline 1993-01-29 & 1993-01-29 & 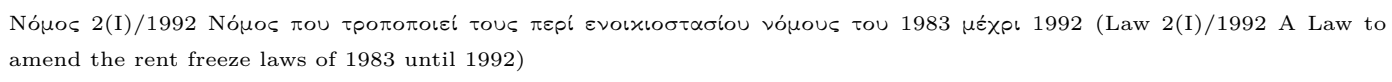 \\
\hline 1995-12-29 & 1995-12-29 & 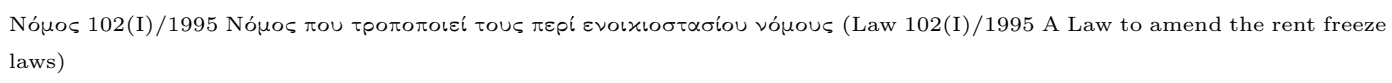 \\
\hline $1998-11-06$ & 1998-11-06 & 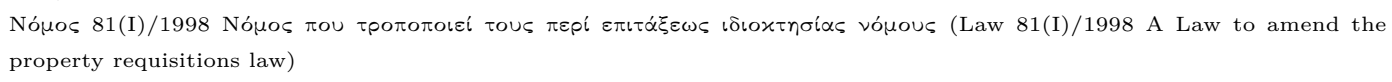 \\
\hline $1999-06-18$ & 1999-06-18 & 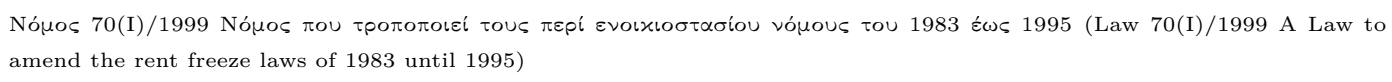 \\
\hline 1999-07-23 & $1999-07-23$ & 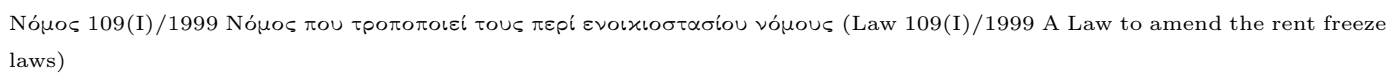 \\
\hline
\end{tabular}




\section{Table 7: List of legal acts (continued)}

\begin{tabular}{|c|c|c|}
\hline $\begin{array}{l}\text { Date of legal } \\
\text { act (yyyy- } \\
\text { mm-dd) }\end{array}$ & $\begin{array}{l}\text { Enactment } \\
\text { or publica- } \\
\text { tion date } \\
\text { (yyyy-mm- } \\
\text { dd) }\end{array}$ & Title of legal act \\
\hline 1999-10-15 & 1999-10-15 & 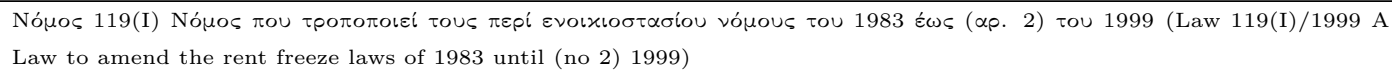 \\
\hline 2001-03-02 & 2001-03-02 & 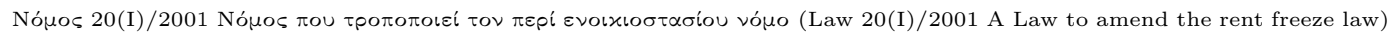 \\
\hline 2002-07-26 & $2002-07-26$ & 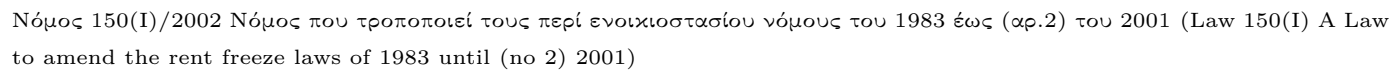 \\
\hline 2003-11-07 & 2003-11-07 & 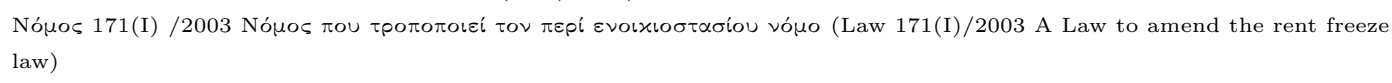 \\
\hline 2006-07-21 & $2006-07-21$ & 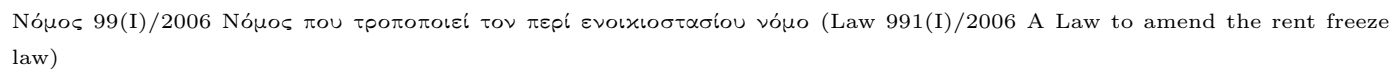 \\
\hline 2007-08-14 & 2007-08-14 & 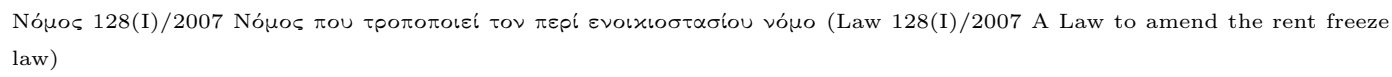 \\
\hline $2013-12-27$ & $2013-12-27$ & 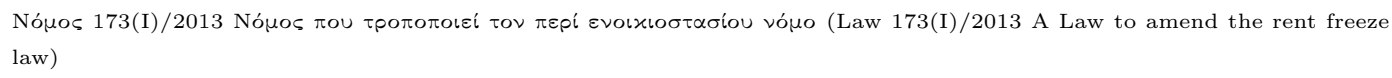 \\
\hline 2014-07-04 & 2014-07-04 & 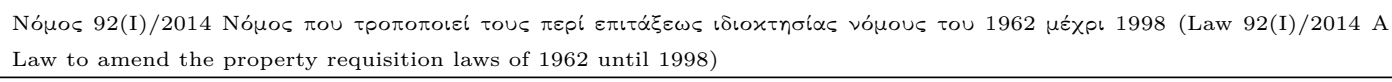 \\
\hline \multicolumn{3}{|r|}{ Czechia $(\mathrm{CZ})$} \\
\hline 1917-01-26 & 1917-01-28 & Verordnung des Gesamtministeriums vom 20. Jänner 1917 über den Schutz der Mieter \\
\hline 1918-01-20 & 1918-01-22 & $\begin{array}{l}\text { Verordnung des Justizministers und Ministers für soziale Fürsorge im Envernehmen mit den beteiligten Ministern vom } 20 . \\
\text { Jänner } 1918 \text { über den Schutz der Mieter }\end{array}$ \\
\hline 1918-03-28 & 1918-03-29 & $\begin{array}{l}\text { Verordnung des Ministers für soziale Fürsorge im Envernehmen mit den Ministern des Innern und der Justiz vom } 28 \text {. März } \\
1918 \text { betreffend Maßnahmen der Wohnungsfürsorge }\end{array}$ \\
\hline $1918-12-23$ & 1919-01-06 & Nařízení o ochraně nájemců \\
\hline 1919-01-29 & 1919-01-29 & Nařízení o zabírání bytů obcemi \\
\hline 1919-02-12 & $1919-02-12$ & Nařízení, kterým se doplňuje a mění nařízení ze dne 17 . prosince 1918 , č. $83 \mathrm{Sb}$. z. a n., o ochraně nájemců \\
\hline 1919-06-21 & $1919-06-21$ & Zákon o zabírání budov neb jejich částí pro účely veřejné \\
\hline 1919-11-15 & 1919-11-15 & Zákon o zabírání bytův obcemi \\
\hline 1920-03-31 & 1920-03-31 & $\begin{array}{l}\text { Nařízení, kterým se prodlužuje účinnost nařízení ministra sociální péče a ministra spravedlnosti ze dne } 17 \text {. prosince } 1918 \text {, č. } \\
83 \text { Sb. z. a n., a ze dne } 9 \text {. února } 1919 \text {, č. } 62 \text { Sb. z. a n., jakož i nařízení ministra s plnou mocí pro Slovensko ze dne } 30 . \\
\text { dubna } 1919 \text {, č. } 77 \text { ( } 3576 \text { pres.), a ze dne } 17 \text {. května } 1919 \text {, č. } 85 \text { (3576-I-pres.), o ochraně nájemců }\end{array}$ \\
\hline 1920-04-03 & 1920-04-03 & Zákon, jímž se doplňuje zákon ze dne 11 . června 1919 , č. $332 \mathrm{Sb}$. z. a n., o zabírání budov neb jejich částí pro účely veřejné \\
\hline $1920-05-03$ & 1920-05-03 & Zákon o ochraně nájemníků \\
\hline 1920-07-03 & 1920-07-03 & Nařízení, kterým se vydávají ustanovení o vyklizení místností najatých a pod \\
\hline 1921-03-31 & 1921-03-31 & Zákon o omezení práva stěhovacího \\
\hline 1921-06-27 & 1921-06-27 & Nařízení, kterým se prodlužuje platnost prozatímních ustanovení o vyklizení místností najatých a pod \\
\hline 1921-09-06 & 1921-09-06 & Zákon o zabírání budov neb jejich částí pro účely veřejné \\
\hline 1921-12-30 & 1921-12-30 & Zákon o prodloužení účinnosti zákona ze dne 8. dubna 1920, č. 275 Sb. z. a n., o ochraně nájemníků \\
\hline $1922-02-16$ & $1922-02-16$ & Zákon, kterým se prodlužuje omezení práva stěhovacího podle zákona ze dne 17 . března 1921 , č. 118 Sb. z. a n. \\
\hline $1922-04-27$ & $1922-04-30$ & Zákon o ochraně nájemníků \\
\hline 1922-08-19 & 1922-08-19 & Zákon o mimořádných opatřeních bytové péče \\
\hline 1923-04-26 & 1923-05-01 & Zákon o ochraně nájemníků \\
\hline 1923-04-30 & $1923-04-30$ & $\begin{array}{l}\text { Zákon, kterým se mění některá ustanovení zákona ze dne 11. července 1922, čís. } 225 \text { Sb. z. a n., o mimořádných opatřeních } \\
\text { bytové péče }\end{array}$ \\
\hline $1924-04-25$ & 1924-05-01 & Zákon o ochraně nájemníků \\
\hline 1924-12-19 & 1924-12-29 & Zákon o prodloužení účinnosti a doplnění zákona o mimořádných opatřeních bytové péče \\
\hline 1925-03-31 & $1925-03-31$ & Zákon o ochraně nájemníků \\
\hline $1926-12-29$ & $1926-12-29$ & Zákon o prodloužení účinnosti a doplnění zákona o mimořádných opatřeních bytové péče \\
\hline $1927-12-30$ & $1927-12-17$ & Zákon o prodloužení účinnosti a doplnění zákona o mimořádných opatřeních bytové péče \\
\hline $1928-03-28$ & & Zákon o stavebním ruchu \\
\hline $1928-03-28$ & $1928-04-01$ & Zákon o ochraně nájemníků \\
\hline $1928-07-11$ & $1928-07-20$ & Zákon o mimořádných opatřeních bytové péče \\
\hline 1929-03-27 & 1929-03-27 & Zákon, kterým se prodlužuje účinnost zákona ze dne 28 . března 1928 , č. 44 Sb. z. a n., o ochraně nájemníků \\
\hline 1929-10-11 & 1929-10-30 & Opatření, kterým se prodlužuje účinnost zákona ze dne 28 . března 1928 , č. $44 \mathrm{Sb}$. z. a n., o ochraně nájemníků \\
\hline 1930-03-27 & 1930-04-01 & Zákon, kterým se prodlužuje a doplňuje zákon ze dne 28 . března 1928 , č. $44 \mathrm{Sb}$. z. a n., o ochraně nájemníků \\
\hline 1930-04-10 & $1930-04-29$ & Zákon o stavebním ruchu \\
\hline 1930-11-26 & 1930-11-29 & Zákon Novely zákonů týkající se bytové péče \\
\hline
\end{tabular}




\section{Table 7: List of legal acts (continued)}

\begin{tabular}{|c|c|c|}
\hline $\begin{array}{l}\text { Date of legal } \\
\text { act (yyyy- } \\
\text { mm-dd) }\end{array}$ & $\begin{array}{l}\text { Enactment } \\
\text { or publica- } \\
\text { tion date } \\
\text { (yyyy-mm- } \\
\text { dd) }\end{array}$ & Title of legal act \\
\hline 1931-12-17 & $1931-12-21$ & Zákon, kterým se doplňují zákony týkající se bytové péče \\
\hline 1932-06-30 & 1932-06-30 & Zákon, kterým se prodlužují zákony týkající se bytové péče \\
\hline 1932-07-22 & 1932-08-16 & Vládní nařízení, kterým se prodlužují zákony týkající se bytové péče \\
\hline 1932-10-31 & $1932-10-31$ & Zákon Novely zákonů týkajících se bytové péče \\
\hline $1933-12-30$ & 1933-12-30 & Zákon, kterým se prodlužují a doplňují zákony týkající se bytové péče \\
\hline $1934-02-28$ & 1934-02-28 & Zákon, kterým se prodlužují a doplňují zákony týkající se bytové péče \\
\hline 1934-04-07 & 1934-03-01 & Vyhláška, kterou se vyhlašuje upravené plné znění zákona o ochraně nájemníků \\
\hline 1934-07-25 & $1934-07-25$ & Vládní nařízení, kterým se mění a doplňují některé zákony týkající se bytové péče \\
\hline $1935-12-31$ & $1935-12-31$ & Zákon, kterým se prodlužují a doplňují zákony týkající se bytové péče \\
\hline 1936-03-31 & 1936-03-31 & Zákon Novely zákonů týkajících se bytové péče \\
\hline 1938-10-12 & 1938-10-14 & Opatření o mimořádných opatřeních bytové péče \\
\hline 1938-11-16 & $1938-11-21$ & Opatření Stálého výboru o mimořádných opatřeních bytové péče \\
\hline 1939-01-21 & & Vládní nařízení o dočasné úpravě některých poměrů nájemních \\
\hline 1939-08-14 & 1939-08-14 & Vládní nařízení, kterým se mění a doplňují některá ustanovení týkající se bytové péče \\
\hline $1939-12-27$ & $1939-12-27$ & $\begin{array}{l}\text { Vládní nařízení, kterým se prodlužuje účinnost opatření Stálého výboru ze dne } 16 \text {. listopadu } 1938 \text {, č. } 288 \text { Sb. z. a n., o } \\
\text { mimořádných opatřeních bytové péče }\end{array}$ \\
\hline 1940-03-28 & 1940-06-01 & Vládní nařízení o ochraně nájemníků \\
\hline 1941-01-12 & 1941-01-12 & Vládní nařízení o zákazu zcizení nemovitostí obecně prospěšných bytových podniků (obecně prospěšných stavebních sdružení) \\
\hline 1941-02-19 & & Vládní nařízení, kterým se mění vládní nařízení ze dne 28. března 1940, č. 177 Sb., o ochraně nájemníků \\
\hline 1941-05-15 & 1941-05-15 & Vládní nařízení o zvláštních opatřeních obcí v bytové péči \\
\hline 1941-06-26 & 1941-07-01 & Vládní nařízení o ochraně nájemníků proti výpovědi \\
\hline 1941-11-20 & $1941-12-31$ & $\begin{array}{l}\text { Vládní nařízení, kterým se prodlužuje účinnost opatření Stálého výboru ze dne 16. listopadu 1938, č. } 288 \text { Sb., o mimořádných } \\
\text { opatřeních bytové péče }\end{array}$ \\
\hline 1941-12-09 & 1941-12-09 & $\begin{array}{l}\text { Vládní nařízení, kterým se mění vládní nařízení ze dne } 26 \text {. února } 1941 \text {, č. } 177 \text { Sb., o zvláštních opatřeních obcí v bytové } \\
\text { péči }\end{array}$ \\
\hline 1943-01-08 & 1943-01-01 & Vládní nařízení, kterým se prodlužuje účinnost některých opatření bytové péče \\
\hline 1943-04-20 & 1943-05-01 & $\begin{array}{l}\text { Vládní nařízení o opatřeních, jimž se usměrňuje bytový trh / RegierungsVO über Maßnahmen zur Lenkung des Wohnungs- } \\
\text { marktes }\end{array}$ \\
\hline 1943-08-04 & 1943-08-04 & $\begin{array}{l}\text { Vládní nařízení, kterým se mění a doplňuje vládní nařízení ze dne } 20 \text {. dubna } 1943 \text {, č. } 103 \text { Sb., o opatřeních, jimiž se } \\
\text { usměrňuje bytový trh }\end{array}$ \\
\hline 1943-09-20 & & Vládní nařízení o úpravě placení nájemného \\
\hline 1944-08-03 & 1944-08-10 & Vládní nařízení o úřadu pro hospodaření s obytnými místnostmi / RegierungsVO über die Wohnraumbewirtschaftungsstelle \\
\hline 1946-08-09 & 1946-08-09 & Zákon o mimořádných opatřeních bytové péče \\
\hline 1948-06-04 & 1948-06-04 & Zákon o hospodaření s byty \\
\hline 1950-06-07 & 1950-06-07 & $\begin{array}{l}\text { Vyhláška Ministerstva práce a sociální péče ze dne } 7 \text {. června } 1950 \text { o úpravě nájemného z bytů a jiných místností dokončených } \\
\text { po } 5 . \text { květnu } 1945\end{array}$ \\
\hline 1950-07-26 & $1950-07-26$ & Zákon o organizaci bytového majetku a Fondu bytového hospodářství \\
\hline 1950-07-26 & 1950-07-26 & Zákon o hospodaření s některými místnostmi \\
\hline 1950-12-19 & 1951-01-01 & Nařízení o důležitých důvodech k výpovědi chráněných nájmů nebo k jich zrušení bez výpovědi \\
\hline $1956-12-27$ & $1956-12-27$ & Zákon o hospodaření s byty \\
\hline 1959-03-25 & 1959-03-25 & Nařízení o opatřeních týkajících se některých věcí užívaných organizacemi socialistického sektoru \\
\hline 1961-12-14 & 1961-12-14 & Zákon, kterým se mění a doplňuje zákon o hospodaření s byty \\
\hline 1962-01-31 & $1962-01-31$ & Vyhláška úplné znění zákona o hospodaření s byty \\
\hline 1962-01-31 & 1962-01-31 & Vyhláška, kterou se provádí zákon o hospodaření s byty \\
\hline 1962-12-12 & $1962-12-12$ & Vyhláška o změně vyhlášky č. 10/1962 Sb., kterou se provádí zákon o hospodaření s byty \\
\hline $1963-10-22$ & $1963-10-22$ & Vyhláška o organizaci bytového hospodářství národních výborů \\
\hline 1964-03-05 & & Zákon občanský zákoník \\
\hline 1964-03-06 & 1964-04-01 & Zákon o hospodaření s byty \\
\hline 1964-03-31 & 1964-03-31 & Vyhláška o úhradě za užívání bytu a za služby spojené s užíváním bytu \\
\hline 1964-09-30 & $1964-09-30$ & Vyhláška, kterou se provádějí některá ustanovení zákona č. 41/1964 Sb., o hospodaření s byty \\
\hline 1966-07-13 & 1966-07-13 & Zákon o osobním vlastnictví bytů \\
\hline 1970-03-12 & $1970-03-12$ & $\begin{array}{l}\text { Zákonné opatření o zániku práva osobního užívání bytu a vyklizení bytu občanů, kteří se protiprávně zdržují mimo území } \\
\text { Československé socialistické republiky }\end{array}$ \\
\hline 1970-09-07 & 1970-09-07 & Nařízení o doplnění vládního nařízení č. 36/1969 Sb., kterým se stanoví další př́ípady, kdy lze přidělit byt ve státním zájmu \\
\hline 1970-12-30 & 1970-12-30 & Vyhláška o některých opatřeních v bytové výstavbě \\
\hline
\end{tabular}




\section{Table 7: List of legal acts (continued)}

\begin{tabular}{|c|c|c|}
\hline $\begin{array}{l}\text { Date of legal } \\
\text { act (yyyy- } \\
\text { mm-dd) }\end{array}$ & $\begin{array}{l}\text { Enactment } \\
\text { or publica- } \\
\text { tion date } \\
\text { (yyyy-mm- } \\
\text { dd) }\end{array}$ & Title of legal act \\
\hline 1971-07-07 & 1971-07-07 & Nariadenie, ktorým sa určujú dalšie prípady, v ktorých je možné pridelit byt v štátnom záujme \\
\hline 1974-03-28 & $1974-03-28$ & $\begin{array}{l}\text { Vyhláška, kterou se zrušuje vyhláška vedoucího Ústřední správy pro rozvoj místního hospodářství č. 80/1963 Sb. o organizaci } \\
\text { bytového hospodářství národních výborů }\end{array}$ \\
\hline 1974-07-25 & $1974-07-25$ & $\begin{array}{l}\text { Vyhláška, kterou se zrušuje vyhláška vedoucího Ústřední správy pro rozvoj místního hospodářství č. 80/1963 Sb., o organizaci } \\
\text { bytového hospodářství národních výborů }\end{array}$ \\
\hline 1975-11-19 & 1975-11-19 & Vyhláška o nadstandardím vybavení bytů \\
\hline $1976-08-26$ & $1976-08-26$ & Vyhláška, kterou se mění a doplňuje vyhláška č. 60/1964 Sb., o úhradě za užívání bytu a za služby spojené s užíváním bytu \\
\hline $1976-12-28$ & $1976-12-28$ & Vyhláška, kterou se mění příloha k vyhlášce č. 127/1975 Sb., o nadstandardním vybavení bytů \\
\hline 1978-04-10 & $1978-04-10$ & Zákon, kterým se mění a doplňuje zákon č. 52/1966 Sb., o osobním vlastnictví bytů \\
\hline 1978-05-06 & 1978-05-06 & Vyhláška o prodeji bytů z národního majetku občanům a o finanční pomoci při modernizaci zakoupených bytů \\
\hline 1983-01-17 & 1983-01-17 & $\begin{array}{l}\text { Vyhláška, kterou se zrušuje vyhláška č. } 127 / 1975 \text { Sb., o nadstandardním vybavení bytů ve znění vyhlášky č. } 165 / 1976 \text { Sb., } \\
\text { kterou se mění př́loha k vyhlášce č. } 127 / 1975 \text { Sb. }\end{array}$ \\
\hline $1988-05-24$ & 1988-05-24 & $\begin{array}{l}\text { Vyhláška, kterou se mění a doplňuje vyhláška č. 60/1964 Sb., o úhradě za užívání bytu a za služby spojené s užíváním bytu, } \\
\text { ve znění vyhlášky č. } 96 / 1976 \text { Sb. }\end{array}$ \\
\hline 1990-05-18 & 1990-05-18 & Nařízení kterým se stanoví další případy, kdy lze přidělit byt ve státním zájmu \\
\hline 1990-07-09 & 1990-07-09 & Nařízení, kterým se stanoví postup národních výborů při prodeji bytů do osobního vlastnictví \\
\hline 1990-10-10 & 1990-11-01 & Zákon o zmírnění následků některých majetkových křivd \\
\hline 1991-05-24 & 1991-05-24 & Zákon České národní rady o přechodu některých věcí z majetku České republiky do vlastnictví obcí \\
\hline $1991-12-18$ & 1992-01-01 & Zákon, kterým se mění, doplňuje a upravuje občanský zákoník \\
\hline 1992-01-16 & 1992-01-16 & $\begin{array}{l}\text { Vyhláška, kterou se mění a doplňuje vyhláška č. 60/1964 Sb., o úhradě za užívání bytu a za služby spojené s užíváním bytu, } \\
\text { ve znění pozdějších předpisů }\end{array}$ \\
\hline 1993-06-29 & 1993-07-01 & Vyhláška o nájemném z bytu a úhradě za plnění poskytovaná s užíváním bytu \\
\hline 1995-02-08 & 1995-02-24 & $\begin{array}{l}\text { Vyhláška, kterou se mění a doplňuje vyhláška Ministerstva financí č. 176/1993 Sb., o nájemném z bytu a úhradě za plnění } \\
\text { poskytovaná s užíváním bytu }\end{array}$ \\
\hline $2002-12-20$ & 2002-12-20 & Nařízení, kterým se stanoví cenové moratorium nájemného z bytů \\
\hline 2003-03-20 & 2003-03-21 & $\begin{array}{l}\text { Nález ve věci návrhu na zrušení nařízení vlády č. } 567 / 2002 \text { Sb., kterým se stanoví cenové moratorium nájemného z bytů, a } \\
\text { na uložení zákazu vládě České republiky pokračovat v zásazích do oblasti cen nájemného z bytu prostřednictvím vydávání } \\
\text { vlastních právních předpisů }\end{array}$ \\
\hline 2006-03-31 & 2006-03-31 & $\begin{array}{l}\text { Zákon o jednostranném zvyšování nájemného z bytu a o změně zákona č. } 40 / 1964 \text { Sb., občanský zákoník, ve znění pozdějších } \\
\text { předpisů }\end{array}$ \\
\hline 2009-05-29 & 2009-06-01 & $\begin{array}{l}\text { Zákon, kterým se mění zákon č. } 107 / 2006 \text { Sb., o jednostranném zvyšování nájemného z bytu a o změně zákona č. } 40 / 1964 \\
\text { Sb., občanský zákoník, ve znění pozdějších předpisů }\end{array}$ \\
\hline \multicolumn{3}{|r|}{ El Salvador (SV) } \\
\hline 1946-03-27 & 1946-03-29 & Decreto No. 14, Ley de emergencia sobre inquilinato \\
\hline 1948-06-14 & $1948-07-26$ & Decreto No. 71 , Ley de inquilinato \\
\hline $1951-12-13$ & $1951-12-13$ & Decreto Legislativo No. 521 \\
\hline 1958-02-18 & 1958-03-01 & Decreto No. 2591, Ley de inquilinato \\
\hline 1974-06-04 & 1974-06-12 & Decreto No. 624 \\
\hline \multicolumn{3}{|r|}{ France (FR) } \\
\hline 1914-08-14 & 1914-08-15 & Décret du 14 août 1914, Décret relatif à la prorogation des délais en matière de loyers \\
\hline 1914-09-01 & 1914-09-02 & Décret du 1 septembre 1914, Décret relatif à la prolongation des délais en matière des loyers \\
\hline 1918-03-09 & 1918-03-10 & Loi du 9 mars 1918, Loi rélative aux modifications apportées aux baux à loyer par l'état de guerre \\
\hline 1919-04-17 & 1919-04-18 & Loi sur la réparation des dommages causés par les faits de la guerre \\
\hline $1919-10-23$ & $1919-10-24$ & $\begin{array}{l}\text { Loi ayant pour objet: 1o de proroger et de modifier l'article } 10 \text { de la loi du } 20 \text { avril 1916; } 20 \text { de proroger et d'étendre les } \\
\text { dispositions du décret du } 13 \text { août } 1919 \text { rélatif à l'affichage des prix de vente; 3o de réprimer la spéculation illicite sur les } \\
\text { loyers }\end{array}$ \\
\hline $1919-10-24$ & $1919-10-24$ & Loi prorogeant les locations verbales contractées entre le ler août 1914 et le 9 mars 1918 \\
\hline 1922-03-31 & 1922-04-01 & Loi du 31 mars 1922, portant fixation définitive de la législation sur les loyers \\
\hline 1923-07-06 & 1923-06-29 & Loi du 6 julliet 1923 prorogeant la loi du 30 décembre 1922 ayant pour objet de surseoir aux expulsions de locataires \\
\hline 1923-12-29 & 1923-12-30 & Loi du 29 décembre 1923, Loi ayant pour but de réprimer la hausse illicite des prix des baux à loyer \\
\hline 1924-07-20 & 1924-07-21 & $\begin{array}{l}\text { Loi du } 20 \text { juillet } 1924 \text { prohibant le changement de destination des locaux affectés à l'habitation et réglementant les locations } \\
\text { en meublé }\end{array}$ \\
\hline 1924-08-02 & 1924-08-03 & $\begin{array}{l}\text { Loi du } 2 \text { août } 1924 \text { ayant pour objet de compléter la législation concernant les locaux d'habitation et les locaux à usage } \\
\text { commercial, industriel et professionel }\end{array}$ \\
\hline
\end{tabular}




\section{Table 7: List of legal acts (continued)}

\begin{tabular}{|c|c|c|}
\hline $\begin{array}{l}\text { Date of legal } \\
\text { act (yyyy- } \\
\text { mm-dd) }\end{array}$ & $\begin{array}{l}\text { Enactment } \\
\text { or publica- } \\
\text { tion date } \\
\text { (yyyy-mm- } \\
\text { dd) }\end{array}$ & Title of legal act \\
\hline 1925-04-25 & $1925-04-25$ & Loi du 25 avril 1925 modifiant et complétant la loi du 2 août 1924 \\
\hline 1926-04-01 & 1926-04-01 & Loi du 1 avril 1926, réglant, à partir du 1er avril 1926, les rapports de bailleurs et des locataires de locaux d'habitations \\
\hline 1929-06-29 & 1929-06-30 & $\begin{array}{l}\text { Loi du } 29 \text { juin 1929, Loi modifiant et complétant la loi du 1er avril } 1926 \text { déterminant les rapports entre les bailleurs et les } \\
\text { locataires de locaux d'habitation }\end{array}$ \\
\hline 1933-06-30 & 1933-07-01 & $\begin{array}{l}\text { Loi du } 30 \text { juin } 1933 \text { modifiant la loi du 1er avril 1926, modifiée par celle du } 29 \text { juin 1929, réglant les rapports des bailleurs } \\
\text { et des locataires de locaux d'habitation }\end{array}$ \\
\hline 1934-06-25 & $1934-06-25$ & $\begin{array}{l}\text { Loi du } 25 \text { juin } 1934 \text { modifiant la loi du 1er avril 1926, modifiée par celle du } 29 \text { juin 1929, réglant les rapports des bailleurs } \\
\text { et des locataires de locaux d'habitation }\end{array}$ \\
\hline 1935-04-04 & 1935-04-05 & Loi du 4 avril 1935 complétant les dispositions de l'article 2 de la loi du 25 juin 1934 \\
\hline 1935-06-30 & 1935-07-01 & $\begin{array}{l}\text { Loi du } 30 \text { juin } 1935 \text { modifiant la loi du ler avril 1926, modifiée par la loi du } 29 \text { juin 1929, réglant les rapports entre les } \\
\text { bailleurs et les locataires de locaux d'habitation et professionels }\end{array}$ \\
\hline 1936-06-30 & 1936-07-01 & $\begin{array}{l}\text { Loi du } 30 \text { juin } 1936 \text { tendant à la modification de la loi du 1er avril 1926, modifiée par les lois des } 29 \text { juin } 1929,30 \text { juin } 1933 \text {, } \\
25 \text { juin 1934, } 4 \text { avril 1935, } 30 \text { juin 1935, reglant les rapports des bailleurs et des locataires de locaux d'habitation }\end{array}$ \\
\hline 1937-06-30 & 1937-07-01 & $\begin{array}{l}\text { Loi du } 30 \text { juin } 1936 \text { tendant à la modification de la loi du 1er avril 1926, modifiée par les lois des } 29 \text { juin } 1929,30 \text { juin } \\
\text { 1933, } 25 \text { juin 1934, } 4 \text { avril 1935, } 30 \text { juin } 1935 \text { et } 30 \text { juin 1936, reglant les rapports des bailleurs et des locataires de locaux } \\
\text { d'habitation }\end{array}$ \\
\hline 1937-12-30 & 1938-01-01 & $\begin{array}{l}\text { Loi du } 31 \text { décembre 1937, tendant à modifier et à compléter la loi di 1er avril 1926, modifiée par la loi du } 29 \text { juin } 1929 \text {, } \\
\text { réglant les rapports des bailleurs et des locataires de locaux d'habitation }\end{array}$ \\
\hline 1937-12-30 & 1938-01-01 & Loi du 31 décembre 1937, relative aux loyers d'immeubles ou de locaux à usage commercial ou industriel \\
\hline 1938-07-11 & $1938-07-13$ & Loi du 11 juillet 1938 sur l'organisation générale de la Nation pour le temps de guerre \\
\hline 1939-07-01 & 1939-07-02 & $\begin{array}{l}\text { Décret du 1er juillet 1939, reportant au 1er octobre } 1939 \text { l'expiration des prolongations de jouissance et des augmentations } \\
\text { de loyer des locaux à usage d'habitation et professionnels }\end{array}$ \\
\hline 1939-07-02 & 1939-07-02 & $\begin{array}{l}\text { Décret du } 2 \text { juillet 1939, tendant à prolonger la loi du } 20 \text { juillet } 1924 \text { prohibant le changement de destination des locaux } \\
\text { affectés à l'habitation et réglementant les locations en meublé }\end{array}$ \\
\hline 1939-09-26 & 1939-09-29 & $\begin{array}{l}\text { Décret du } 26 \text { septembre } 1939 \text { reportant au ler avril } 1940 \text { l'expiration des prolongations de jouissance et des augmentations } \\
\text { de loyer des locaux à usage d'habitation et professionnels }\end{array}$ \\
\hline 1939-09-26 & 1939-10-05 & Décret du 26 septembre 1939 réglant les rapports entre bailleurs et locataires en temps de guerre \\
\hline 1939-11-29 & $1939-12-01$ & $\begin{array}{l}\text { Décret portant modification de la loi du } 28 \text { juin } 1938 \text { tendant à régler le statut de la co-propriéte des immeubles divisés par } \\
\text { appartements }\end{array}$ \\
\hline 1939-11-29 & 1939-12-08 & $\begin{array}{l}\text { Conditions d'application de l'article } 23 \text { du décret du } 26 \text { september } 1939 \text { rélatif aux rapports entre bailleurs et locataires } \\
\text { pendant la durée des hostilités }\end{array}$ \\
\hline 1940-06-01 & 1940-06-02 & $\begin{array}{l}\text { Décret du 1er juin 1940, modifiant le décret du } 26 \text { septembre } 1939 \text { sur les rapports entre balleurs et locataires en temps de } \\
\text { guerre }\end{array}$ \\
\hline 1940-11-25 & $1940-12-11$ & $\begin{array}{l}\text { Loi du } 25 \text { novembre } 1940 \text { relative au point de départ de la réduction de loyers, dont bénéficient certains locataires en temps } \\
\text { de guerre }\end{array}$ \\
\hline 1940-12-11 & 1940-12-19 & $\begin{array}{l}\text { Loi du } 11 \text { décembre } 1940 \text { portant réglementation de l'affichage et de la déclaration ainsi que du recensement des locaux } \\
\text { vacants à usage d'habitation ou professionnel }\end{array}$ \\
\hline 1941-02-26 & $1941-03-10$ & Loi du 28 février 1941, relative au payement des loyers arriérés des locaux d'habitation ou à usage professionnel \\
\hline 1941-02-28 & $1941-03-15$ & Loi du 28 février 1941 relative à la majoration abusive des loyers des locaux d'habitation ou à usage professionnel \\
\hline 1944-02-01 & $1944-02-05$ & Loi No. 50 du 1er février 1944 relative aux locaux d'habitation ou à usage professionnel \\
\hline 1945-04-10 & 1945-04-11 & Ordonnance No. 45-609 du 10 avril 1945 relative aux travaux préliminaires à la reconstruction \\
\hline 1945-06-28 & 1945-06-29 & $\begin{array}{l}\text { Ordonnance No. 45-1421 du } 28 \text { juin } 1945 \text { portant: 1o institution d'un service national du logement; 2o institution d'une } \\
\text { caisse nationale d'entretien et d'amélioration de l'habitat urbain et rural; 3o prorogation de la loi du } 1 \mathrm{er} \text { avril } 1926 \text { et de } \\
\text { l'acte dit loi du ler février } 1944 \text { relatif aux locaux d'habitation ou à usage professionel; 4o majoration de loyers }\end{array}$ \\
\hline 1945-06-30 & $1945-07-08$ & Ordonnance No. 45-1483 du 30 juin 1945 relative aux prix \\
\hline 1945-10-11 & $1945-10-19$ & $\begin{array}{l}\text { Ordonnance No. } 45-2394 \text { du } 11 \text { octobre } 1945 \text { instituant des mesures exceptionnelles et temporaires en vue de remédier à la } \\
\text { crise du logement }\end{array}$ \\
\hline 1947-09-16 & 1947-09-21 & $\begin{array}{l}\text { Décret No. 47-213 du } 16 \text { janvier } 1947 \text { portant application de l'ordonnance No. } 45-2394 \text { du } 11 \text { octobre } 1945 \text { instituant des } \\
\text { mesures exceptionnelles et temporaires en vue de remédier à la crise du logement }\end{array}$ \\
\hline 1948-09-01 & 1948-09-02 & $\begin{array}{l}\text { Loi n } 48-1360 \text { du ler septembre } 1948 \text { réglant les rapports entre bailleurs et locataires ou occupants de locaux d'habitation } \\
\text { ou à usage professionnel }\end{array}$ \\
\hline 1948-12-10 & & $\begin{array}{l}\text { Décret } \mathrm{n}^{\circ} 48-1881 \text { du } 10 \text { décembre } 1948 \text { déterminant les prix de base au mètre carré des locaux d'habitation ou à usage } \\
\text { professionnel }\end{array}$ \\
\hline 1953-08-09 & 1953-08-10 & Décret n 53-700 du 9 août 1953 adaptant le régime des loyers à la situation économique et sociale \\
\hline
\end{tabular}




\section{Table 7: List of legal acts (continued)}

\begin{tabular}{|c|c|c|}
\hline $\begin{array}{l}\text { Date of legal } \\
\text { act (yyyy- } \\
\text { mm-dd) }\end{array}$ & $\begin{array}{l}\text { Enactment } \\
\text { or publica- } \\
\text { tion date } \\
\text { (yyyy-mm- } \\
\text { dd) }\end{array}$ & Title of legal act \\
\hline 1954-07-15 & $1954-07-16$ & 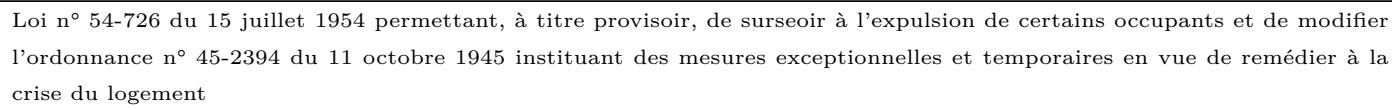 \\
\hline 1954-07-26 & 1954-07-27 & Décret $n^{\circ} 54-766$ du 26 juillet 1954 portant codification des textes législatifs concernant l'urbanisme et l'habitation \\
\hline 1955-07-11 & 1955-07-14 & Décret $n^{\circ} 55-933$ du 11 juillet 1955 portant application du livre III du code de l'urbanisme et de l'habitation \\
\hline 1956-06-18 & 1956-06-19 & Loi $\mathrm{n}^{\circ} 56-588$ du 18 juin 1956 , relative à la réquisition des locaux commerciaux vacants ou inoccupés \\
\hline 1957-01-05 & 1957-01-06 & $\begin{array}{l}\text { Loi } \mathrm{n}^{\circ} 57-6 \text { du } 5 \text { janvier } 1957 \text { modifiant et completant le décret n } 53960 \text { du } 30 \text { septembre } 1953 \text { réglant les rapports entre } \\
\text { bailleurs et locataires en ce qui concerne le renouvellement des baux à loyer d'immeubles ou de locaux à usage commercial, } \\
\text { industriel ou artisanal }\end{array}$ \\
\hline 1957-01-05 & 1957-01-06 & $\begin{array}{l}\text { Décret } n^{\circ} 57-9 \text { du } 5 \text { janvier } 1957 \text { modifiant le décret n } 48-1881 \text { du } 10 \text { décembre } 1948 \text {, art. } 4 \text { déterminant les prix de base au } \\
\text { métre carré des locaux d'habitation ou à l'usage professionnel }\end{array}$ \\
\hline 1958-12-27 & 1958-12-28 & $\begin{array}{l}\text { Décret n } 58-1347 \text { du } 27 \text { décembre } 1958 \text { modifiant la loi du 1er séptembre } 1948 \text { réglant les rapports entre bailleurs et locataires } \\
\text { ou occupants de locaux d'habitation ou à usage professionnel }\end{array}$ \\
\hline 1959-09-10 & 1959-09-11 & $\begin{array}{l}\text { Décret n } 59-1060 \text { du } 10 \text { septembre } 1959 \text { modifiant l'article } 24 \text {-bis de la loi du 1er septembre } 1948 \text { réglant les rapports entre } \\
\text { bailleurs et locataires ou occupants de locaux d'habitation ou à usage professionnel, modifié par le décret nº } 58-1347 \text { du } 27 \\
\text { décembre } 1958\end{array}$ \\
\hline 1960-10-01 & 1960-10-04 & $\begin{array}{l}\text { Décret } n^{\circ} 60-1064 \text { du } 1 \text { er octobre } 1960 \text { relatif aux modalités de calcul des loyers de certains locaux a usage d'habitation ou } \\
\text { professionnel }\end{array}$ \\
\hline 1960-10-01 & 1960-10-04 & $\begin{array}{l}\text { Décret } \mathrm{n}^{\circ} 60-1057 \text { complétant l'article } 32 \text {-bis ajouté par le décret n } \mathrm{n}^{\circ} 58-1347 \text { du } 27 \text { décembre } 1958 \text { à la loi } \mathrm{n}^{\circ} 48-1360 \text { du } \\
\text { 1er séptembre } 1948 \text { portant modification et codification de la législation relative aux rapports des bailleurs et locataires ou } \\
\text { occupants de locaux d'habitation ou à usage professionnel et instituant des allocations de logement }\end{array}$ \\
\hline 1962-08-04 & 1962-08-07 & $\begin{array}{l}\text { Loi } \mathrm{n}^{\circ} 62-902 \mathrm{du} 4 \text { août } 1962 \text { complétant et modifiant la loi } \mathrm{n}^{\circ} 48-1360 \mathrm{du} \text { ler séptembre } 1948 \text { portant modification et } \\
\text { codification de la législation relative aux rapports des bailleurs et locataires ou occupants de locaux d'habitation ou à usage } \\
\text { professionnel, modifiant la loi } \mathrm{n}^{\circ} 56-672 \mathrm{du} 9 \text { juillet } 1956 \text { instituant diverses mesures de protection en faveur des militaires } \\
\text { rappellés ou maintenus provisoirement sous les drapeaux, et rétablissant l'article } 1751 \text { du code civil }\end{array}$ \\
\hline 1964-12-23 & 1964-12-24 & Loi de finances rectificative pour $1964\left(n^{\circ} 64-1278\right.$ du 23 décembre 1964) \\
\hline 1965-07-10 & 1965-07-11 & Loi No. 65-557 du 10 juillet 1965 fixant le statut de la copropriété des immeubles bâtis \\
\hline 1970-07-09 & $1970-07-10$ & $\begin{array}{l}\text { Loi } \mathrm{n}^{\circ} 70-598 \text { du } 9 \text { juillet } 1970 \text { modifiant et complétant la loi } \mathrm{n}^{\circ} 48-1360 \text { du } 1 \text { er séptembre } 1948 \text { portant modification et } \\
\text { codification de la législation relative aux rapports des bailieurs et locataires ou occupants de locaux d'habitation ou à usage } \\
\text { professionnel. }\end{array}$ \\
\hline 1970-07-09 & 1970-07-10 & $\begin{array}{l}\text { Loi } \mathrm{n}^{\circ} 70-599 \text { du } 9 \text { juillet } 1970 \text { modifiant la loi } \mathrm{n}^{\circ} 51-1372 \mathrm{du} \text { ler décembre } 1951 \text { et propageant diverses dispositions transitoires } \\
\text { prises en raison de la crise du logement }\end{array}$ \\
\hline 1982-06-22 & 1982-06-23 & Loi n $82-526$ du 22 juin 1982 rélative aux droits et obligations des locataires et des bailleurs [Quilliot] \\
\hline 1986-12-23 & 1986-12-02 & $\begin{array}{l}\text { Loi } \mathrm{n}^{\circ} 86-1290 \mathrm{du} 23 \text { décembre } 1986 \text { tendant à favoriser l'investissement locatif, l'accession à la propriété de logements } \\
\text { sociaux et le développement de l'offre foncière [Mehaignerie] }\end{array}$ \\
\hline 1989-07-06 & 1989-07-08 & $\begin{array}{l}\text { Loi } \mathrm{n}^{\circ} \text { 89-462 du } 6 \text { juillet } 1989 \text { tendant à améliorer les rapports locatifs et portant modification de la loi } \mathrm{n}^{\circ} 86-1290 \text { du } 23 \\
\text { décembre } 1986 \text { [Malandin ou Mermaz] }\end{array}$ \\
\hline 1998-07-29 & $1998-07-31$ & Loi nº 98-657 du 29 juillet 1998 d'orientation relative à la lutte contre les exclusions \\
\hline 2012-07-20 & 2012-08-01 & $\begin{array}{l}\text { Décret n² } 2012-894 \text { du } 20 \text { juillet } 2012 \text { relatif à l'évolution de certains loyers, pris en application de l'article } 18 \text { de la loi } n^{\circ} \\
89-462 \text { du } 6 \text { juillet } 1989\end{array}$ \\
\hline 2014-03-26 & 2014-03-26 & Loi n 2014-366 du 24 mars 2014 pour l'accès au logement et un urbanisme rénové (1) [Loi ALUR] \\
\hline \multicolumn{3}{|r|}{ Germany (DE) } \\
\hline 1914-06-10 & 1914-06-10 & G, betreffend Bürgschaften des Reichs zur Förderung des Baues von Kleinwohnungen für Reichs- und Militärbedienstete \\
\hline 1914-08-04 & 1914-08-04 & G, betreffend den Schutz der infolge des Krieges an Wahrnehmung ihrer Rechte behinderten Personen \\
\hline 1915-10-07 & 1915-10-07 & Bekanntmachung über das Kündigungsschutz der Hintergebliebenen von Kriegsteilnehmern \\
\hline 1915-12-15 & 1915-12-15 & Bekanntmachung, betreffend Einigungsämter \\
\hline $1917-07-26$ & $1917-07-26$ & Bekanntmachung zum Schutze der Mieter \\
\hline 1918-08-24 & $1918-08-24$ & $\begin{array}{l}\text { G zur Abänderung des } \S 1 \text { Abs. } 1 \text { des G, betreffend Bürgschaften des Reichs zur Förderung des Baues von Kleinwohnungen } \\
\text { für Reichs- und Militärbedienstete }\end{array}$ \\
\hline 1918-09-23 & 1918-09-23 & Bekanntmachung über Maßnahmen gegen Wohnungsmangel \\
\hline 1918-09-23 & 1918-09-23 & Bekanntmachung zum Schutze der Mieter \\
\hline 1918-10-31 & $1918-10-31$ & Bestimmungen des Bundesrats für die Gewährung von Baukostenzuschüssen aus Reichsmitteln \\
\hline 1919-12-09 & 1919-12-09 & VO zur Behebung der dringendsten Wohnungsnot \\
\hline 1920-01-10 & 1920-01-10 & Bestimmungen des Reichsrats über die Gewährung von Darlehen aus Reichsmitteln zur Schaffung neuer Wohnungen \\
\hline 1920-05-11 & 1920-05-11 & G über Maßnahmen gegen Wohnungsmangel \\
\hline
\end{tabular}




\section{Table 7: List of legal acts (continued)}

\begin{tabular}{|c|c|c|}
\hline $\begin{array}{l}\text { Date of legal } \\
\text { act (yyyy- } \\
\text { mm-dd) }\end{array}$ & $\begin{array}{l}\text { Enactment } \\
\text { or publica- } \\
\text { tion date } \\
\text { (yyyy-mm- } \\
\text { dd) }\end{array}$ & Title of legal act \\
\hline $1921-02-12$ & 1921-02-12 & G, betreffend die vorläufige Förderung des Wohnungsbaues \\
\hline 1921-07-11 & 1921-07-11 & G, betreffend Verlängerung der Geltungsdauer des $\mathrm{G}$ über Maßnahmen gegen Wohnungsmangel \\
\hline 1922-03-20 & 1922-03-20 & G über Verlängerung der Geltungsdauer des WohnungsmangelG und der SammelheizungsVO \\
\hline 1922-03-24 & 1922-03-24 & ReichsmietenG \\
\hline 1923-03-26 & 1923-03-26 & G über Verlängerung der Geltungsdauer des WohnungsmangelG \\
\hline 1923-06-01 & 1923-06-01 & G über Mieterschutz und Mieteinigungsämter \\
\hline 1923-07-28 & 1923-07-28 & WohnungsmangelG \\
\hline 1926-06-30 & 1926-06-30 & G über Mieterschutz und Mieteinigungsämter \\
\hline 1926-07-10 & 1926-07-01 & G zur Änderung des ReichsmietenG \\
\hline 1927-03-11 & 1927-03-11 & VO über Festsetzung einer Mindesthöhe der gesetzlichen Miete \\
\hline 1927-06-30 & 1927-06-30 & G zur Verlängerung der Geltungsdauer des MieterschutzG und des ReichsmietenG \\
\hline $1927-12-24$ & $1927-12-24$ & G zur Verlängerung des MieterschutzG und des ReichsmietenG \\
\hline 1928-02-17 & 1928-02-17 & G über Mieterschutz und Mieteinigungsämter \\
\hline $1928-02-20$ & $1928-02-20$ & ReichsmietenG \\
\hline 1930-03-08 & 1930-03-08 & G zur Verlängerung der Geltungsdauer des ReichsmietenG \\
\hline 1930-12-02 & 1930-12-02 & VO des Reichspräsidenten zur Sicherung von Wirtschaft und Finanzen \\
\hline 1931-12-08 & 1933-04-01 & 4. VO des Reichspräsidenten zur Sicherung von Wirtschaft und Finanzen und zum Schütze des inneren Friedens \\
\hline 1933-04-27 & 1933-04-27 & G über Mieterschutz und Mieteinigungsämter \\
\hline 1936-04-18 & 1936-04-20 & G zur Änderung des ReichsmietenG und des MieterschutzG \\
\hline 1936-11-26 & 1936-12-01 & VO über das Verbot von Preiserhöhungen \\
\hline $1937-12-04$ & $1937-12-04$ & 1. VO zur Ausführung der VO über Kündigungsschutz für Miet- und Pachträume \\
\hline 1938-08-31 & 1938-08-31 & 2. VO zur Ausführung der VO über Kündigungsschutz für Miet- und Pachträume \\
\hline 1939-04-20 & 1939-04-20 & Verordnung zur Erleichterung der Wohnungsbeschaffung für kinderreiche Familien \\
\hline 1939-04-30 & 1939-04-30 & G über Mietverhältnisse mit Juden \\
\hline 1939-09-05 & 1939-09-05 & 3. VO zur Ausführung der VO über Kündigungsschutz für Miet- und Pachträume \\
\hline 1940-08-14 & 1940-08-14 & 5. VO zur Ausführung der VO über Kündigungsschutz für Miet- und Pachträume \\
\hline 1940-09-10 & 1940-09-10 & VO zur Änderung und Ergänzung des G über Mietverhältnisse mit Juden \\
\hline 1941-01-15 & 1941-01-15 & G zur Änderung des Reichsmietengesetzes \\
\hline 1941-07-29 & 1941-07-29 & VO über das Verbot der Umwandlung von Wohnungen in Räume anderer Art \\
\hline 1942-08-14 & 1942-08-14 & VO über das Verbot der Zweckentfremdung von Wohnungen \\
\hline $1942-12-15$ & $1942-12-15$ & MieterschutzG \\
\hline 1943-02-27 & 1943-02-27 & VO zur Wohnraumlenkung \\
\hline 1943-06-21 & 1943-06-21 & VO zur Wohnraumversorgung der luftkriegsbetroffenen Bevölkerung \\
\hline 1946-03-08 & 1946-03-08 & KontrollratsG Nr. 18 WohnungsG \\
\hline 1950-04-24 & 1950-04-24 & 1. WohnungsbauG \\
\hline 1950-06-15 & 1950-06-15 & G Nr. A - 9 der Alliierten Hohen Kommission \\
\hline $1951-11-27$ & 1951-11-27 & VO über Ausnahmen vom Mieterschutz \\
\hline 1951-11-29 & 1951-11-29 & VO PR Nr. $71 / 51$ über Maßnahmen auf dem Gebiete des Mietpreisrechts \\
\hline 1953-03-31 & $1953-03-31$ & WohnraumberwirtschaftungsG \\
\hline $1953-08-25$ & $1953-08-25$ & G zur Änderung und Ergänzung des 1. WohnungsbauG \\
\hline $1955-07-27$ & $1955-07-27$ & G über Maßnahmen auf dem Gebiete des Mietpreisrechts (1. BundesmietenG) \\
\hline 1956-06-27 & 1956-06-27 & 2. WohnungsbauG (Wohnungsbau- und FamilienheimG) \\
\hline $1960-06-23$ & $1966-01-01$ & G über den Abbau der Wohnungszwangswirtschaft \\
\hline 1963-07-25 & $1963-07-25$ & VO über die angemessen erhöhte Miete nach der Mietpreisgabe \\
\hline 1963-07-29 & 1963-07-29 & G zur Änderung der Fristen des G über den Abbau der Wohnungszwangswirtschaft und über ein soziales Miet- und Wohnrecht \\
\hline $1965-08-24$ & 1968-01-01 & $\begin{array}{l}\text { G zur Änderung des Schlußtermins für den Abbau der Wohnungszwangswirtschaft und für weitere Maßnahmen auf dem } \\
\text { Gebiete des Mietpreisrechts }\end{array}$ \\
\hline $1965-08-24$ & 1965-08-24 & $\begin{array}{l}\text { G zur verstärkten Eigentumsbildung im Wohnungsbau und zur Sicherung der Zweckbestimmung von Sozialwohnungen } \\
\text { (WoBauÄndG 1965) }\end{array}$ \\
\hline $1967-12-21$ & $1967-12-21$ & $\begin{array}{l}\text { 2. G zur Änderung des Schlußtermins für den Abbau der Wohnungszwangswirtschaft und für weitere Maßnahmen auf dem } \\
\text { Gebiete des Mietpreisrechts }\end{array}$ \\
\hline $1967-12-21$ & $1967-12-21$ & G zur Verwirklichung der mehrjährigen Finanzplanung des Bundes, II. Teil FinanzänderungsG 1967. Vom 21.12.1967 \\
\hline $1968-12-20$ & 1968-12-20 & G zur Änderung mietpreisrechtlicher Vorschriften \\
\hline $1970-06-18$ & $1970-06-18$ & $\begin{array}{l}\text { G zur Änderung mietpreisrechtlicher und wohnungsrechtlicher Vorschriften in der Freien und Hansestadt Hamburg sowie in } \\
\text { der kreisfreien Stadt München und im Landkreis München }\end{array}$ \\
\hline
\end{tabular}




\section{Table 7: List of legal acts (continued)}

\begin{tabular}{|c|c|c|}
\hline $\begin{array}{l}\text { Date of legal } \\
\text { act (yyyy- } \\
\text { mm-dd) }\end{array}$ & $\begin{array}{l}\text { Enactment } \\
\text { or publica- } \\
\text { tion date } \\
\text { (yyyy-mm- } \\
\text { dd) }\end{array}$ & Title of legal act \\
\hline 1971-11-04 & 1971-11-04 & $\begin{array}{l}\text { G zur Verbesserung des Mietrechts und zur Begrenzung des Mietanstiegs sowie zur Regelung von Ingenieur- und Architek- } \\
\text { tenleistungen }\end{array}$ \\
\hline 1971-11-25 & 1971-11-25 & G über den Kündigungsschutz für Mietverhältnisse über Wohnraum \\
\hline 1971-12-17 & 1971-12-17 & G zur Durchführung des langfristigen Wohnungsbauprogramms \\
\hline 1972-10-30 & $1972-10-30$ & $\begin{array}{l}\text { 2. G zur Änderung mietpreisrechtlicher und wohnungsrechtlicher Vorschriften in der Freien und Hansestadt Hamburg sowie } \\
\text { in der kreisfreien Stadt München und im Landkreis München }\end{array}$ \\
\hline 1974-12-18 & 1974-12-18 & 2. G über den Kündigungsschutz für Mietverhältnisse über Wohnraum \\
\hline 1976-08-18 & 1976-08-18 & G zur Änderung des BundesbauG \\
\hline 1976-09-01 & $1976-09-01$ & Wohnungsbau- und FamilienheimG — II. WoBauG \\
\hline 1980-02-20 & $1980-02-20$ & WohnungsbauänderungsG 1980 — WoBauÄndG 1980 \\
\hline 1982-12-20 & $1982-12-20$ & G zur Erhöhung des Angebots an Mietwohnungen \\
\hline 1985-07-11 & 1985-07-11 & Wohnungsbau- und FamilienheimG - II. WoBauG \\
\hline 1986-12-08 & 1986-12-08 & G über das BauGbuch \\
\hline 1990-05-17 & $1990-05-17$ & $\begin{array}{l}\text { G zur Erleichterung des Wohnungsbaus im Planungs- und Baurecht sowie zur Änderung mietrechtlicher Vorschriften } \\
\text { (Wohnungsbau-Erleichterungsgesetz - WoBauErlG) }\end{array}$ \\
\hline 1990-08-14 & $1990-08-14$ & Wohnungsbau- und FamilienheimG — II. WoBauG \\
\hline 1993-04-22 & 1993-04-22 & $\begin{array}{l}\text { G zur Erleichterung von Investitionen und der Ausweisung und Bereitstellung von Wohnbauland (Investitionserleichterungs- } \\
\text { und WohnbaulandG) }\end{array}$ \\
\hline 1993-07-21 & 1993-07-21 & 4. G zur Änderung mietrechtlicher Vorschriften \\
\hline 1994-08-19 & 1994-08-19 & Wohnungsbau- und FamilienheimG — II. WoBauG \\
\hline 1998-08-18 & 1998-08-18 & $\begin{array}{l}\text { G zur Änderung des BauGbuchs und zur Neuregelung des Rechts der Raumordnung (Bau- und RaumordnungsG } 1998- \\
\text { BauROG) }\end{array}$ \\
\hline 2001-06-25 & 2001-06-25 & G zur Neugliederung, Vereinfachung und Reform des Mietrechts (MietrechtsreformG) \\
\hline 2001-09-13 & 2001-09-13 & G zur Reform des Wohnungsbaurechtes \\
\hline 2003-12-29 & 2003-12-29 & HaushaltsbegleitG 2004 (HBeglG 2004) \\
\hline 2006-09-05 & 2006-09-05 & Föderalismusreform-BegleitG \\
\hline 2013-03-11 & 2013-03-11 & $\begin{array}{l}\text { G über die energetische Modernisierung von vermietetem Wohnraum und über die vereinfachte Durchsetzung von Räu- } \\
\text { mungstiteln (MietRÄndG) }\end{array}$ \\
\hline 2013-07-15 & 2013-07-15 & G zur Errichtung eines Sondervermögens "Aufbauhilfe" und zur Änderung weiterer G (AufbauhilfeG) \\
\hline 2015-04-21 & 2015-06-01 & $\begin{array}{l}\text { G zur Dämpfung des Mietanstiegs auf angespannten Wohnungsmärkten und zur Stärkung des Bestellerprinzips bei der } \\
\text { Wohnungsvermittlung (MietNovG) }\end{array}$ \\
\hline 2015-10-20 & 2015-10-20 & AsylverfahrensbeschleuningungsG \\
\hline \multicolumn{3}{|r|}{ Greece (GR) } \\
\hline 1899-07-09 & 1899-07-09 & 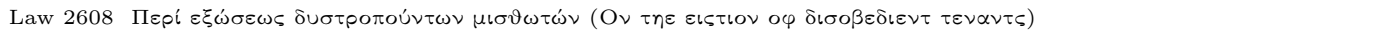 \\
\hline 1922-07-22 & 1922-07-22 & 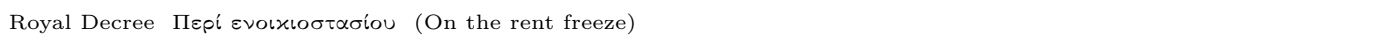 \\
\hline 1922-11-23 & 1922-11-23 & 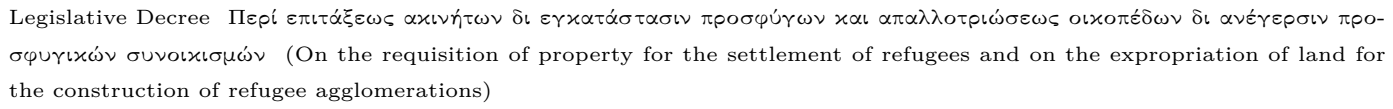 \\
\hline 1922-11-23 & $1922-11-23$ & 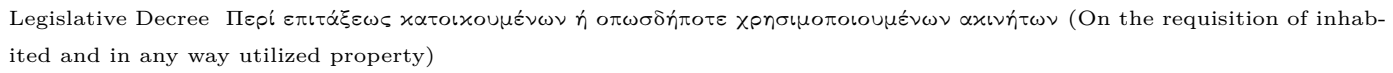 \\
\hline 1923-04-21 & 1923-04-21 & 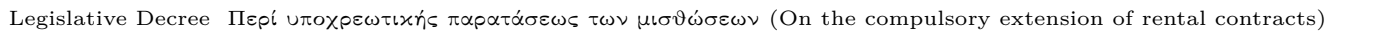 \\
\hline 1923-05-19 & 1923-05-19 & 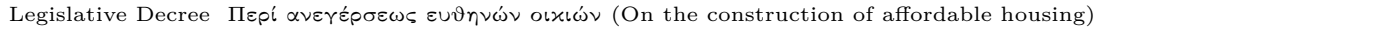 \\
\hline 1923-12-29 & 1924-01-01 & 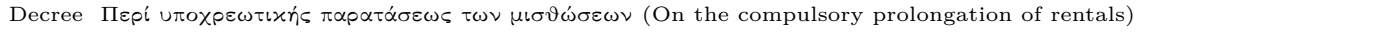 \\
\hline 1925-02-12 & 1925-03-01 & 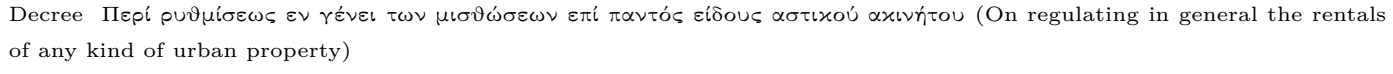 \\
\hline 1925-03-30 & 1925-04-01 & 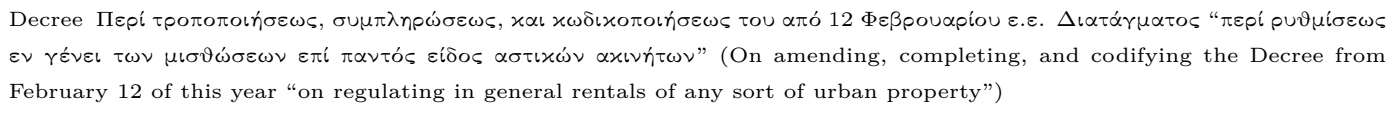 \\
\hline 1925-07-13 & 1925-07-13 & 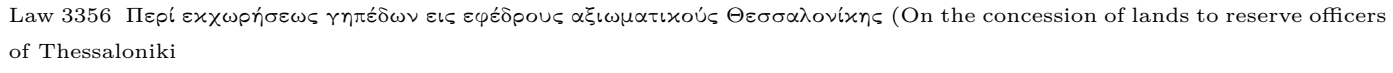 \\
\hline 1926-02-26 & $1926-02-26$ & 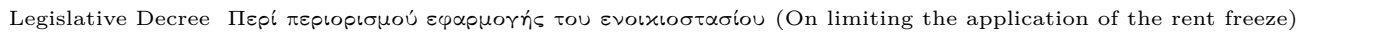 \\
\hline 1927-04-07 & 1927-04-07 & 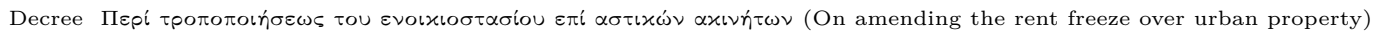 \\
\hline 1927-07-01 & 1927-07-01 & 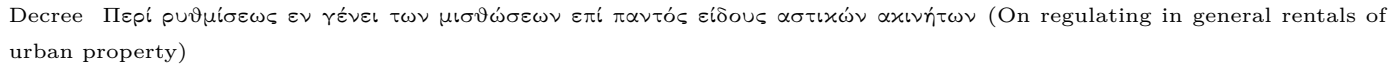 \\
\hline
\end{tabular}




\section{Table 7: List of legal acts (continued)}

\begin{tabular}{|c|c|c|}
\hline $\begin{array}{l}\text { Date of legal } \\
\text { act (yyyy- } \\
\text { mm-dd) }\end{array}$ & $\begin{array}{l}\text { Enactment } \\
\text { or publica- } \\
\text { tion date } \\
\text { (yyyy-mm- } \\
\text { dd) }\end{array}$ & Title of legal act \\
\hline 1929-01-12 & 1929-01-12 & 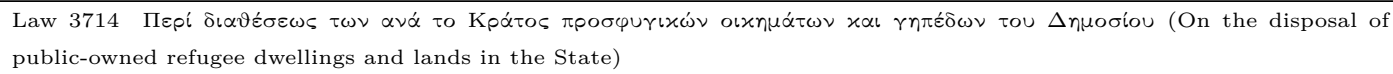 \\
\hline $1929-02-28$ & $1929-02-28$ & 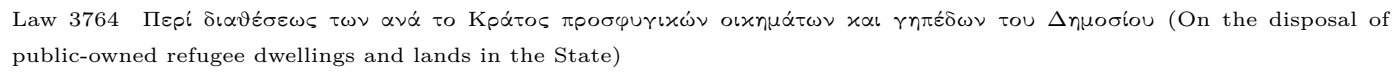 \\
\hline 1930-06-21 & 1930-07-11 & 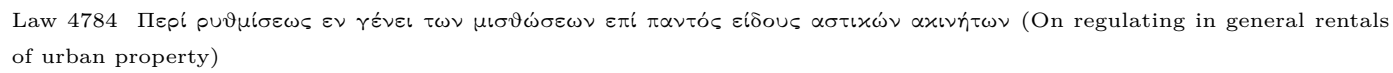 \\
\hline 1931-04-08 & 1931-04-08 & 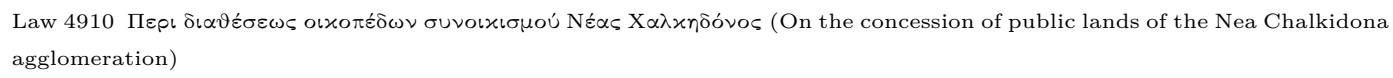 \\
\hline 1932-12-02 & 1932-12-02 & 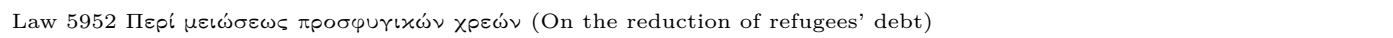 \\
\hline 1933-10-14 & 1933-10-14 & 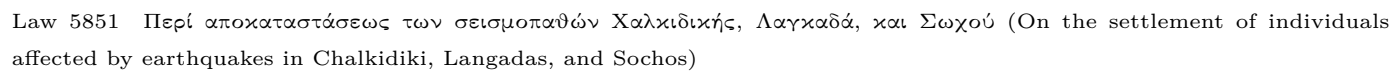 \\
\hline 1934-02-21 & 1934-02-21 & 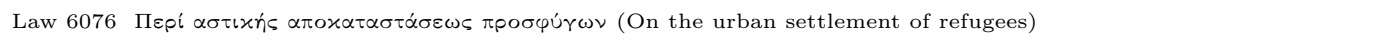 \\
\hline $1936-01-24$ & 1936-01-24 & 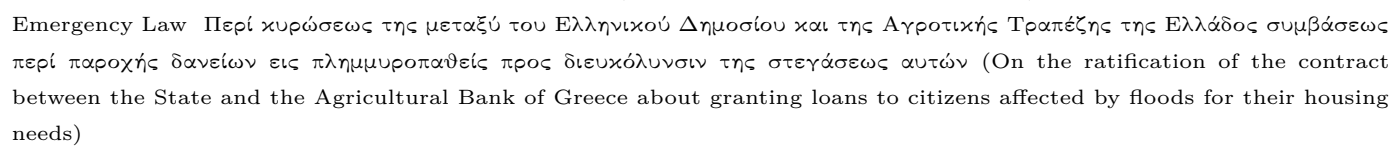 \\
\hline $1936-12-24$ & $1936-12-24$ & 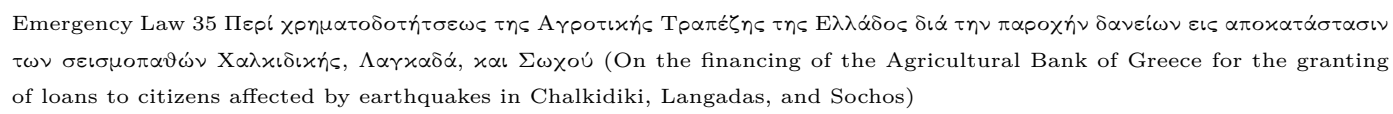 \\
\hline $1939-07-24$ & 1939-07-24 & 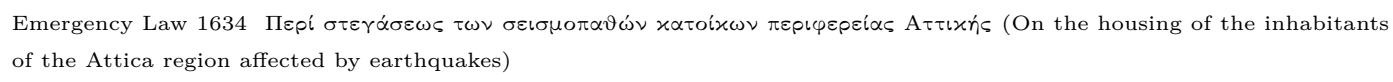 \\
\hline 1942-08-01 & 1942-07-01 & 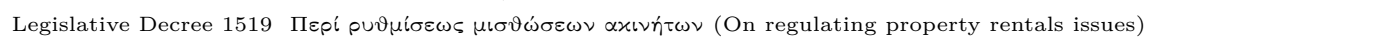 \\
\hline $1942-10-28$ & $1942-10-28$ & 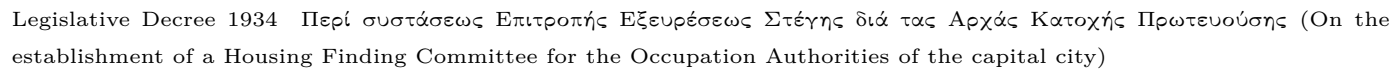 \\
\hline 1943-10-31 & 1943-10-01 & 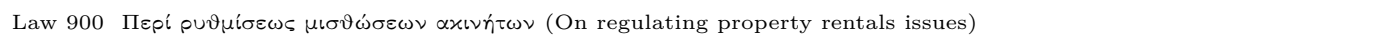 \\
\hline 1943-11-05 & 1943-10-05 & 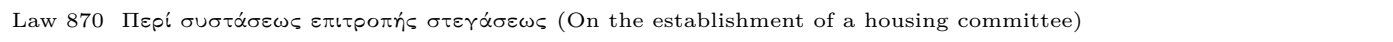 \\
\hline 1943-11-29 & 1943-11-29 & 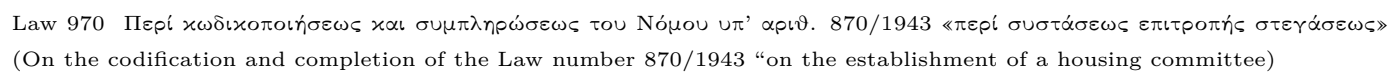 \\
\hline 1944-03-07 & 1944-03-07 & 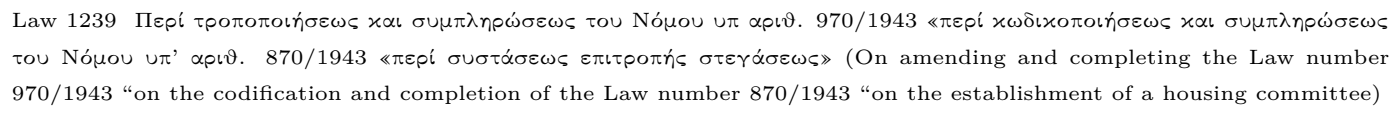 \\
\hline 1944-05-04 & 1944-04-01 & 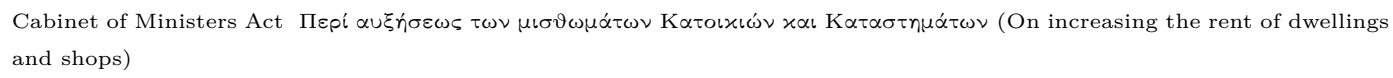 \\
\hline 1944-05-09 & 1944-05-09 & 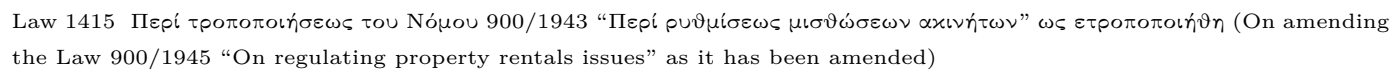 \\
\hline 1944-05-09 & 1944-05-09 & 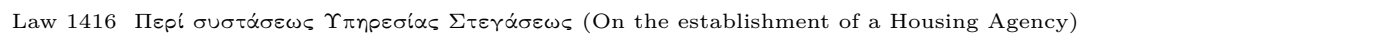 \\
\hline 1944-12-07 & 1947-12-07 & 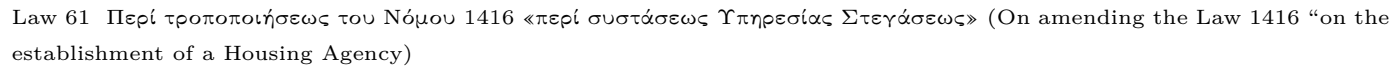 \\
\hline $1945-03-24$ & $1945-03-24$ & 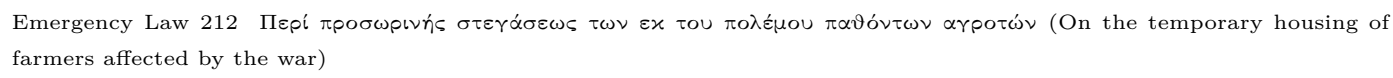 \\
\hline 1945-04-11 & 1945-04-11 & 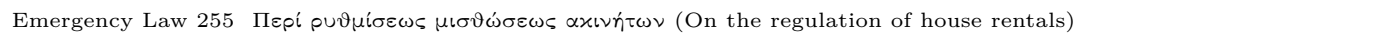 \\
\hline $1945-07-30$ & $1945-07-30$ & 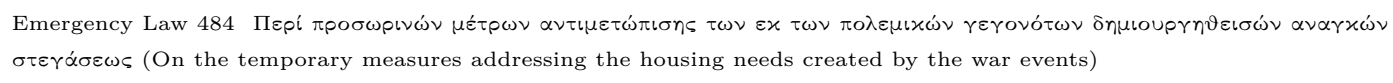 \\
\hline $1945-08-23$ & 1945-08-23 & 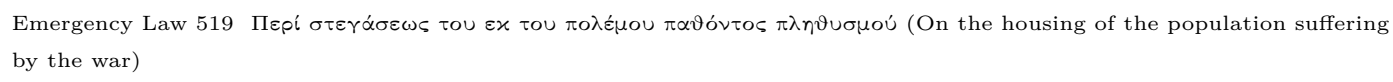 \\
\hline $1946-02-26$ & $1946-02-26$ & 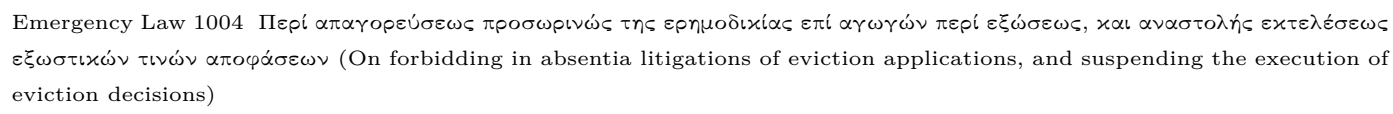 \\
\hline $1946-05-11$ & 1946-05-11 & 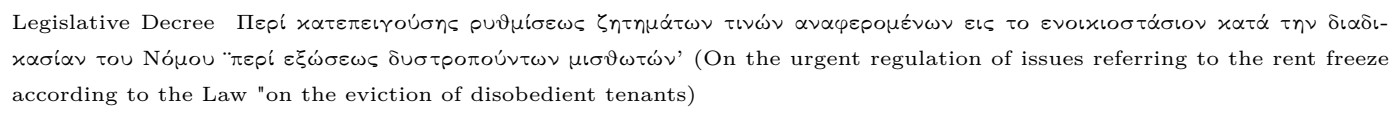 \\
\hline 1946-05-11 & 1946-05-11 & 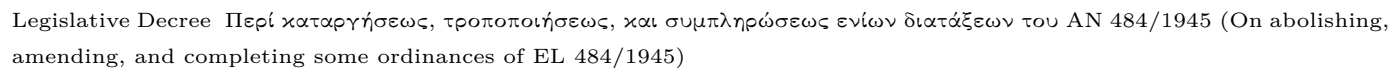 \\
\hline 1946-09-09 & 1946-09-09 & 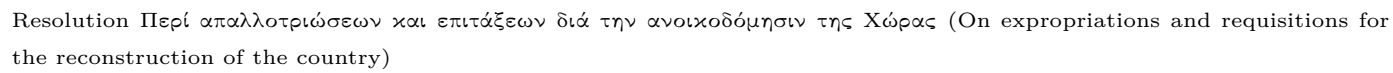 \\
\hline
\end{tabular}




\section{Table 7: List of legal acts (continued)}

\begin{tabular}{|c|c|c|}
\hline $\begin{array}{l}\text { Date of legal } \\
\text { act (yyyy- } \\
\text { mm-dd) }\end{array}$ & $\begin{array}{l}\text { Enactment } \\
\text { or publica- } \\
\text { tion date } \\
\text { (yyyy-mm- } \\
\text { dd) }\end{array}$ & Title of legal act \\
\hline 1946-09-30 & 1946-09-30 & 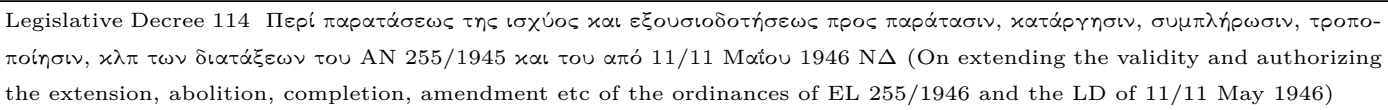 \\
\hline 1946-11-28 & $1946-11-28$ & 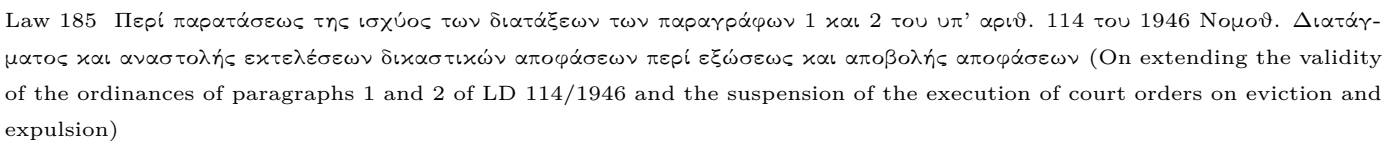 \\
\hline 1946-12-30 & 1947-01-01 & 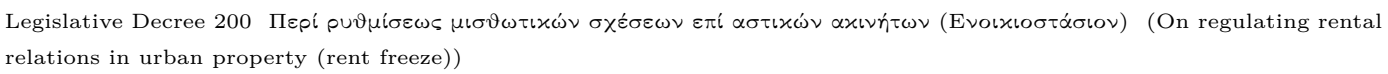 \\
\hline 1947-10-05 & 1947-10-05 & 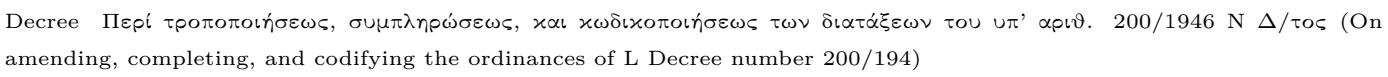 \\
\hline 1947-10-31 & 1947-10-31 & 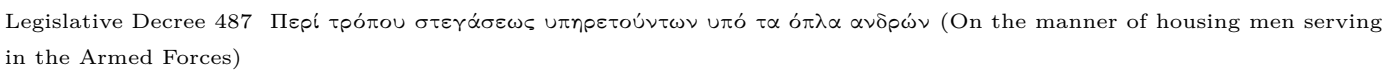 \\
\hline 1948-05-07 & $1948-10-31$ & 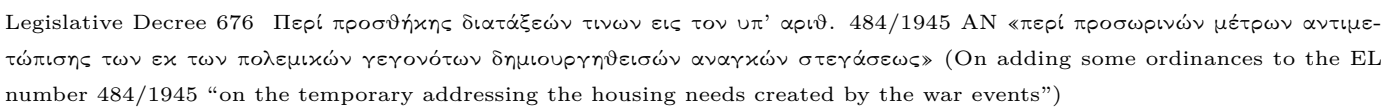 \\
\hline 1948-08-02 & 1948-08-02 & 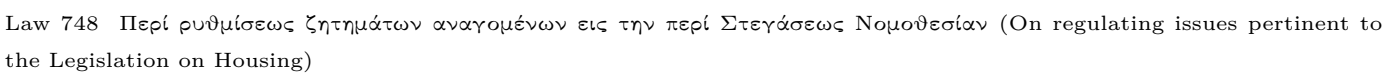 \\
\hline 1949-04-28 & 1949-04-28 & 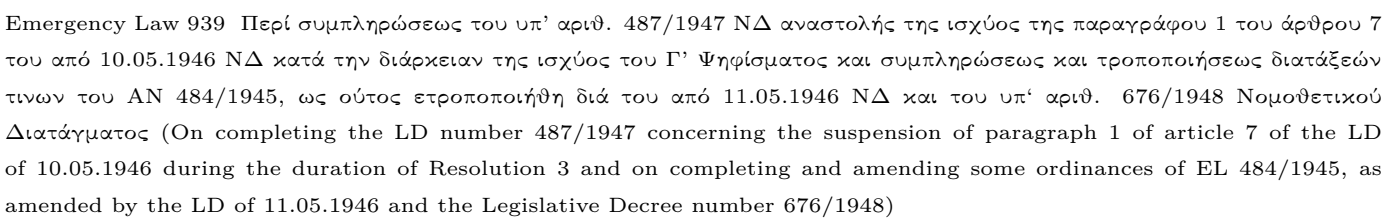 \\
\hline 1950-10-17 & 1950-10-17 & 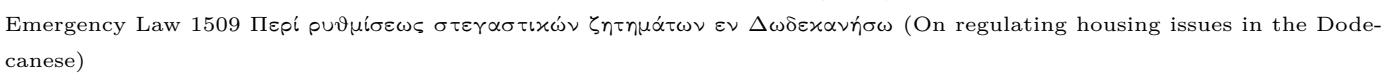 \\
\hline 1951-01-27 & 1951-01-27 & 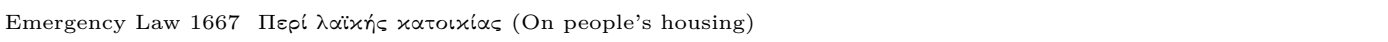 \\
\hline 1952-04-15 & $1952-04-15$ & 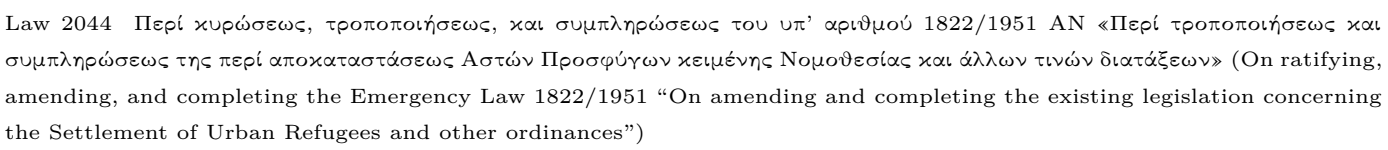 \\
\hline 1953-02-09 & 1953-02-09 & 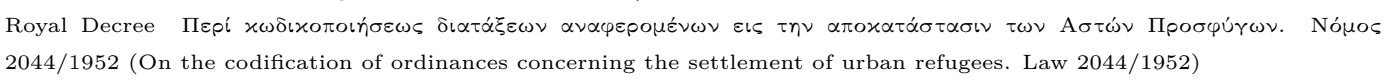 \\
\hline $1953-11-12$ & $1953-11-12$ & 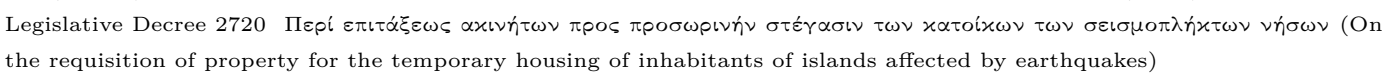 \\
\hline $1955-02-28$ & $1955-02-28$ & 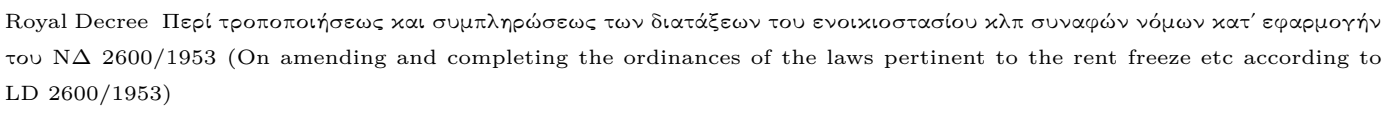 \\
\hline 1955-06-30 & $1955-06-30$ & 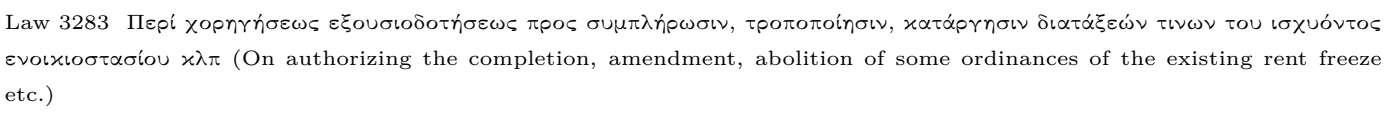 \\
\hline $1957-02-27$ & $1957-02-27$ & 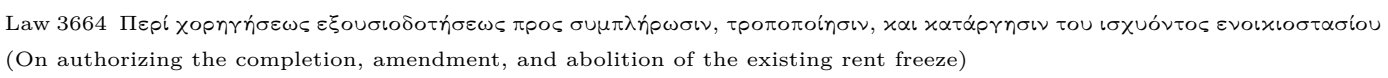 \\
\hline $1957-05-27$ & $1957-05-27$ & 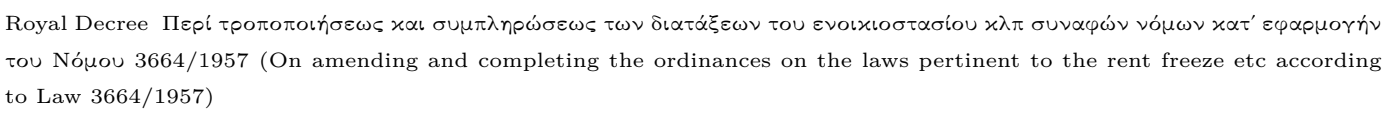 \\
\hline 1959-09-23 & 1959-09-23 & 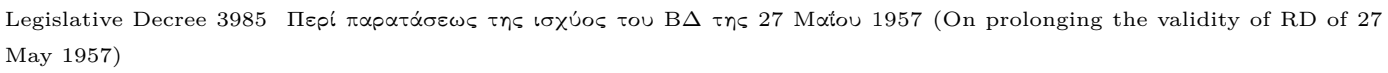 \\
\hline $1960-12-24$ & $1960-12-24$ & 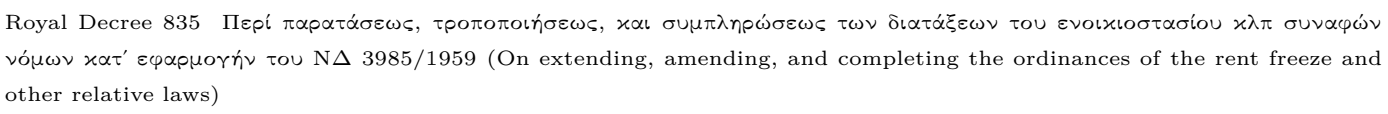 \\
\hline
\end{tabular}




\section{Table 7: List of legal acts (continued)}

\begin{tabular}{|c|c|c|}
\hline $\begin{array}{l}\text { Date of legal } \\
\text { act (yyyy- } \\
\text { mm-dd) }\end{array}$ & $\begin{array}{l}\text { Enactment } \\
\text { or publica- } \\
\text { tion date } \\
\text { (yyyy-mm- } \\
\text { dd) }\end{array}$ & Title of legal act \\
\hline $1962-12-27$ & $1962-12-27$ & 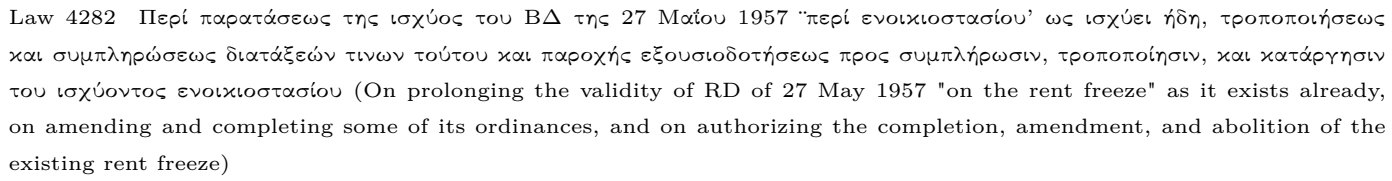 \\
\hline $1963-12-07$ & 1963-12-07 & 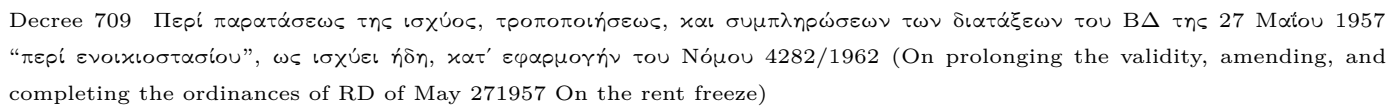 \\
\hline 1978-07-28 & 1978-07-27 & 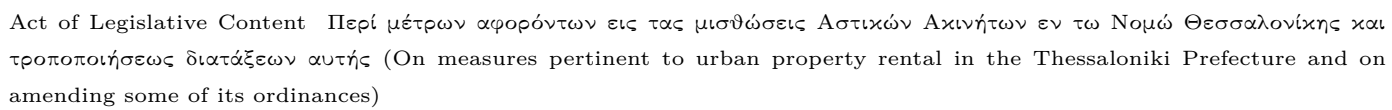 \\
\hline 1978-07-28 & $1978-07-28$ & 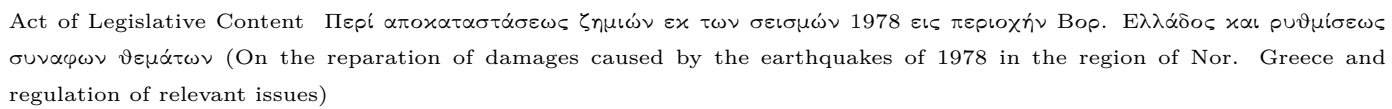 \\
\hline 1978-08-09 & 1978-08-09 & 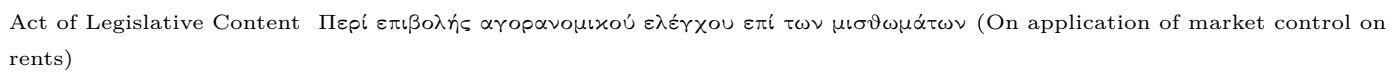 \\
\hline 1980-03-31 & 1980-03-21 & 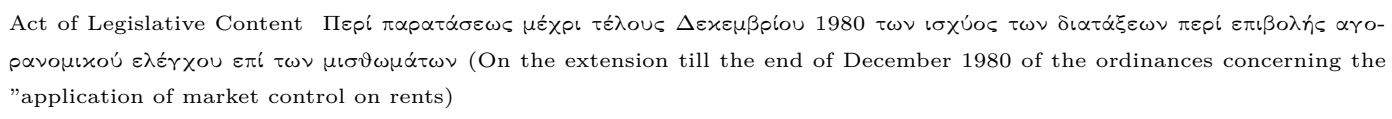 \\
\hline $1980-12-30$ & $1980-12-30$ & 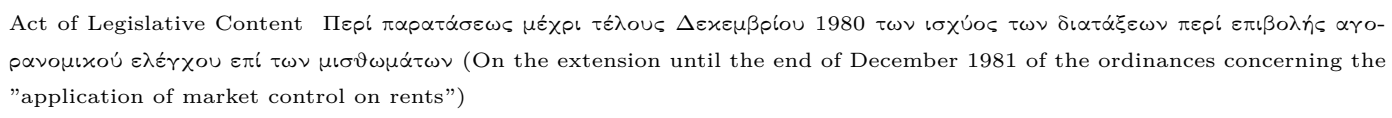 \\
\hline 1982-03-08 & 1982-03-08 & 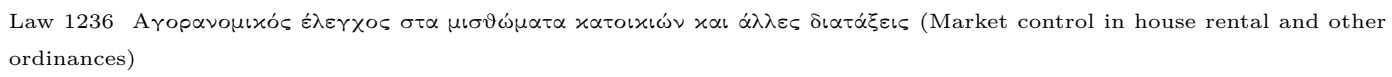 \\
\hline 1984-08-01 & 1984-08-01 & 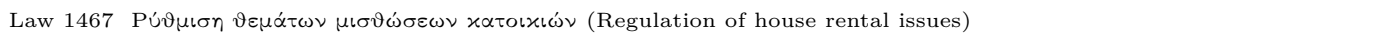 \\
\hline 1986-06-06 & 1986-02-01 & 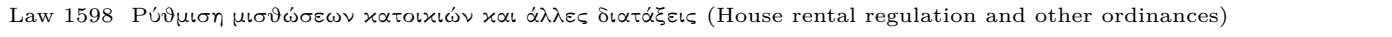 \\
\hline 1987-03-27 & 1987-02-01 & 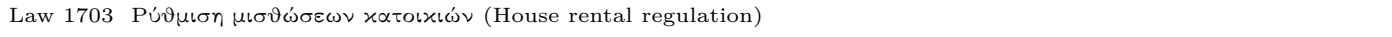 \\
\hline 1988-10-05 & 1988-06-01 & 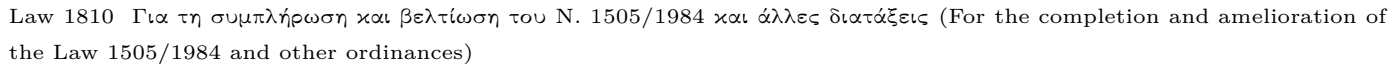 \\
\hline 1990-02-13 & $1990-02-13$ & 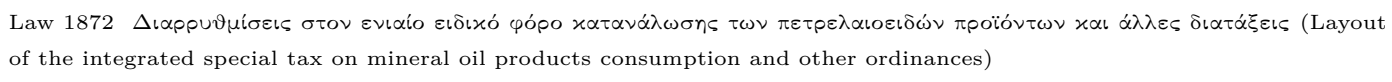 \\
\hline $1990-02-21$ & $1990-02-21$ & 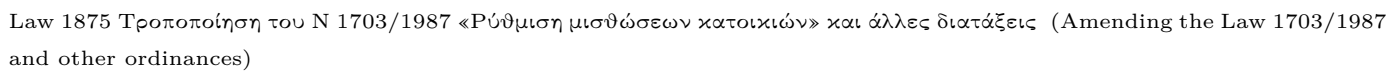 \\
\hline $1990-09-17$ & $1990-09-17$ & 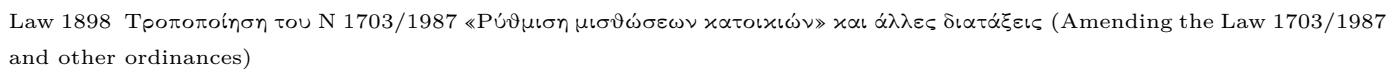 \\
\hline 1991-06-24 & $1991-06-24$ & 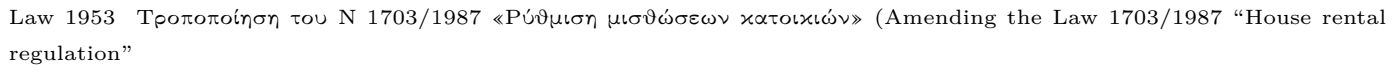 \\
\hline 1993-02-18 & $1993-02-18$ & 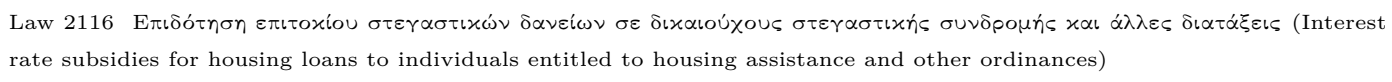 \\
\hline $1993-06-28$ & $1993-07-01$ & 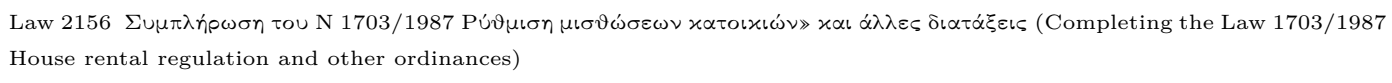 \\
\hline 1994-09-01 & 1994-09-01 & 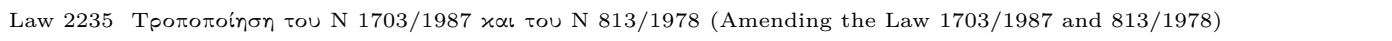 \\
\hline $2000-02-16$ & $2000-02-16$ & 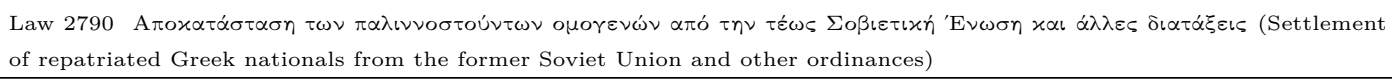 \\
\hline \multicolumn{3}{|r|}{ Iceland (IS) } \\
\hline 1917-09-12 & 1917-09-12 & Lög nr. 24 um húsaleigu í Reykjavík [Act on rent in Reykjavik] \\
\hline $1919-11-28$ & $1919-11-28$ & Lög nr. 45 viðauka við viðaukalög nr. 24, 12. september 1917 , um húsaleigu í Reykjavík \\
\hline $1921-06-27$ & $1921-06-27$ & Lög nr. 50, 27. júni 1921, um húsnæði í Reykjavík \\
\hline 1926-06-15 & 1927-05-14 & Lög nr. 25 um húsaleigu í Reykjavík [Act on rent in Reykjavik] \\
\hline 1939-04-10 & 1939-04-10 & Frumvarp til laga um breyting á lögum nr. 10 4. april 1939, um gengisskráningu og rádstafanir i bví sambandi \\
\hline $1940-05-14$ & 1940-05-14 & Frumvarp til laga um húsaleigu [Bill on rent] 1940 \\
\hline 1943-04-07 & 1943-04-07 & Lög nr. 39 7. april 1943 um húsaleigu \\
\hline $1950-05-25$ & $1950-05-25$ & Frumvarp til laga [49. mál] um breyting á lögum nr. 39 7. apríl 1943, um húsaleigu [Law nr. 56/1950] \\
\hline $1952-05-14$ & 1952-05-14 & Removal of rent control, according to the Law nr. 56/1950. \\
\hline 1979-05-11 & 1979-05-11 & Frumvarp til laga um húsaleigusamninga \\
\hline
\end{tabular}




\section{Table 7: List of legal acts (continued)}

\begin{tabular}{|c|c|c|}
\hline $\begin{array}{l}\text { Date of legal } \\
\text { act (yyyy- } \\
\text { mm-dd) }\end{array}$ & $\begin{array}{l}\text { Enactment } \\
\text { or publica- } \\
\text { tion date } \\
\text { (yyyy-mm- } \\
\text { dd) }\end{array}$ & Title of legal act \\
\hline $1994-04-22$ & 1995-01-01 & Húsaleigulög nr. 36 [Rent act] \\
\hline \multicolumn{3}{|r|}{ Ireland (IE) } \\
\hline $1915-11-25$ & $1915-11-25$ & Increase of rent and Mortgage Interest (War Restrictions) Act \\
\hline 1917-07-10 & 1917-07-10 & Courts (Emergency restrictions) Act \\
\hline 1918-05-02 & 1918-05-02 & Increase of rent and Mortgage Interest (Amendments) Act \\
\hline 1919-04-02 & 1919-04-02 & Increase of rent and mortgage interest (restrictions) act \\
\hline 1920-07-02 & 1920-07-02 & Increase of rent and mortgage interest (restrictions) act \\
\hline $1923-06-22$ & 1923-06-24 & Increase of Rent and Mortgage Interest (Restrictions) Act 1923 \\
\hline 1926-06-24 & $1926-06-24$ & Increase of Rent and Mortgage Interest (Restrictions) Act 1926 \\
\hline $1928-06-21$ & $1928-06-21$ & Increase of Rent and Mortgage Interest (Restrictions) Act 1928 \\
\hline $1929-06-25$ & $1929-06-25$ & Increase of Rent and Mortgage Interest (Restrictions) Act 1929 \\
\hline $1930-06-24$ & $1930-06-24$ & Increase of Rent and Mortgage Interest (Restrictions) Act 1930 \\
\hline $1931-12-22$ & $1931-12-22$ & Landlord and Tenant Act, 1931 \\
\hline 1943-04-21 & 1943-04-21 & Landlord and Tenant (Amendment) Act, 1943 \\
\hline 1946-03-12 & 1946-03-12 & Rent Restrictions Act 1946 \\
\hline 1949-07-30 & 1949-07-30 & Rent Restrictions (Amendment) Act 1949 \\
\hline $1950-12-20$ & $1950-12-20$ & Rent Restrictions (Continuance and Amendment) Act, 1950 \\
\hline $1952-12-09$ & $1952-12-31$ & Rent Restrictions (Continuance and Amendment) Act 1952 \\
\hline 1953-12-08 & 1953-12-31 & Rent Restrictions (Continuance and Amendment) Act 1953 \\
\hline 1954-02-25 & $1954-02-25$ & Rent Restrictions (Amendment) Act 1954 \\
\hline 1954-12-09 & $1954-12-31$ & Rent Restrictions (Continuance and Amendment) Act 1954 \\
\hline $1955-11-30$ & $1955-12-31$ & Rent Restrictions (Continuance and Amendment) Act 1955 \\
\hline $1956-12-18$ & $1956-12-31$ & Rent Restrictions (Continuance and Amendment) Act, 1956 \\
\hline $1957-12-12$ & $1957-12-31$ & Rent Restrictions (Continuance and Amendment) Act 1957 \\
\hline $1958-12-16$ & $1958-12-31$ & Rent Restrictions (Continuance and Amendment) Act 1958 \\
\hline 1959-12-08 & $1959-12-31$ & Rent Restrictions (Continuance and Amendment) Act 1959 \\
\hline 1960-12-21 & $1960-12-21$ & Rent Restrictions Act 1960 \\
\hline 1967-05-09 & 1967-05-09 & Rent Restrictions (Amendment) Act 1967 \\
\hline $1981-07-25$ & $1981-07-25$ & Rent Restrictions (Temporary Provisions) Act 1981 \\
\hline $1982-05-21$ & $1982-05-21$ & Housing (Private Rented Dwellings) Act, 1982 \\
\hline \multicolumn{3}{|r|}{ Italy (IT) } \\
\hline $1915-06-03$ & $1915-06-04$ & Decreto Luogotenenziale n. 788 riguardante provvedimenti per i pagamenti dei fitti \\
\hline $1916-12-26$ & $1916-12-30$ & Decreto Luogotenenziale n. 1769 che coordina e proroga le disposizioni emanate sugli affitti degli immobili urbani \\
\hline 1917-03-08 & $1917-03-08$ & $\begin{array}{l}\text { Decreto Luogotenenziale n. } 403 \text {, concernente norme relative all'obbligo assunto dai proprietari di immobili urbani di } \\
\text { prrovvedere al riscaldamento }\end{array}$ \\
\hline 1917-12-30 & 1918-01-01 & $\begin{array}{l}\text { Decreto Luogotenenziale n. 2056, concernente la proroga dei contrattii di locazione relativi alle case di abitazione, anche } \\
\text { rurali e il divieto da parte dei locatori di richiedere una pigione superiore a quella anteriormente corrisposta, demandosi le } \\
\text { relative controversie al giudizio della Commissione arbitrale istituita dal decreto Luogotenenziale } 8 \text { marzo } 1917 \mathrm{n} .403\end{array}$ \\
\hline 1918-08-11 & 1918-08-12 & $\begin{array}{l}\text { Decreto Luogotenenziale n. } 1076 \text { concernente modificazioni al decreto Luogotenenziale } 30 \text { dicembre } 1917 \text {, n. } 2046 \text { sugli affitti } \\
\text { e le pigioni }\end{array}$ \\
\hline $1919-03-27$ & $1919-03-28$ & Decreto-legge Luogotenenziale n. 370 contenente disposizioni sugli affitti e le pigioni delle case di abitazione \\
\hline 1919-04-24 & $1919-04-25$ & $\begin{array}{l}\text { Decreto-legge Luogotenenziale n. } 618 \text { contenente disposizioni sugli affitti e le pigioni delle case di abitazione della città di } \\
\text { Roma }\end{array}$ \\
\hline 1919-08-15 & 1919-08-15 & $\begin{array}{l}\text { Regio decreto n. } 1440 \text { che detta norme per il pagamento delle quote di affitto non corrisposte dagli inquilini durante il } \\
\text { servizio militare }\end{array}$ \\
\hline $1919-08-15$ & $1919-08-15$ & $\begin{array}{l}\text { Regio decreto n. } 1514 \text { che stabilisce norme circa i contratti di affitto di fabbricati urbani e parte di essi, serventi a uso } \\
\text { botteghe, negozi, magazzini, uffici amministrativi e studi commerciali e industriali" }\end{array}$ \\
\hline 1920-01-04 & 1920-01-05 & $\begin{array}{l}\text { Regio decreto-legge n. } 1 \text { che reca provvedimenti provvisori per mitigare le difficoltà dei cittadini e dei viaggiatori riguardo } \\
\text { agli alloggi }\end{array}$ \\
\hline $1920-04-18$ & $1920-05-02$ & $\begin{array}{l}\text { Regio decreto-legge n. } 477 \text { contenente nuove disposizioni sugli affitti e le pigioni delle case di abitazione e degli edifici urbani } \\
\text { ad uso di bottega, negozio, magazzino, studio, ufficio e simili }\end{array}$ \\
\hline 1921-04-03 & 1921-04-06 & $\begin{array}{l}\text { Regio decreto-legge } 3 \text { aprile } 1921, \mathrm{n} \text {. } 331 \text {, che proroga i contrati di locazione di appartamenti o di case di abitazione, } \\
\text { contemplati nei numeri } 1,2,3,4,5 \text { dell'art. } 1 \text { del decreto n. } 477 \text { del } 1920 \text {, e stabilisce altresi nuove norme per le locazioni } \\
\text { dei negozi }\end{array}$ \\
\hline
\end{tabular}




\section{Table 7: List of legal acts (continued)}

\begin{tabular}{|c|c|c|}
\hline $\begin{array}{l}\text { Date of legal } \\
\text { act (yyyy- } \\
\text { mm-dd) }\end{array}$ & $\begin{array}{l}\text { Enactment } \\
\text { or publica- } \\
\text { tion date } \\
\text { (yyyy-mm- } \\
\text { dd) }\end{array}$ & Title of legal act \\
\hline 1921-11-08 & 1921-11-20 & $\begin{array}{l}\text { Regio decreto-legge } 8 \text { novembre 1921, n. 1561, concernente la proroga di contrati di locazione di appartamenti o case ad uso } \\
\text { di abitazione }\end{array}$ \\
\hline $1922-10-23$ & $1922-10-27$ & $\begin{array}{l}\text { Regio decreto-legge } 23 \text { ottobre } 1922 \text {, n. } 1355 \text {, contenente norme per i contratti di locazione di case ad uso di abitazione e } \\
\text { provvedimenti per agevolare le costruzioni }\end{array}$ \\
\hline 1923-01-07 & 1923-01-14 & $\begin{array}{l}\text { Regio decreto-legge } 7 \text { gennaio } 1923, \mathrm{n} .8 \text {, contenente disposizioni circa le locazioni di immobili urbani e i commissari del } \\
\text { governo per le abitazioni }\end{array}$ \\
\hline 1927-06-16 & 1927-06-22 & Regio decreto-legge 16 giugno 1927, n. 948, Norme sui prezzi delli locazioni di immobili urbani \\
\hline 1934-04-14 & 1934-04-16 & Regio decreto-legge 14 aprile $1934, \mathrm{n} .563$, contente disposizioni per la riduzione delle pigioni \\
\hline 1936-10-05 & 1936-10-05 & $\begin{array}{l}\text { Regio decreto-legge } 5 \text { ottobre } 1936, \text { n. } 1746 \text {, recante disposizioni contro i perturbamenti del mercato e gli iasprimenti del } \\
\text { costo della vita }\end{array}$ \\
\hline 1938-06-16 & 1938-10-05 & Regio decreto-legge 16 giugno 1938-XVI, n. 1387. Norme per la disciplina dei prezzi delle merci, dei servizi e degli affitti \\
\hline 1940-06-19 & 1940-06-19 & $\begin{array}{l}\text { Regio decreto-legge } 19 \text { giugno 1940-XVIII, n. 953. Blocco dei prezzi delle merci e dei servizi, delle costruzioni edilizie, degli } \\
\text { impianti industriali e delle pigioni }\end{array}$ \\
\hline 1941-03-12 & 1941-03-29 & $\begin{array}{l}\text { Regio decreto-legge } 12 \text { marzo 1941, n. 142, Proroga per tutta la durata dell'attuale stato di guerra del blocco dei prezzi delle } \\
\text { merci e dei servizi, delle costruzioni edilizie, degli impianti industriali e delle pigioni }\end{array}$ \\
\hline 1942-03-24 & 1942-03-25 & Regio decreto-legge 24 marzo 1942, n. 200, Norme relativi agli affitti degli immobili urbani \\
\hline 1942-08-29 & 1942-08-29 & $\begin{array}{l}\text { Regio decreto-legge } 29 \text { agosto } 1942, \mathrm{n} .1189 \text {, Disposizioni in materia di subaffitto di appartamenti vuoti o mobiliati e norme } \\
\text { integrative dei Regi decreti-legge } 12 \text { marzo 1941-XIX, n. 142, e } 24 \text { marzo } 1942-X X \text {, n. } 200\end{array}$ \\
\hline 1943-01-25 & 1943-04-10 & $\begin{array}{l}\text { Regio decreto-legge } 25 \text { gennaio 1943, n. 162, contenente disposizioni circa la sospensione delle ciausole di divieto di subaffitto } \\
\text { contenute nei contratti di locazione di appartamenti per uso di abitazione, e disposizioni in materia di riduzione dei canoni } \\
\text { di affitto degli immobili danneggiati in seguito ad eventi bellici }\end{array}$ \\
\hline 1943-03-11 & 1943-03-11 & $\begin{array}{l}\text { Regio decreto-legge } 11 \text { marzo 1943, n. 100, relativo alla proroga, fino a sei mesi dopo la cessazione dell'attuale stato di } \\
\text { guerra, del blocco dei prezzi delle merci e dei servizi, delle costruzioni edilizie, degli impianti industriali e delle pigioni }\end{array}$ \\
\hline 1943-03-15 & 1943-03-24 & Regio decreto-legge 15 marzo 1943-XXI, n. 107. Disciplina degli alloggi per gli sfollati \\
\hline 1943-11-11 & 1943-11-18 & Regio decreto-legge 11 novembre 1943 , n. 6/B, contenente norme di eccezione alla esecuzione degli sfratti \\
\hline $1944-12-28$ & 1945-01-14 & $\begin{array}{l}\text { Decreto legislativo Luogotenenziale } 28 \text { dicembre } 1944 \text {, n. } 415 \text {, concernente la nomina e le attribuzioni dei commissari gover- } \\
\text { nativi per gli allogi }\end{array}$ \\
\hline 1945-06-04 & 1945-07-04 & $\begin{array}{l}\text { Decreto legislativo Luogotenenziale } 4 \text { giugno } 1945, \mathrm{n} .332 \text {, Norme complementari e di attuazione del decreto legislativo } \\
\text { Luogotenenziale } 28 \text { dicembre } 1944 \text {, n. } 415 \text {, sulla requisizione in uso e assegnazione in locazione di alloggi, nei Communi per } \\
\text { i quali sia nominato il commissario governativo per gli allogi }\end{array}$ \\
\hline 1945-06-09 & $1945-06-24$ & $\begin{array}{l}\text { Decreto legislativo Luogotenenziale } 9 \text { giugno } 1945 \text {, n. } 305 \text {, recante provvedimenti relativi al ricovero delle persone rimaste } \\
\text { senza tetto in dipendenza di azioni belliche }\end{array}$ \\
\hline 1945-10-12 & 1945-10-29 & Decreto legislativo luogotenenziale 12 ottobre 1945, n. 669. Disciplina delle locazioni degli immobili urbani \\
\hline 1946-12-06 & 1946-12-02 & $\begin{array}{l}\text { Decreto legislativo del capo provvisorio dello stato } 6 \text { dicembre } 1946 \text {, n. } 428 \text {. Proroga dei termini in materia di locazioni di } \\
\text { immobili urbani }\end{array}$ \\
\hline 1947-06-30 & 1947-08-09 & $\begin{array}{l}\text { Decreto legislativo del capo provvisorio dello stato } 30 \text { giugno } 1947, \text { n. } 548 \text {. Nuove norme sui Commissariati governativi degli } \\
\text { alloggi }\end{array}$ \\
\hline 1948-05-05 & 1948-09-29 & Decreto legislativo 5 maggio 1948 , n. 596. Proroga dei contratti di locazione e di sublocazione degli immobili urbani \\
\hline $1948-12-30$ & 1948-12-31 & Legge 30 dicembre $1948, \mathrm{n} .1471$. Proroga delle vigenti disposizioni in materia di locazione e sublocazione di immobili urbani \\
\hline $1950-05-23$ & 1950-05-24 & $\begin{array}{l}\text { Legge del } 23 \text { maggio } 1950 \text {, n. 253. Disposizioni generali e immobili soggetti a regime vincolistico Disposizioni per le locazioni } \\
\text { e sublocazioni di immobili urbani }\end{array}$ \\
\hline $1967-06-27$ & 1967-06-29 & D.L. 27 giugno 1967, n. 460. Disciplina transitoria delle locazioni di immobili urbani \\
\hline $1978-07-27$ & $1978-07-30$ & Legge 27 luglio 1978, n. 392. Disciplina delle locazioni di immobili urbani \\
\hline $1979-12-15$ & 1979-12-15 & $\begin{array}{l}\text { Decreto-legge } 15 \text { dicembre } 1979 \text {, n. } 629 \text {. Dilazione dell'esecuzione dei provvedimenti di rilascio per gli immobili adibiti ad } \\
\text { uso di abitazione e provvedimenti urgenti per l'edilizia }\end{array}$ \\
\hline $1986-10-26$ & $1986-10-26$ & Decreto-legge 29 ottobre 1986, n. 708. Misure urgenti per fronteggiare l'eccezionale carenza di disponibilita' abitative \\
\hline $1988-12-30$ & $1988-12-30$ & Decreto-legge 30 dicembre 1988, n. 551. Misure urgenti per fronteggiare l'eccezionale carenza di disponibilita' abitative \\
\hline 1998-12-09 & $1998-12-15$ & Legge 9 dicembre 1998 , n. 431. Disciplina delle locazioni e del rilascio degli immobili adibiti ad uso abitativo \\
\hline \multicolumn{3}{|r|}{ Liechtenstein (LI) } \\
\hline 1939-09-01 & 1939-09-01 & $\begin{array}{l}\text { Bundesratsbeschluss vom 1. September } 1939 \text { betreffend die Kosten der Lebenshaltung und den Schutz der regulären Mark- } \\
\text { tordnung (Switzerland) }\end{array}$ \\
\hline 1942-11-03 & 1942-11-06 & Verordnung der Fürstlichen Regierung vom 3. November 1942 betreffend Mieterschutz \\
\hline 1974-11-14 & 1975-01-15 & $\begin{array}{l}\text { Gesetz vom 14. November } 1974 \text { über die Abänderung des Fünfundzwanzigsten Hauptstückes des Allgemeinen bürgerlichen } \\
\text { Gesetzbuches }\end{array}$ \\
\hline
\end{tabular}




\section{Table 7: List of legal acts (continued)}

\begin{tabular}{|c|c|c|}
\hline $\begin{array}{l}\text { Date of legal } \\
\text { act (yyyy- } \\
\text { mm-dd) }\end{array}$ & $\begin{array}{l}\text { Enactment } \\
\text { or publica- } \\
\text { tion date } \\
\text { (yyyy-mm- } \\
\text { dd) }\end{array}$ & Title of legal act \\
\hline \multicolumn{3}{|r|}{ Luxembourg (LU) } \\
\hline 1906-05-29 & 1906-11-03 & Loi du 29 mai 1906 sur les habitations à bon marché \\
\hline 1914-12-14 & $1914-12-20$ & Loi du 14 décembre 1914 portant modification de la loi du 29 mai 1906 sur les habitations à bon marché \\
\hline 1918-06-04 & 1918-06-09 & $\begin{array}{l}\text { Arrêté grand-ducal du } 4 \text { juin } 1918 \text { portant institution d'offices de conciliation pour les contestations entre bailleurs et } \\
\text { locataires }\end{array}$ \\
\hline 1919-06-13 & 1919-06-15 & Arrêté grand-ducal du 13 juin 1919 portant institution de tribunaux arbitraux des loyers \\
\hline 1920-03-29 & 1920-04-02 & $\begin{array}{l}\text { Loi du } 29 \text { mars } 1920 \text { en vue d'empêcher que les locataires ne soient contraints, sans motifs graves à déménager, de prévenir } \\
\text { la hausse exagérée des loyers, et de loger les familles expulsées }\end{array}$ \\
\hline 1921-07-29 & 1921-08-07 & Loi du 29 juillet 1921 portant modification de celle du 29 mars 1920 sur les logements \\
\hline $1922-04-25$ & $1922-04-26$ & Arrêté grand-ducal du 25 avril 1922 sur les logements \\
\hline $1922-05-10$ & $1922-05-16$ & Loi du 10 mai 1922 portant modification de l'art. 1er de celle du 29 juillet 1921 sur les logements \\
\hline $1922-10-24$ & $1922-10-28$ & Arrêté grand-ducal du 24 octobre 1922 sur les logements \\
\hline $1924-12-24$ & 1925-01-01 & Loi du 24 décembre 1924 sur les logements \\
\hline $1927-02-25$ & 1927-03-08 & Loi du 25 février 1927 sur les logements \\
\hline $1939-09-30$ & $1939-09-30$ & Arrêté grand-ducal du 30 septembre 1939 portant institution de tribunaux arbitraux en matière de bail à loyer \\
\hline 1945-01-10 & 1945-02-12 & Arrêté grand-ducal du 10 janvier 1945 concernant la fixation des loyers \\
\hline $1945-12-24$ & 1946-01-01 & $\begin{array}{l}\text { Arrêté grand-ducal du } 24 \text { décembre } 1945 \text { portant modification de l'arrêté grand-ducal du } 10 \text { janvier } 1945 \text { concernant la } \\
\text { fixation des loyers }\end{array}$ \\
\hline 1946-06-28 & 1946-07-01 & Loi du 28 juin 1946 ayant pour objet de remédier à la pénurie des logements et portant augmentation des prix des loyers \\
\hline 1947-03-21 & 1947-03-25 & Loi du 21 mars 1947 concernant la fixation des loyers \\
\hline 1948-10-30 & 1948-10-30 & Loi du 30 octobre 1948 concernant la protection des personnes condamnées à déguerpir de leur logement \\
\hline $1950-07-20$ & $1950-07-23$ & $\begin{array}{l}\text { Loi du } 20 \text { juillet } 1950 \text { portant modification de la loi du } 28 \text { juin } 1946 \text { ayant pour objet de remédier à la pénurie des logements } \\
\text { ainsi que de la loi du } 21 \text { mars } 1947 \text { concernant la fixation des loyers et de l'arrêté grand-ducal du } 30 \text { septembre } 1939 \text { portant } \\
\text { institution de tribunaux arbitraux en matière de bail à louer et des dispositions modificatives de cet arrêté }\end{array}$ \\
\hline 1955-02-14 & $1955-02-26$ & $\begin{array}{l}\text { Loi du } 14 \text { février } 1955 \text { portant modification et coordination des dispositions légales et règlementaires en matière de baux à } \\
\text { loyer }\end{array}$ \\
\hline $1979-02-25$ & 1979-03-01 & Loi du 25 février 1979 concernant l'aide au logement \\
\hline $1983-07-23$ & $1983-07-31$ & $\begin{array}{l}\text { Loi du } 23 \text { juillet } 1983 \text { ayant pour objet 1) de modifier la loi du } 25 \text { février } 1979 \text { concernant l'aide au logement 2) de modifier } \\
\text { la loi du } 29 \text { mai } 1906 \text { sur les habitations à bon marché }\end{array}$ \\
\hline 1987-08-27 & 1987-08-31 & Loi du 27 août 1987 portant réforme de la législation sur les baux à loyer \\
\hline 1992-03-17 & 1992-04-02 & $\begin{array}{l}\text { Loi du } 17 \text { mars } 1992 \text { modifiant la loi du } 14 \text { février } 1955 \text { portant modification et coordination des dispositions légales et } \\
\text { réglementaires en matière de baux à loyer, telle qu'elle a été modifiée }\end{array}$ \\
\hline 1993-07-15 & 1993-07-20 & Loi du 15 juillet 1993 portant modification de la loi modifiée du 25 février 1979 concernant l'aide au logement \\
\hline 1998-04-20 & 1998-04-23 & Loi du 20 avril 1998 modifiant la loi modifiée du 25 février 1979 concernant l'aide au logement \\
\hline 2002-11-08 & 2002-12-01 & Loi du 8 novembre 2002 modifiant la loi du 25 février 1979 concernant l'aide au logement \\
\hline 2006-09-21 & 2006-11-01 & Loi du 21 septembre 2006 sur le bail à usage d'habitation et modifiant certaines dispositions du Code civil \\
\hline 2014-12-19 & 2014-12-24 & Loi du 19 décembre 2014 relative à la mise en oeuvre du paquet d'avenir - première partie (2015) \\
\hline 2015-08-05 & 2015-09-04 & $\begin{array}{l}\text { Loi du } 5 \text { août } 2015 \text { modifiant la loi modifiée du } 21 \text { septembre } 2006 \text { sur le bail à usage d'habitation et modifiant certaines } \\
\text { dispositions du Code civil }\end{array}$ \\
\hline 2015-09-02 & 2015-10-03 & Loi du 2 septembre 2015 portant abolition des districts \\
\hline 2015-12-09 & 2017-01-01 & $\begin{array}{l}\text { Loi du } 9 \text { décembre } 2015 \text { portant introduction d'une subvention de loyer et modifiant: a) la loi modifiée du } 25 \text { février } 1979 \\
\text { concernant l'aide au logement; b) la loi modifiée du } 29 \text { avril } 1999 \text { portant création d'un droit à un revenu minimum garanti; } \\
\text { c) la loi modifiée du } 12 \text { septembre } 2003 \text { relative aux personnes handicapées. } \\
\text { Loi du } 23 \text { décembre } 2016 \text { portant mise en ouvre de la réforme fiscale } 2017\end{array}$ \\
\hline \multicolumn{3}{|r|}{ Madagascar (MG) } \\
\hline $1927-04-29$ & 1927-05-03 & Décret du 29 avril 1927 réglementant les loyers des locaux à usage d'habitation dans la colonie de Madagascar et dépendances \\
\hline 1931-09-11 & 1931-09-19 & $\begin{array}{l}\text { Décret du } 11 \text { septembre } 1931 \text { réglementant les loyers des locaux à usage d'habitation dans la colonie de Madagascar et } \\
\text { dépendances }\end{array}$ \\
\hline 1936-10-16 & 1936-10-20 & Décret du 16 octobre 1936 \\
\hline $1937-10-16$ & $1937-10-20$ & Décret du 16 octobre 1937, réglementation des loyers des locaux à usage d'habitation à Madagascar \\
\hline 1938-10-31 & 1938-11-11 & Décret du 31 octobre 1938, réglementation des loyers des locaux à usage d'habitation à Madagascar \\
\hline 1939-07-01 & $1940-01-13$ & Décret du 1 juillet 1939 tendant à accorder aux mobilisés des délais pour le payement de leurs loyer \\
\hline $1939-12-26$ & $1940-01-13$ & Décret du 26 décembre 1939 relatif au payement des loyers des mobilisés \\
\hline 1940-12-11 & 1941-08-23 & $\begin{array}{l}\text { Loi du } 11 \text { décembre } 1940 \text { portant réglementation de l'affichage et de la déclaration ainsi que du recensement des locaux } \\
\text { vacants à usage d'habitation ou professionnel }\end{array}$ \\
\hline
\end{tabular}




\section{Table 7: List of legal acts (continued)}

\begin{tabular}{|c|c|c|}
\hline $\begin{array}{l}\text { Date of legal } \\
\text { act (yyyy- } \\
\text { mm-dd) }\end{array}$ & $\begin{array}{l}\text { Enactment } \\
\text { or publica- } \\
\text { tion date } \\
\text { (yyyy-mm- } \\
\text { dd) }\end{array}$ & Title of legal act \\
\hline $1941-02-28$ & 1941-08-23 & Loi du 28 février 1941 relative à la majoration abusive des loyers des locaux d'habitation ou à usage professionnel \\
\hline $1941-07-26$ & $1941-08-23$ & $\begin{array}{l}\text { Décret du } 26 \text { juillet } 1941 \text { rendant applicables à Madagascar les dispositions de la loi du } 28 \text { février } 1941 \text { rélative à la majoration } \\
\text { abusive des loyers des locaux d'habitation ou à usage professionnel }\end{array}$ \\
\hline 1941-07-26 & $1941-08-23$ & $\begin{array}{l}\text { Décret du } 26 \text { juillet } 1941 \text { rendant applicables à Madagascar les dispositions de l'acte dit loi du } 11 \text { décembre } 1940 \text { portant } \\
\text { réglementation de l'affichage et de la déclaration ainsi que du recensement des locaux vacants à usage d'habitation ou } \\
\text { professionnel }\end{array}$ \\
\hline 1943-04-20 & 1943-04-20 & Ordonnance du 20 avril 1943 sur le rétablissement de la légalité républicaine \\
\hline $1945-04-30$ & 1945-05-01 & Décret No. 45-872 du 30 avril 1945 réglementant les loyers des locaux à usage d'habitation en Afrique équatioriale française \\
\hline 1946-06-14 & 1946-07-06 & $\begin{array}{l}\text { Décret No. 45-1463 du } 14 \text { juin } 1946 \text { qui étend à Madagascar et Dépendances les dispositions du décret du } 30 \text { avril } 1945 \\
\text { réglementant les loyers des locaux d'habitation en Afrique équatoriale francaise }\end{array}$ \\
\hline 1946-11-27 & $1946-12-24$ & $\begin{array}{l}\text { Arrêté portant application du décret No. } 46-2821 \text { du } 27 \text { novembre } 1946 \text { qui institue, à Madagascar et Dépendances, des } \\
\text { mesures exceptionnelles en vue de remédier à la crise du logement et portant création d'un service du logement dans les } \\
\text { principales localités de l'Île }\end{array}$ \\
\hline $1947-03-27$ & 1947-05-03 & $\begin{array}{l}\text { Décret No. 47-571 du } 27 \text { mars } 1947 \text { complétant l'article } 16 \text { du décret du } 30 \text { avril } 1945 \text { réglementant les loyers des locaux } \\
\text { d'habitation en Afrique Equatoriale francaise étendu à Madagascar et Dépendances par décret du } 14 \text { juin } 1946\end{array}$ \\
\hline 1948-12-29 & 1949-01-15 & $\begin{array}{l}\text { Décret No. 48-1958 du } 29 \text { décembre } 1948 \text { tendant à proroger d'une année les dispositions du décret No. } 46-2821 \text { du } 27 \\
\text { novembre } 1946 \text { instituant à Madagascar et Dépendances des mesures exceptionnelles en vue de remédier à la crise du logement }\end{array}$ \\
\hline 1950-02-08 & 1950-02-11 & Arrêté du 8 février 1950 réglementant les loyers des locaux d'habitation à Madagascar et dépendances \\
\hline 1950-03-17 & $1950-04-22$ & $\begin{array}{l}\text { Décret No. 50-366 du } 17 \text { mars } 1950 \text { prorogeant d'une année les disposition du décret No. } 46-2821 \text { du } 27 \text { novembre } 1946 \\
\text { instituant à Madagascar et Dépendances des mesures exceptionnelles en vue de remédier à la crise du logement }\end{array}$ \\
\hline 1951-04-23 & 1951-04-28 & Arrêté $\mathrm{N}^{\circ} 126-\mathrm{AP} / 4 / \mathrm{CG} / 51$ du 23 avril 1951 réglementant les loyers des locaux d'habitation à Madagascar et dépendances \\
\hline 1953-12-19 & $1953-12-26$ & Arrêté $N^{\circ} 2462-\mathrm{AP} / 4 / 53$ du 19 décembre 1953 portant blocage des loyers des immeubles ou locaux à usage d'habitation \\
\hline 1962-10-01 & $1962-10-12$ & Ordonnance No. 62-100 du 1er octobre 1962 portant réglementation des baux et loyers des locaux d'habitation \\
\hline \multicolumn{3}{|r|}{ Mali $(\mathrm{ML})$} \\
\hline 1952-06-30 & 1952-07-03 & Décret $n^{\circ} 52-764$ du 30 juin 1952 portant réglementation des loyers des locaux d'habitation en Afrique occidentale française \\
\hline $1967-09-27$ & $1967-09-27$ & $\begin{array}{l}\text { Décret } N^{\circ} 146 / \mathrm{PG}-\mathrm{RM} \text { du } 27 \text { septembre } 1967 \text { portant Réglementation des loyers des locaux d'habitation en République du } \\
\text { Mali }\end{array}$ \\
\hline \multicolumn{3}{|r|}{ Mexico, Distrito Federal (MX-DF) } \\
\hline 1942-07-10 & $1942-07-24$ & $\begin{array}{l}\text { Decreto por el cual se previene que no podrán ser aumentadas las rentas de ocupación de inmuebles, mientras rija la suspensión } \\
\text { de garantías individuales }\end{array}$ \\
\hline 1943-09-24 & 1943-11-11 & $\begin{array}{l}\text { Decreto que prorroga en el Distrito Federal, por el tiempo que dure el estado de guerra en que se encuentra el país, toda } \\
\text { clase de contratos de arrendamiento de casas-habitación vigentes }\end{array}$ \\
\hline 1946-02-11 & 1946-05-08 & $\begin{array}{l}\text { Decreto que dispone no se aumenten los precios de arrendamiento de casas locales, así como que se consideren forzosamente } \\
\text { prorrogados los plazos de arrendamiento en beneficio de los inquilinos }\end{array}$ \\
\hline $1947-12-30$ & $1947-12-31$ & $\begin{array}{l}\text { Decreto que dispone que no podrán ser aumentadas las rentas de las casas o locales destinados a los usos que indica, así como } \\
\text { que los plazos de arrendamiento se considerarán forzosamente prorrogados hasta por un año, en beneficio de los inquilinos }\end{array}$ \\
\hline $1948-12-24$ & 1949-01-01 & $\begin{array}{l}\text { Decreto que prorroga por ministerio de la ley, sin alteración de ninguna de sus cláusulas, salvo lo que dispone el artículo que } \\
\text { el mismo especifica, los contratos de arrendamiento de las casas o locales que se citan }\end{array}$ \\
\hline $1984-12-28$ & 1985-02-07 & Decreto de reformas y adiciones a diversas disposiciones relacionadas con inmuebles en arrendamiento \\
\hline $1992-12-21$ & $1996-12-31$ & Decreto que abroga el diverso que prorroga los contratos de arrendamiento de las casas o locales que se citan \\
\hline 1993-07-14 & $1993-07-21$ & $\begin{array}{l}\text { Decreto por el que se reforman, adicionan y derogan diversas disposiciones del Código Civil para el Distrito Federal en } \\
\text { materia comun, y para toda la republlca en materia federal; Código de procedimientos civiles para el Distrito Federal y ley } \\
\text { federal de proteccion al consumidor }\end{array}$ \\
\hline 2000-05-25 & 2000-05-25 & Reformada su denominación, G.O. 25 de mayo de 2000) Código Civil para el Distrito Federal \\
\hline \multicolumn{3}{|r|}{ Monaco (MC) } \\
\hline 1915-03-09 & 1915-03-23 & Ordonnance Souveraine relative à la réduction du prix des loyers dus en vertu de baux \\
\hline $1917-04-12$ & $1917-04-17$ & Ordonnance Souveraine relative aux baux à loyer et aux créances hypothécaires \\
\hline 1919-07-16 & 1919-07-29 & Loi No. 19 elative aux baux à loyer et aux créances hypothécaires \\
\hline 1920-01-23 & 1920-02-03 & Loi No. 25 portant modification de la Loi No. 19 , du 16 juillet 1919 , relative aux baux à loyer et aux créances hypothécaires \\
\hline $1921-06-18$ & $1921-06-28$ & Loi No. 48 portant maintien en jouissance des locataires de locaux d'habitation \\
\hline $1922-07-23$ & 1922-08-01 & Loi No. 59 portant modification de la législation sur les loyers en ce qui concerne les locaux à usage d'habitation \\
\hline $1924-07-19$ & 1924-07-29 & Loi No. 78 portant Règlementation nouvelle des rapports entre propriétaires et locataires à partir du 1 er octobre 1924 \\
\hline 1926-06-12 & 1926-06-17 & $\begin{array}{l}\text { Loi No. } 95 \text { du } 12 \text { juin } 1926 \text { portant Règlementation nouvelle des rapports entre propriétaires et locataires à partir du } 1 \text { er } \\
\text { octobre } 1924\end{array}$ \\
\hline
\end{tabular}




\section{Table 7: List of legal acts (continued)}

\begin{tabular}{|c|c|c|}
\hline $\begin{array}{l}\text { Date of legal } \\
\text { act (yyyy- } \\
\text { mm-dd) }\end{array}$ & $\begin{array}{l}\text { Enactment } \\
\text { or publica- } \\
\text { tion date } \\
\text { (yyyy-mm- } \\
\text { dd) }\end{array}$ & Title of legal act \\
\hline $1926-12-21$ & 1926-12-30 & Loi No. 100 portant modification des articles 3,14 et 31 de la Loi No. 95 \\
\hline $1927-05-28$ & 1927-06-23 & $\begin{array}{l}\text { Loi No. } 106 \text { portant prorogation des dispositions de l'article } 23 \text { de la Loi No. } 95 \text { du } 12 \text { juin } 1926 \text { visant la majoration } \\
\text { temporaire et exceptionnelle des loyers des baux en cours }\end{array}$ \\
\hline $1928-06-27$ & 1928-08-02 & $\begin{array}{l}\text { Loi No. } 115 \text { portant majoration, à dater du ler octobre } 1928 \text {, des loyers d'occupant de locaux d'habitation maintenus en } \\
\text { jouissance jusqu'au } 30 \text { septembre } 1930 \text {, par la Loi No. } 95 \text { du } 12 \text { juin } 1926\end{array}$ \\
\hline 1928-07-18 & 1928-08-02 & $\begin{array}{l}\text { Loi No. } 117 \text { portant: 1o prorogation de la loi No. } 106 \text { du } 15 \text { juin } 1927 \text { sur la majoration temporaire et exceptionnelle des } \\
\text { loyers des baux en cours des locaux d'habitation et assimilés; 2o Révision des baux commerciaux et industriels en cours au } \\
\text { ler octobre } 1928\end{array}$ \\
\hline $1929-07-25$ & 1929-10-10 & $\begin{array}{l}\text { Loi No. } 120 \text { portant prorogation nouvelle de l'article } 31 \text { de la Loi No. } 95 \text { du } 12 \text { juin } 1926 \text {, visant les locaux affectés à } \\
\text { l'habitation et acquis en vue de l'exécution de travaux d'utilité publique }\end{array}$ \\
\hline 1930-07-07 & $1930-08-14$ & $\begin{array}{l}\text { Loi réglant les rapports entre locataires et bailleurs en ce qui concerne le renouvellement des baux à loyer d'immeubles ou } \\
\text { de locaux à usage commercial et industriel }\end{array}$ \\
\hline 1930-07-29 & 1930-08-14 & $\begin{array}{l}\text { Loi No. } 146 \text { portant règlementation du maintien en jouissance des occupants de locaux affectés à l'habitation ou à l'exercice } \\
\text { d'une profession }\end{array}$ \\
\hline 1932-05-23 & 1932-06-02 & Ordonnance Souveraine concernant les loyers \\
\hline 1936-02-27 & 1936-03-05 & Loi portant révision du prix des locations commerciales et industrielles en cours au 1er juillet 1935 \\
\hline 1938-07-24 & 1938-08-04 & Loi No. 245 portant règlementation du maintien en jouissance des occupant des locaux affectés à l'habitation \\
\hline 1939-09-27 & 1939-09-28 & Loi concernant les loyers des locaux d'habitation \\
\hline 1940-09-16 & 1940-09-19 & $\begin{array}{l}\text { Ordonnance-loi portant modification de l'article } 8 \text { de la Loi No. } 260 \text { du } 27 \text { septembre } 1939 \text { sur les Loyers des Locaux } \\
\text { d'Habitation }\end{array}$ \\
\hline 1940-12-05 & 1940-12-05 & Ordonnance-loi No. 305 concernant les loyers d'habitation \\
\hline 1943-09-08 & 1943-09-16 & Ordonnance-loi No. 367 portant réglementation du maintien en jouissance des occupants des locaux affectés à l'habitation \\
\hline 1943-09-08 & 1943-09-16 & $\begin{array}{l}\text { Ordonnance-loi No. } 369 \text { étendant aux réfugiés des localités des Alpes-Maritimes le bénéfice de l'Ordonnance-Loi No. } 367 \text { du } \\
8 \text { septembre } 1943\end{array}$ \\
\hline 1943-10-01 & 1943-10-07 & Ordinnance-Loi No. 370 portant modification de l'Ordonnance-Loi No. 367 sur les loyers des locaux d'habitation \\
\hline 1946-04-19 & 1946-04-25 & Loi No. 437 relative aux conditions et au prix de location des locaux d'habitation \\
\hline 1947-08-18 & 1947-09-11 & Loi $\mathrm{n}^{\circ} 468$ du 18 août 1947 relative aux locaux à usage d'habitation \\
\hline 1948-07-17 & 1948-07-22 & Loi $\mathrm{n}^{\circ} 482$ sur les locaux à usage d'habitation \\
\hline 1949-03-25 & 1949-04-04 & Loi $n^{\circ} 497$ relative aux conditions de location des locaux à usage d'habitation \\
\hline 1949-11-17 & 1949-11-28 & $\begin{array}{l}\text { Loi n }{ }^{\circ} 511 \text { portant modification de l'article } 14 \text { de la Loi n } 497 \text { du } 25 \text { mars } 1949 \text { relative aux conditions de location des locaux } \\
\text { à usage d'habitation }\end{array}$ \\
\hline 1951-06-26 & 1951-07-09 & $\begin{array}{l}\text { Loi } \mathrm{n}^{\circ} 545 \text { portant modification de la Loi } \mathrm{n}^{\circ} 497 \text { du } 25 \text { mars } 1949 \text { relative aux conditions de location des locaux à usage } \\
\text { d'habitation }\end{array}$ \\
\hline 1952-07-04 & 1952-07-14 & $\begin{array}{l}\text { Loi } \mathrm{n}^{\circ} 566 \text { portant modification de la Loi } \mathrm{n}^{\circ} 497 \text {, du } 25 \text { mars } 1949 \text {, relative aux conditions de Location des Locaux à usage } \\
\text { d'habitation modifiée par la Loi } \mathrm{n}^{\circ} 511 \text {, du } 17 \text { novembre } 1949 \text {, et par la Loi } \mathrm{n}^{\circ} 545 \text {, du } 26 \text { juin } 1951\end{array}$ \\
\hline $1954-07-15$ & 1954-07-26 & $\begin{array}{l}\text { Loi } n^{\circ} 596 \text { portant modification de la Loi n } 497 \text {, du } 25 \text { mars } 1949 \text { relative aux conditions de location des locaux à usage } \\
\text { d'habitation }\end{array}$ \\
\hline 1955-06-02 & 1955-06-20 & $\begin{array}{l}\text { Loi } \mathrm{n}^{\circ} 601 \text { modifiant l'article } 44 \text { de la Loi } \mathrm{n}^{\circ} 497 \text {, du } 25 \text { mars } 1949 \text {, relative aux conditions de location des locaux à usage } \\
\text { d'habitation, modifiée et complétée par les Lois } \mathrm{n}^{\circ} 566 \mathrm{du} 4 \text { juillet } 1952 \text { et } \mathrm{n}^{\circ} 596 \mathrm{du} 15 \text { juillet } 1954\end{array}$ \\
\hline 1959-09-17 & 1959-09-21 & $\begin{array}{l}\text { Ordonnance-loi n } 669 \text { du } 17 \text { septembre } 1959 \text { modifiant et codifiant la législation relative aux conditions de location des } \\
\text { locaux à usage d'habitation }\end{array}$ \\
\hline $1970-06-25$ & 1970-10-01 & $\begin{array}{l}\text { Loi } n^{\circ} 887 \text { portant limitation du champ d'application de l'Ordonnance-Loi n }{ }^{\circ} 669 \mathrm{du} 17 \text { septembre } 1959 \text { modifiant et codifiant } \\
\text { la législation relative aux conditions de location des locaux à usages d'habitation }\end{array}$ \\
\hline $1988-07-18$ & $1988-07-22$ & Loi $\mathrm{n}^{\circ} 1.118$ du 18 juillet 1988 relative aux conditions de location de certains locaux à usage d'habitation \\
\hline $2000-12-28$ & $2000-12-29$ & $\begin{array}{l}\text { Loi } \mathrm{n}^{\circ} 1.235 \mathrm{du} 28 \text { décembre } 2000 \text { relative aux conditions de location de certains locaux à usage d'habitation construits ou } \\
\text { achevés avant le } 1 \text { er septembre } 1947\end{array}$ \\
\hline $2004-12-21$ & 2004-12-24 & $\begin{array}{l}\text { Loi } \mathrm{n}^{\circ} 1.291 \mathrm{du} 21 \text { décembre } 2004 \text { modifiant la loi } \mathrm{n}^{\circ} 1.235 \mathrm{du} 28 \text { décembre } 2000 \text { relative aux conditions de location de } \\
\text { certains locaux à usage d'habitation construits ou achevés avant le ler septembre } 1947\end{array}$ \\
\hline \multicolumn{3}{|r|}{ Morocco (MA) } \\
\hline 1913-08-12 & 1913-08-12 & Dahir du 12 août 1913 (9 ramadan 1331) formant Code des obligations et des contrats \\
\hline $1920-02-25$ & 1920-02-25 & Dahir du 25 février 1920 ( 4 joumada II 1338) réprimant la spéculation illicite sur les loyers \\
\hline 1928-05-05 & 1928-05-08 & $\begin{array}{l}\text { Dahir du } 5 \text { mai } 1928 \text { (15 kaada 1346) portant modifications au dahir du } 25 \text { février } 1920 \text { (4 joumada II 1338) réprimant la } \\
\text { spéculation illicite sur les loyers }\end{array}$ \\
\hline 1928-05-05 & 1928-05-08 & Dahir du 5 mai 1928 (15 kaada 1346) édictant des mesures temporaires au regard des baux à loyers \\
\hline
\end{tabular}




\section{Table 7: List of legal acts (continued)}

\begin{tabular}{|c|c|c|}
\hline $\begin{array}{l}\text { Date of legal } \\
\text { act (yyyy- } \\
\text { mm-dd) }\end{array}$ & $\begin{array}{l}\text { Enactment } \\
\text { or publica- } \\
\text { tion date } \\
\text { (yyyy-mm- } \\
\text { dd) }\end{array}$ & Title of legal act \\
\hline 1930-03-21 & 1930-03-21 & $\begin{array}{l}\text { Dahir du } 21 \text { mars } 1930 \text { (20 chaoual 1348) réglant les rapports entre locataires et bailleurs, en ce qui concerne le renouvellement } \\
\text { des baux à loyers d'immeubles ou de locaux à usage commercial, industriel }\end{array}$ \\
\hline 1935-08-29 & 1935-08-30 & $\begin{array}{l}\text { Dahir du } 29 \text { août } 1935 \text { ( } 28 \text { joumada I } 1354 \text { ) relatif à la révision du prix des loyers de tous emplacements, locaux, appartements } \\
\text { ou chambres loués nus ou meublé, à usage d'habitation ou professionnel }\end{array}$ \\
\hline 1941-02-10 & 1941-02-21 & Dahir du 10 février 1941 (13 moharrem 1360) édictant des mesures spéciales au regard des loyers \\
\hline $1941-04-23$ & 1941-05-02 & $\begin{array}{l}\text { Dahir du } 23 \text { avril } 1941 \text { ( } 25 \text { rebia I 1360) interprétatif du dahir du } 5 \text { mai } 1928 \text { (15 kaada 1346) édictant des mesures temporaires } \\
\text { au regard des baux à loyers }\end{array}$ \\
\hline 1941-04-23 & 1941-05-02 & Dahir du 23 avril 1941 (25 rebia I 1360) prescrivant la déclaration des locaux vacants \\
\hline 1941-05-06 & 1941-05-06 & Dahir du 6 mai 1941 (9 rebia II 1360) relatif à la fixation des tarifs des locations en meublé \\
\hline 1941-08-19 & $1941-08-22$ & $\begin{array}{l}\text { Dahir du } 25 \text { rejeb } 1360 \text { (19 août 1941) interdisant l'habitat des juifs sujets marocains dans les secteurs européens des } \\
\text { municipalités }\end{array}$ \\
\hline 1941-08-19 & 1905-03-25 & Dahir du 25 rejeb 1360 (19 août 1941) relatif au dégagement des locaux à usage d'habitation \\
\hline 1941-08-19 & 1941-08-19 & Dahir du 25 rejeb 1360 (19 août 1941) relatif aux déterminations des locaux à usage d'habitation \\
\hline 1943-04-17 & $1943-04-23$ & $\begin{array}{l}\text { Dahir du } 17 \text { avril } 1943 \text { (11 rebia II 1362) édictant des mesures spéciales à l'égard des loyers des locaux à usage d'habitation } \\
\text { dans les médinas et les quartiers indigènes des villes nouvelles }\end{array}$ \\
\hline $1943-11-30$ & 1943-11-30 & $\begin{array}{l}\text { Dahir du } 30 \text { novembre } 1943 \text { ( } 2 \text { hija 1362) édictant des mesures spéciales à l'égard des loyers des locaux à usage d'habitation } \\
\text { dans les médinas et les quartiers indigènes des villes nouvelles }\end{array}$ \\
\hline 1944-03-10 & 1944-03-17 & Dahir du 10 mars 1944 (14 rebia I 1363) portant majoration du prix des loyers \\
\hline $1946-05-28$ & 1946-06-21 & Dahir du 28 mai 1946 (26 joumada II 1365) portant majoration du prix des loyers \\
\hline 1948-01-17 & 1948-01-30 & $\begin{array}{l}\text { Dahir du } 17 \text { janvier } 1948 \text { ( } 5 \text { rebia I 1367) réglant les rapports entre locataires et bailleurs, en ce qui concerne le renouvellement } \\
\text { des baux à loyers d'immeubles ou de locaux à usage commercial, industriel ou artisanal }\end{array}$ \\
\hline 1948-02-17 & 1948-03-03 & $\begin{array}{l}\text { Dahir du } 17 \text { février } 1948 \text { (6 rebia II 1367) portant majoration du prix des loyers des locaux à usage d'habitation ou profes- } \\
\text { sionnel }\end{array}$ \\
\hline 1949-05-23 & $1949-05-27$ & Dahir du 23 mai 1949 (26 rejeb 1368) instituant la liberté des loyers des locaux à usage professionnel \\
\hline $1949-05-23$ & 1949-05-27 & Dahir du 23 mai 1949 (26 rejeb 1368) portant majoration des loyers des locaux à usage d'habitation \\
\hline 1950-04-15 & $1950-07-28$ & $\begin{array}{l}\text { Dahir du } 15 \text { avril } 1950 \text { ( } 27 \text { joumada II 1369) réglementant les loyers des locaux à usage d'habitation dans le médinas et } \\
\text { quartiers marocains des villes nouvelles }\end{array}$ \\
\hline $1950-12-01$ & $1950-12-01$ & $\begin{array}{l}\text { Dahir du } 1 \text { décembre } 1950 \text { (20 safar 1370) abrogeant le dahir du } 25 \text { février } 1920 \text { (4 joumada II 1338) et édictant de nouvelles } \\
\text { dispositions réprimant la spéculation illicite sur les loyers }\end{array}$ \\
\hline 1951-02-17 & 1951-03-02 & Dahir du 17 février 1951 (10 joumada I 1370) relatif aux loyers \\
\hline 1952-01-30 & 1952-01-30 & $\begin{array}{l}\text { Dahir du } 30 \text { janvier } 1952 \text { ( } 3 \text { joumada I 1371) modifiant le dahir du } 17 \text { janvier } 1948 \text { ( } 5 \text { rebia I 1367) réglant les rapports entre } \\
\text { locataires et bailleurs en ce qui concerne le renouvellement des baux à loyers d'immeubles ou de locaux à usage commercial, } \\
\text { industriel ou artisanal }\end{array}$ \\
\hline $1952-07-22$ & 1952-10-01 & $\begin{array}{l}\text { Dahir du } 22 \text { juillet } 1952 \text { ( } 29 \text { chaoual 1371) réglementant les loyers des locaux à usage d'habitation dans le médinas et quartiers } \\
\text { marocains des villes nouvelles }\end{array}$ \\
\hline 1954-04-22 & 1954-04-28 & Dahir du 22 avril 1954 (18 chaabane 1373) relatif aux loyers \\
\hline 1955-06-30 & $1955-06-30$ & Dahir du 30 juin 1955 (9 kaada 1374) relatif aux loyers des locaux d'habitation sis dans les villes nouvelles \\
\hline $1980-12-25$ & $1981-01-21$ & $\begin{array}{l}\text { Dahir no. 1-80-315 du } 17 \text { safar } 1401 \text { ( } 25 \text { décembre 1980) portant promulgation de la loi no. 6-79 organisant les rapports } \\
\text { contractuels entre les bailleurs et les locataires des locaux d'habitation ou à usage professionel }\end{array}$ \\
\hline 1999-08-25 & 1999-10-07 & Dahir n 1-99-210 du 13 joumada I 1420 (25 août 1999) portant promulgation de la loi nº 63-99, B.O du 7 octobre 1999 \\
\hline 2007-11-30 & 2007-12-20 & $\begin{array}{l}\text { Loi } n^{\circ} 07-03 \text { relative à la révision du montant du loyer des locaux à usage d'habitation ou usage professionnel, commercial, } \\
\text { industriel ou artisanal }\end{array}$ \\
\hline 2013-11-19 & 2014-02-28 & $\begin{array}{l}\text { Dahir n } 111.13 .1 \text { du } 15 \text { moharrem } 1435(19 / 11 / 2013) \text { promulguant la loi nº67.12 publié au BO n6208 du 28/12/2013 p. } \\
7328\end{array}$ \\
\hline \multicolumn{3}{|r|}{ New Zealand (NZ) } \\
\hline 1916-08-07 & 1916-08-07 & War Legislation Amendment Act \\
\hline 1921-02-11 & $1921-02-11$ & Housing Amendment Act 1921-1922 \\
\hline $1922-10-31$ & $1922-10-31$ & Finance Act 1922 \\
\hline $1923-07-31$ & $1923-07-31$ & Rent Restriction Act 1924 \\
\hline $1926-08-31$ & $1926-08-31$ & Rent Restriction Act 1926 \\
\hline 1930-07-31 & 1930-07-31 & Rent Restriction Act 1930 \\
\hline 1931-07-31 & 1931-07-31 & Rent Restriction Extension Act 1931 \\
\hline 1932-11-19 & 1932-11-19 & Rent Restriction Act 1932 \\
\hline $1933-10-28$ & $1933-10-28$ & Rent Restriction Act 1933 \\
\hline $1934-10-31$ & $1934-10-31$ & Rent Restriction Act 1934 \\
\hline
\end{tabular}




\section{Table 7: List of legal acts (continued)}

\begin{tabular}{|c|c|c|}
\hline $\begin{array}{l}\text { Date of legal } \\
\text { act (yyyy- } \\
\text { mm-dd) }\end{array}$ & $\begin{array}{l}\text { Enactment } \\
\text { or publica- } \\
\text { tion date } \\
\text { (yyyy-mm- } \\
\text { dd) }\end{array}$ & Title of legal act \\
\hline $1935-10-24$ & 1935-10-24 & Rent Restriction Act 1935 \\
\hline 1936-06-11 & 1936-06-11 & $\begin{array}{l}\text { An act to make temporary Provision for the Restriction of Increases in the Rent of certain Classes of Dwellinghouses, for } \\
\text { the Determination of Fair Rents therefor, and for certain Matters incidental thereto [Fair rents act] }\end{array}$ \\
\hline 1937-09-30 & 1937-09-30 & Fair Rents Amendment Act 1937 \\
\hline 1939-10-07 & 1939-10-07 & Fair Rents Amendment Act 1939 \\
\hline 1941-09-29 & 1941-09-29 & Fair Rents Amendment Act 1941 \\
\hline $1942-10-26$ & 1942-10-26 & Fair Rents Amendment Act 1942 \\
\hline $1942-12-15$ & 1942-12-15 & Economic Stabilization Emergency Regulations 1942 \\
\hline $1947-11-27$ & 1947-11-27 & Fair Rents Amendment Act 1947 \\
\hline 1948-12-03 & 1948-12-03 & $\begin{array}{l}\text { An Act to Consolidate and Amend Certain Enactments Relating to Tenancies of Dwellinghouses and Other Properties } \\
\text { [Tenancy act] }\end{array}$ \\
\hline $1950-12-20$ & 1950-12-20 & The emergency forces tenancy regulations \\
\hline $1955-10-21$ & 1955-10-21 & Tenancy Act 1955 \\
\hline 1956-11-06 & 1956-11-06 & The tenancy regulations 1956 \\
\hline 1973-10-02 & 1973-10-02 & Rent Appeal Act 1973 \\
\hline 1974-01-28 & 1974-01-28 & The Rent Appeal Act Commencement Order 1974 \\
\hline 1978-04-24 & 1978-04-24 & The Rent Appeal (Fee) Regulations 1978 \\
\hline 1984-02-01 & 1984-04-01 & The Rent Limitations Regulations 1984 \\
\hline $1986-12-17$ & 1987-02-01 & $\begin{array}{l}\text { An Act to reform and restate the law relating to residential tenancies, to define the rights and obligations of landlords and } \\
\text { tenants of residential properties, to establish a tribunal to determine expeditiously disputes arising between such landlords } \\
\text { and tenants, to establish a fund in which bonds payable by such tenants are to be held, and to repeal the Tenancy Act } 1955 \\
\text { and the Rent Appeal Act } 1973 \text { and their amendments [Residential Tenancies Act] }\end{array}$ \\
\hline \multicolumn{3}{|r|}{ Nicaragua $(\mathrm{NI})$} \\
\hline 1939-09-27 & 1939-09-29 & $\begin{array}{l}\text { Ley de inquilinato, Decreto No. 14; Aprobada el } 27 \text { de Septiembre de 1939. Publicada en La Gaceta No. } 211 \text { del } 29 \text { de } \\
\text { Septiembre de } 1939 .\end{array}$ \\
\hline 1942-08-29 & 1942-08-29 & Decreto Legislativo No. 214 de 29 de Agosto de 1942 \\
\hline 1944-08-02 & 1944-08-11 & $\begin{array}{l}\text { Ley de inquilinato, Decreto No. 299, Aprobado el } 02 \text { de Agosto de 1944. Publicado en La Gaceta No. } 166 \text { del } 11 \text { de Agosto } \\
\text { de } 1944 .\end{array}$ \\
\hline 1948-08-26 & 1948-09-02 & $\begin{array}{l}\text { Ley de inquilinato, Decreto legislativo No.92 MG Aprobado el } 26 \text { de Agosto de } 1948 \text {. Publicado en La Gaceta No.192 del } 2 \\
\text { de Septiembre de } 1948 .\end{array}$ \\
\hline $1957-10-18$ & 1957-11-01 & $\begin{array}{l}\text { Ley de inquilinato, Decreto No. 281; Aprobado el } 18 \text { de Octubre de } 1957 \text {. Publicado en La Gaceta No. } 248 \text { del } 01 \text { de } \\
\text { Noviembre de } 1957 \text {. }\end{array}$ \\
\hline $1977-11-25$ & 1977-12-01 & $\begin{array}{l}\text { Ley de inquilinato, Decreto 664. Aprobado el } 25 \text { de Noviembre de 1977. Publicado en La Gaceta No. } 273 \text { del } 1 \text { de Diciembre } \\
\text { de } 1977 .\end{array}$ \\
\hline 1990-12-06 & 1991-01-16 & $\begin{array}{l}\text { Ley de inquilinato, Ley No. 118, Aprobada el } 6 \text { de Diciembre de 1990. Publicada en La Gaceta No. } 11 \text { del } 16 \text { de Enero de } \\
1991 .\end{array}$ \\
\hline \multicolumn{3}{|r|}{ Norway (NO) } \\
\hline $1915-12-17$ & 1915-12-17 & Provisorisk anordning angaaende husleie \\
\hline 1916-05-10 & 1916-05-10 & Lov om kommunal regulering av husleie (Tenancy Act) \\
\hline 1916-08-26 & 1916-08-26 & Provisorisk anordning om forbud mot opsigelse av leieboere \\
\hline 1916-11-10 & 1916-11-10 & Provisorisk anordning om forbud mot bruk av beboelsesleilighet til forretningslokale \\
\hline $1916-12-22$ & 1916-12-22 & Provisorisk anordning om forandringer i de provisoriske anordninger om husleie av 26/8 og 10/11 1916 \\
\hline $1917-05-25$ & 1917-05-25 & Lov om tvungen avstaaelse av bruksret til husrum \\
\hline 1917-07-13 & 1917-07-13 & Midlertidig lov om indskrænkning i utlændingers adgang til at opholde sig i visse kommuner \\
\hline 1917-09-08 & 1917-09-08 & $\begin{array}{l}\text { Provisorisk anordning om forandring i provisor. Anordn. om forbud mot opsigelse av leieboere av } 26 \text { august } 1916 \text { og om } \\
\text { forbud mot offentlig }\end{array}$ \\
\hline $1917-10-12$ & $1917-10-12$ & $\begin{array}{l}\text { Provisorisk anordning om forandring i provisor. Anordn. Om forbud mot bruk av beboelsesleilighet til forretningslokale av } \\
10 \text { november } 1916\end{array}$ \\
\hline $1917-12-14$ & $1917-12-14$ & Lov nr. 21 om kommunal regulering av husleie \\
\hline 1918-07-12 & 1918-07-12 & Lov nr. 1 om boligforholdene (boligloven) \\
\hline 1919-07-23 & 1919-07-23 & Lov nr. 5 om tillegg til og forandring i lov om boligforholdene av 12 juli 1918 \\
\hline 1920-06-12 & 1920-06-12 & Lov nr. 1 om forandring i lov av 25 mai 1917 om tvungen avståelse av brukrsrett til husrom \\
\hline 1920-07-09 & 1920-07-09 & Midlertidig lov om tvungen fordeling av husrum \\
\hline 1926-07-09 & 1926-08-01 & Lov om endringer i lov om boligforholdene av 12 juli 1918 med tilleggslover av 23 juli 1919 \\
\hline
\end{tabular}




\section{Table 7: List of legal acts (continued)}

\begin{tabular}{|c|c|c|}
\hline $\begin{array}{l}\text { Date of legal } \\
\text { act (yyyy- } \\
\text { mm-dd) }\end{array}$ & $\begin{array}{l}\text { Enactment } \\
\text { or publica- } \\
\text { tion date } \\
\text { (yyyy-mm- } \\
\text { dd) }\end{array}$ & Title of legal act \\
\hline 1929-06-26 & 1929-06-26 & Lov om endringer i lov om boligforholdene av 12 juli 1918 med tilleggslover av 23 juli 1919 og 9 juli 1926 \\
\hline $\begin{array}{l}1934-03-24 \\
1935-06-25\end{array}$ & 1934-03-24 & $\begin{array}{l}\text { Lov om endringer i lov om boligforholdene av } 12 \text { juli } 1918 \text { med tilleggslover av } 23 \text { juli } 1919,9 \text { juli } 1926 \text { og } 26 \text { juni } 1929 \\
\text { Midlertidig lov av } 25 \text { juni } 1935 \text { om innskrenkning i adgangen til utkastelse av leietagere i Oslo [Temporary Act of } 25 \text { June } \\
1935 \text { on the limitation of access to the eviction of tenants in Oslo] }\end{array}$ \\
\hline 1936-06-25 & 1936-07-01 & $\begin{array}{l}\text { Midlertidig lov av } 25 \text { juni } 1936 \text { om innskrenkning i adgangen til utkastelse av leietagere i Oslo [Temporary Act of } 25 \text { June } \\
1936 \text { on the limitation of access to the eviction of tenants in Oslo] }\end{array}$ \\
\hline 1938-06-24 & $1938-06-24$ & $\begin{array}{l}\text { Lov om forlenget gyldighet av mid-24 juni. lertidig lov av } 25 \text { juni } 1936 \text { om innskrenk- Nr. } 11 \text {. ning i adgangen til utkastelse } \\
\text { av leietagere i Oslo } \mathrm{m} \text {. v. (lov nr. } 11 \text { av } 24 \text { juni 1938) }\end{array}$ \\
\hline 1939-06-16 & 1939-07-01 & Lov 16. juni 1939 nr. 6 om husleie [Landlord and Tenant Act 1939] \\
\hline 1953-06-26 & 1953-06-26 & $\begin{array}{l}\text { Lov av 26. juni } 1953 \mathrm{om} \text { kontroll og regulering av priser, utbytte og konkurranseforhold [Act of } 26 \text { June } 1953 \text { on the control } \\
\text { and regulation of prices, dividends and competitive conditions] }\end{array}$ \\
\hline 1954-06-25 & 1954-06-25 & Midlertidig lov av 25. juni 1954 om regulering av leie for husrom $\mathrm{m} . \mathrm{v}$. \\
\hline 1957-06-28 & 1957-07-01 & Lov av 28. juni 1957 om regulering av leie for husrom $\mathrm{m} . \mathrm{v}$. \\
\hline 1960-02-04 & & Lov nr. 2 im borettslag \\
\hline 1964-06-20 & $1964-07-01$ & Midlertidig lov om regulering av leie for husrom m. v. av 20. juni 1964 [Provisional act on rent restriction of 20 June 1964] \\
\hline 1967-07-07 & 1967-07-01 & Midlertidig lov om regulering av leie for husrom m.v. (Provisional Act No. 13 of 7 July 1967 on rent restriction) \\
\hline 1999-03-26 & 1999-03-26 & Lov 17/1999 om husleieavtaler (Landlord and Tenant Act 1999) \\
\hline \multicolumn{3}{|r|}{ Panama (PA) } \\
\hline 1932-11-15 & 1932-11-21 & Ley No. 18 sobre inquilinato \\
\hline 1935-01-05 & 1935-01-09 & Ley No. 8 sobre inquilinato \\
\hline 1942-12-01 & 1942-12-01 & Decreto Ley No. 43 \\
\hline 1945-07-13 & 1945-07-13 & Decreto No. 1231 por el cual se toman medidas sobre inquilinato \\
\hline 1959-10-26 & 1960-01-04 & $\begin{array}{l}\text { Ley No. } 26 \text { por la cual se ordena una rebaja de los alquileres en casas de inquilinato y se adoptan medidas para solucionar } \\
\text { el problema de las viviendas de las personas de recursos limitados }\end{array}$ \\
\hline 1968-10-14 & 1968-10-14 & $\begin{array}{l}\text { Decreto de Gabinete No. } 3 \text { por el cual se congelan los precios de los alquileres de las casas de inquilinatos y apartamentos } \\
\text { cuyo canon de arrendamiento no exceda de B./ } 80,00 \text { mensuales }\end{array}$ \\
\hline 1973-10-04 & 1973-10-22 & Ley No. 93 se dictan medidas sobre los arrendamientos \\
\hline 1974-03-12 & 1974-03-12 & Ley No. 28 por la cual se modifica y adiciona artículos de la Ley 93 de 4 de octubre de 1973 \\
\hline $1974-05-15$ & 1974-06-01 & $\begin{array}{l}\text { Decreto no. } 37 \text { por el cual se excluye del ámbito de aplicación de la ley } 93 \text { de } 4 \text { de octubre de } 1973 \text {, tal como quedó } \\
\text { reformada por la ley } 28 \text { de } 12 \text { de marzo de } 1974 \text {, los contratos de arrendamientos de bienes inmuebles que se regirán por la } \\
\text { libre contratación }\end{array}$ \\
\hline 1994-12-07 & 1995-03-30 & $\begin{array}{l}\text { Decreto ejecutivo No. } 294 \text { por el cual se excluye del ambito de aplicacion de la ley } 93 \text { de } 4 \text { de octubre de } 1973 \text {, tal como } \\
\text { quedo reformado por ley } 28 \text { de } 12 \text { de marzo de } 1974 \text {, salvo lo dispuesto en los articulos } 4-8,10,13,16,19,20,65,66,68 \\
\text { los contratos de arrendamiento... }\end{array}$ \\
\hline 1995-01-10 & 1995-01-24 & $\begin{array}{l}\text { Decreto ejecutivo No. } 7 \text { excluye del ambito de aplicacion de la ley } 93 \text { de } 4 \text { de octubre de } 1973 \text {, como quedo modificado por } \\
\text { la ley } 28 \text { de } 12 / 3 / 1974 \text {, excepto los articulos } 4,5,6,7,8,10,13,16,19,65,66 \text { y } 68 \text {; y articulo } 1 \text { numeral } 3 \text { del decreto } 37 \text { de } \\
15 / 5 / 1974\end{array}$ \\
\hline \multicolumn{3}{|r|}{ Peru (PE) } \\
\hline 1920-05-12 & 1920-05-12 & Ley No. 4123 Prohibiendo aumentar el alquiler de las habitaciones que no exceda de diez libras mensuales \\
\hline 1928-03-02 & 1928-01-01 & Ley No. 6074 Ley de inquilinato \\
\hline 1932-11-03 & 1932-11-03 & $\begin{array}{l}\text { Ley } 7655 \text { declarando en todo su vigor hasta el } 31 \text { de diciembre de } 1932 \text { los efectos de la ley } \mathrm{n}^{\circ} 7550 \text {, sobre contratos de } \\
\text { alquiler de casas habitaciones }\end{array}$ \\
\hline 1938-10-20 & 1938-10-20 & $\begin{array}{l}\text { Ley } 8766 \text { disponiendo que a partir del } 20 \text { de octubre de } 1938 \text { y hasta el } 31 \text { de octubre de } 1940 \text {, la renta de las casas, } \\
\text { departamentos o piezas destinadas a habitación, alquilados o que se alquilen durante la vigencia de esta ley, en las provincias } \\
\text { de Lima y Callao, no será superior a la vigente el } 1^{\circ} \text { de enero de } 1938 \text {. El ministerio de salud pública, trabajo y previsión } \\
\text { social impondrá multas a los infractores }\end{array}$ \\
\hline $1941-02-26$ & 1940-11-01 & $\begin{array}{l}\text { Ley } 9348 \text { prorrogando por dos años los efectos de las leyes nos. } 8766 \text { y } 9095 \text {, que prohiben el aumento de alquileres, y } \\
\text { haciendo extensivos a todo el territorio nacional los beneficios de dichas leyes }\end{array}$ \\
\hline $1943-01-22$ & $1943-01-22$ & $\begin{array}{l}\text { Ley } 9779 \text { prorrogando hasta el } 26 \text { de febrero de } 1945 \text { la vigencia de las leyes nos. 8766, 9095, 9348 y 9349, que prohiben el } \\
\text { aumento de alquileres }\end{array}$ \\
\hline 1945-08-24 & 1945-08-24 & $\begin{array}{l}\text { Ley } 10222 \text { prohibiendo el alza de alquileres de casas-habitación en toda la república y suspendiendo la tramitación de los } \\
\text { juicios de desahucio y de aviso de despedida de casas-habitación }\end{array}$ \\
\hline $1946-11-21$ & $1946-11-21$ & $\begin{array}{l}\text { Ley } 10716 \text { comprendiendo en las disposiciones de la ley } \mathrm{n}^{\circ} 10222 \text { los inmuebles urbanos de la república, cualquiera que sea } \\
\text { el uso a que estén destinados; y fijando el monto máximo de la merced conductiva en casos de subarrendamiento }\end{array}$ \\
\hline
\end{tabular}




\section{Table 7: List of legal acts (continued)}

\begin{tabular}{|c|c|c|}
\hline $\begin{array}{l}\text { Date of legal } \\
\text { act }(\text { yyyy- } \\
\text { mm-dd) }\end{array}$ & $\begin{array}{l}\text { Enactment } \\
\text { or publica- } \\
\text { tion date } \\
\text { (yyyy-mm- } \\
\text { dd) }\end{array}$ & Title of legal act \\
\hline 1948-11-04 & 1948-11-04 & $\begin{array}{l}\text { Decreto-Ley } 10895 \text { prohibiendo la iniciación de juicios de aviso de despedida de casas-habitación así como los contratos de } \\
\text { subarriendo de las mismas }\end{array}$ \\
\hline $1957-03-22$ & $1957-03-22$ & $\begin{array}{l}\text { Ley } 12820 \text { exceptuando a las municipalidades de la República del régimen de las limitaciones prescritas en las Leyes Nos. } \\
10222,10716 \text { y } 10895 \text {, en lo referente a los inmuebles de su propiedad }\end{array}$ \\
\hline 1975-06-10 & 1975-06-10 & Decreto-ley 21168 cortan juicios de desahucio que no sean por falta de pago de alquiler o por casa única \\
\hline $1977-09-20$ & $1977-09-20$ & Decreto-Ley 21938 el Gobierno establece el régimen de alquiler para los predios destinados a casa-habitación \\
\hline 1979-04-11 & 1979-04-11 & Decreto-Ley 22492 excluyen de régimen de Alquiler a predios para casa-habitación \\
\hline 1991-11-05 & 1991-11-05 & Decreto Legislativo 709, Ley de Promoción a la Inversión Privada en Predios para Arrendamiento \\
\hline \multicolumn{3}{|r|}{ Philippines (PH) } \\
\hline 1937-08-21 & 1937-08-21 & $\begin{array}{l}\text { Proclamation No. } 173 \text {, s. } 1937 \text {, Enjoining all branches, subdivisions, agencies, and instrumentalities of the Commonwealth } \\
\text { Government to extend their cooperation in rendering the necessary aid to the refugees from China and prohibiting, as an } \\
\text { emergency measure, the raise in house rentals and prices of foodstuffs and other prime necessities of life }\end{array}$ \\
\hline 1943-01-04 & 1943-01-04 & Executive Order No. 117 Regulating house rentals in the city of Manila \\
\hline 1945-10-15 & 1945-10-15 & Commonwealth Act No. 689, An Act to Penalize Speculation or Rents of Buildings Destined for Dwelling Purposes \\
\hline 1946-10-18 & 1946-10-18 & $\begin{array}{l}\text { Republic act no. } 66 \text { an act to amend Commonwealth act numbered six hundred and eighty-nine, entitled "An act to penalize } \\
\text { speculation on rents of buildings destined for dwelling purposes" }\end{array}$ \\
\hline 1947-06-21 & 1947-06-21 & Executive Order No. 62 , s. 1947 , Regulating rentals for houses and lots for residential buildings \\
\hline $1948-12-23$ & $1948-12-23$ & $\begin{array}{l}\text { Executive Order No. 191, s. 1948, Extending the provisions of Executive Order No. 62, dated June 21, 1947; entitled } \\
\text { "Regulating Rentals for Houses and Lots for Residential Buildings," until December 31, } 1949\end{array}$ \\
\hline 1949-06-18 & 1949-07-03 & Republic Act No. 386, An act to ordain and institute the Civil Code of the Philippines \\
\hline 1970-06-17 & 1970-06-17 & $\begin{array}{l}\text { Republic Act No. } 6126 \text {, An act to regulate rentals of dwelling units or of land on which another's dwelling is located for one } \\
\text { year and penalizing violations thereof }\end{array}$ \\
\hline 1971-06-14 & 1971-06-14 & $\begin{array}{l}\text { R.A. } 6359 \text {, An act to regulate rentals for two years, of dwelling units or of land on which another's dwelling is located and } \\
\text { penalizing violations thereof, and for other purposes }\end{array}$ \\
\hline $1972-10-12$ & 1972-10-12 & $\begin{array}{l}\text { Presidential Decree No. 20, Amending certain provisions of republic act no. } 6359 \text {, entitled "An act to regulate rentals for } \\
\text { the years of dwelling units or of land on which another's dwelling is located and penalizing violations thereof, and for other } \\
\text { purposes" }\end{array}$ \\
\hline 1979-04-10 & 1979-04-10 & $\begin{array}{l}\text { Batas Pambansa 25, An act regulating rentals of dwelling units or of land on which another's dwelling is located and for } \\
\text { other purposes }\end{array}$ \\
\hline 1979-09-21 & 1979-09-21 & $\begin{array}{l}\text { Presidential Decree No. } 1642 \text {, s. } 1979 \text {, freezing the rates of rental, above three hundred pesos a month, of residential and } \\
\text { commercial buildings, houses, apartments and dwelling units in metropolitan Manila at current levels }\end{array}$ \\
\hline 1985-06-12 & 1985-06-12 & $\begin{array}{l}\text { Batas Pambansa Blg. 877, An act providing for the stabilization and regulation of, rentals of certain residential units for } \\
\text { other purposes }\end{array}$ \\
\hline $1987-12-28$ & 1988-01-01 & $\begin{array}{l}\text { R.A. } 6643 \text {, An act extending the effectivity of batas pambansa blg. } 877 \text {, entitled "An act providing for the stabilization and } \\
\text { regulation of rentals of certain residential units and for other purposes," for another two years }\end{array}$ \\
\hline 1989-12-30 & 1990-01-01 & $\begin{array}{l}\text { R.A. } 6828 \text {, An act extending the effectivity of batas pambansa blg. } 877 \text { entitled "An act providing for the stabilization and } \\
\text { regulation of rentals of certain residential units and for other purposes" for another three years, amending thereby section } \\
\text { one of republic act numbered sixty-six hundred and forty-three }\end{array}$ \\
\hline $1992-12-28$ & 1993-01-01 & $\begin{array}{l}\text { R.A. } 7644 \text {, An act further extending the rent control period for certain residential units, amending thereby batas pambansa } \\
\text { blg. } 877 \text {, entitled "An act providing for the stabilization and regulation of rentals of certain residential units and for other } \\
\text { purposes," as amended }\end{array}$ \\
\hline 1997-12-22 & 1998-01-01 & $\begin{array}{l}\text { R.A. } 8437 \text {, An act further extending the rent control period for certain residential units amending thereby batas pambansa } \\
\text { blg. } 877 \text { entitled: "An act providing for the stabilization and regulation of rentals of certain residential units, and for other } \\
\text { purposes, as amended" }\end{array}$ \\
\hline $2001-12-22$ & 2002-01-01 & $\begin{array}{l}\text { R.A. 9161, An act estabilishing reforms in the regulation of rentals of certain residential units, providing the mechanisms } \\
\text { therefor and for other purposes [Rental Reform Act of 2002] }\end{array}$ \\
\hline 2005-12-21 & $2005-12-21$ & $\begin{array}{l}\text { Republic Act No. 9341, An act establishing reforms in the regulation of rent of certain residential units, providing the } \\
\text { mechanisms therefor and for other purposes [Rent Control Act of 2005] }\end{array}$ \\
\hline 2009-07-14 & 2009-07-14 & $\begin{array}{l}\text { Republic Act No. 9653, An act establishing reforms in the regulation of rent of certain residential units, providing the } \\
\text { mechanisms therefor and for other purposes }\end{array}$ \\
\hline 2013-12-16 & $2013-12-16$ & HUDCC Resolution No. 2, Serie of 2013, Extension of period of regulation for the rent control act coverage \\
\hline 2015-06-08 & 2015-06-08 & HUDCC Resolution No. 1, Serie of 2015, Adjustment of coverage and rates of increases of the Rent Control Act \\
\hline \multicolumn{3}{|r|}{ Poland (PL) } \\
\hline 1918-07-15 & 1918-08-10 & orów \\
\hline
\end{tabular}




\section{Table 7: List of legal acts (continued)}

\begin{tabular}{|c|c|c|}
\hline $\begin{array}{l}\text { Date of legal } \\
\text { act (yyyy- } \\
\text { mm-dd) }\end{array}$ & $\begin{array}{l}\text { Enactment } \\
\text { or publica- } \\
\text { tion date } \\
\text { (yyyy-mm- } \\
\text { dd) }\end{array}$ & Title of legal act \\
\hline 1918-09-04 & 1918-09-10 & Ustawa tymczaspwa o ochronie lokatorów \\
\hline 1919-01-16 & 1919-01-25 & Dekret o ochronie lokatorów i zapobieganiu brakowi mieszkań \\
\hline 1919-06-28 & 1919-06-28 & Ustawa z dnia 28 czerwca 1919 r. o ochronie lokatorów \\
\hline $1920-12-18$ & 1921-01-01 & Ustawa z dnia 18 grudnia 1920 r. o ochronie lokatorów \\
\hline 1922-04-04 & 1922-05-24 & Ustawa z dnia 4 kwietnia 1922 r. o obowiązku zarządów gmin miejskich dostarczania pomieszczeń \\
\hline 1923-06-01 & 1923-06-15 & $\begin{array}{l}\text { Ustawa z dnia } 1 \text { czerwca } 1923 \text { r. przedłużająca moc obowiązującą ustawy z dnia } 4 \text { kwietnia } 1922 \text { r. o obowiązku zarządów } \\
\text { gmin miejskich dostarczania pomieszczeń }\end{array}$ \\
\hline 1924-04-11 & 1924-04-11 & Ustawa z dnia 11 kwietnia 1924 r. o ochronie lokatorów \\
\hline 1926-03-27 & 1926-03-27 & Ustawa z dnia 27 marca 1926 r. zmieniająca ustawę o ochronie lokatorów \\
\hline $1926-12-29$ & 1926-12-29 & $\begin{array}{l}\text { Rozporządzenie Prezydenta Rzeczypospolitej z dnia } 29 \text { grudnia } 1926 \text { r. sprawie zmiany postanowień art. } 6 \text { ustawy o ochronie } \\
\text { lokatorów }\end{array}$ \\
\hline $1927-06-27$ & 1927-06-27 & $\begin{array}{l}\text { Rozporządzenie Prezydenta Rzeczypospolitej z dnia } 27 \text { czerwca } 1927 \text { r. w sprawie zmiany postanowień art. } 6 \text { ustawy o } \\
\text { ochronie lokatorów }\end{array}$ \\
\hline $1927-12-19$ & 1927-12-19 & $\begin{array}{l}\text { Rozporządzenie Prezydenta Rzeczypospolitej z dnia } 19 \text { grudnia } 1927 \text { r. w sprawie zmiany postanowień art. } 6 \text { ustawy o } \\
\text { ochronie lokatorów }\end{array}$ \\
\hline 1928-02-07 & 1928-02-07 & Rozporządzenie Prezydenta Rzeczypospolitej z dnia 7 lutego 1928 r. o uzupełnieniu ustawy o ochronie lokatorów \\
\hline 1928-03-14 & 1928-03-14 & $\begin{array}{l}\text { Rozporządzenie Prezydenta Rzeczypospolitej z dnia } 14 \text { marca } 1928 \text { r. zmieniające postanowienia zawarte w ustawie o ochronie } \\
\text { lokatorów o opłatach za dostarczanie wody i za kanały }\end{array}$ \\
\hline 1928-11-28 & 1928-11-28 & Ustawa z dnia 28 listopada 1928 r. zmieniająca ustawę z dnia 11 kwietnia 1924 r. o ochronie lokatorów \\
\hline 1931-11-07 & 1931-11-07 & Ustawa z dnia 7 listopada 1931 r. zmieniająca ustawę o ochronie lokatorów \\
\hline $1933-10-27$ & 1933-10-27 & Rozporządzenie Prezydenta Rzeczypospolitej z dnia 27 października 1933 r. zmieniające ustawę o ochronie lokatorów \\
\hline 1935-11-14 & 1935-12-01 & $\begin{array}{l}\text { Dekret Prezydenta Rzeczypospolitej z dnia } 14 \text { listopada } 1935 \text { r. w sprawie obniżenia komornego oraz zmiany ustawy o } \\
\text { ochronie lokatorów }\end{array}$ \\
\hline $1936-02-25$ & $1936-02-25$ & $\begin{array}{l}\text { Rozporządzenie Ministra Sprawiedliwości z dnia } 25 \text { lutego } 1936 \text { r. wydane w porozumieniu z Ministrem Spraw Wewnętrznych } \\
\text { o likwidacji urzędów rozjemczych do spraw najmu }\end{array}$ \\
\hline 1944-09-07 & 1944-09-13 & Dekret Polskiego Komitetu Wyzwolenia Narodowego z dnia 7 września 1944 r. o komisjach mieszkaniowych \\
\hline $1945-10-26$ & 1945-11-21 & Dekret z dnia 26 października 1945 r. o własności i użytkowaniu gruntów na obszarze m. st. Warszawy \\
\hline $1945-12-21$ & 1946-02-13 & Dekret z dnia 21 grudnia 1945 r. o publicznej gospodarce lokalami i kontroli najmu \\
\hline $1948-07-28$ & 1948-09-01 & Dekret z dnia 28 lipca 1948 r. o najmie lokali \\
\hline 1959-01-30 & 1959-02-12 & Ustawa z dnia 30 stycznia 1959 r. - Prawo lokalowe \\
\hline 1974-04-10 & 1974-08-01 & Ustawa z dnia 10 kwietnia 1974 r. Prawo lokalowe \\
\hline 1994-06-24 & 1994-06-24 & Ustawa z 24 czerwca 1994 o odrębnej własności lokali \\
\hline 1994-07-02 & 1994-07-02 & Ustawa z dnia 2 lipca 1994 r. o najmie lokali mieszkalnych i dodatkach mieszkaniowych \\
\hline 2001-06-21 & 2002-01-01 & Ustawa z dnia 21 czerwca 2001 r. o ochronie praw lokatorów, mieszkaniowym zasobie gminy iozmianie Kodeksu cywilnego \\
\hline 2002-10-02 & 2002-10-02 & OTK-A 2002, nr 5, poz. 62 (decision by Constitutional Court) \\
\hline 2003-05-09 & 2003-07-14 & $\begin{array}{l}\text { Ustawa z dnia } 9 \text { maja } 2003 \text { r. ozmianie ustawy oochronie praw lokatorów, mieszkaniowym zasobie gminy iozmianie Kodeksu } \\
\text { cywilnego }\end{array}$ \\
\hline $2004-12-17$ & 2004-12-17 & $\begin{array}{l}\text { Ustawa z dnia } 17 \text { grudnia } 2004 \mathrm{r} \text {. o zmianie ustawy o ochronie praw lokatorów, mieszkaniowym zasobie gminy i o zmianie } \\
\text { Kodeksu cywilnego oraz o zmianie niektórych ustaw }\end{array}$ \\
\hline $2004-12-22$ & 2004-12-22 & $\begin{array}{l}\text { Ustawa z dnia } 22 \text { grudnia } 2004 \mathrm{r} \text {. o zmianie ustawy o ochronie praw lokatorów, mieszkaniowym zasobie gminy i o zmianie } \\
\text { Kodeksu cywilnego }\end{array}$ \\
\hline 2006-12-15 & 2007-01-01 & $\begin{array}{l}\text { Ustawa z dnia } 15 \text { grudnia } 2006 \text { r. o zmianie ustawy o ochronie praw lokatorów, mieszkaniowym zasobie gminy i o zmianie } \\
\text { Kodeksu cywilnego }\end{array}$ \\
\hline 2009-12-17 & 2009-12-17 & $\begin{array}{l}\text { Ustawa z dnia } 17 \text { grudnia } 2009 \text { r. o zmianie ustawy o ochronie praw lokatorów, mieszkaniowym zasobie gminy i o zmianie } \\
\text { Kodeksu cywilnego oraz o zmianie niektórych innych ustaw }\end{array}$ \\
\hline 2011-08-31 & 2011-08-31 & $\begin{array}{l}\text { Ustawa z dnia } 31 \text { sierpnia } 2011 \mathrm{r} \text {. o zmianie ustawy o ochronie praw lokatorów, mieszkaniowym zasobie gminy i o zmianie } \\
\text { Kodeksu cywilnego oraz ustawy - Kodeks postępowania cywilnego }\end{array}$ \\
\hline $2015-12-16$ & 2015-12-16 & $\begin{array}{l}\text { Ustawa z dnia } 16 \text { grudnia } 2015 \text { r. o zmianie ustawy o ochronie praw lokatorów, mieszkaniowym zasobie gminy i o zmianie } \\
\text { Kodeksu cywilnego }\end{array}$ \\
\hline \multicolumn{3}{|r|}{ Portugal (PT) } \\
\hline $1910-11-12$ & 1910-11-12 & Lei de 12 de novembro de 1910 \\
\hline $1914-11-23$ & $1914-11-23$ & $\begin{array}{l}\text { Decreto nr. } 1079 \text {, proibindo aos proprietários dos prédios urbanos, cujas rendas, à data do mesmo decreto não ultrapassem } \\
\text { determinadas quantias, o elevarem o valor dessas rendas }\end{array}$ \\
\hline $1917-09-28$ & 1917-09-08 & Lei nr. 828 \\
\hline 1918-04-24 & $1918-04-24$ & Decreto n. ${ }^{\circ} 4137$ \\
\hline
\end{tabular}




\section{Table 7: List of legal acts (continued)}

\begin{tabular}{|c|c|c|}
\hline $\begin{array}{l}\text { Date of legal } \\
\text { act (yyyy- } \\
\text { mm-dd) }\end{array}$ & $\begin{array}{l}\text { Enactment } \\
\text { or publica- } \\
\text { tion date } \\
\text { (yyyy-mm- } \\
\text { dd) }\end{array}$ & Title of legal act \\
\hline $1918-06-27$ & $1918-06-27$ & Decreto n. ${ }^{\circ} 4499$ \\
\hline 1919-04-17 & 1919-04-17 & Decreto n. ${ }^{\circ} 5411$, Arrendamento de prédios rústicos e urbanos \\
\hline 1923-09-10 & 1923-09-10 & Decreto n. ${ }^{\circ} 9118$ \\
\hline 1924-09-04 & 1923-12-03 & Lei n. ${ }^{\circ} 1662$, Arrendamento de prédios urbanos \\
\hline 1925-05-19 & 1925-05-19 & Decreto n. ${ }^{\circ} 10774$ \\
\hline 1926-11-06 & 1926-11-06 & Decreto $n .^{\circ} 12617$ \\
\hline $1927-11-28$ & $1927-11-28$ & Decreto $n .^{\circ} 14630$ \\
\hline 1928-03-30 & 1928-03-30 & Decreto $n .^{\circ} 15289$ \\
\hline 1928-04-04 & 1928-04-04 & Decreto n. ${ }^{\circ} 15315$ \\
\hline 1945-04-06 & 1945-04-06 & Decreto-Lei n. ${ }^{\circ} 34486$ \\
\hline $1946-04-25$ & $1946-04-25$ & Decreto-Lei n. ${ }^{\circ} 35611$ \\
\hline 1947-04-07 & 1947-04-07 & Decreto-Lei n. ${ }^{\circ} 36212$ \\
\hline $1948-06-22$ & 1948-06-22 & Lei nr. 2030 \\
\hline $1962-10-25$ & $1962-10-25$ & Decreto-Lei n. ${ }^{\circ} 44645$ \\
\hline $1966-11-25$ & 1967-06-01 & Decreto-Lei n. ${ }^{\circ} 47344$, Código Civil \\
\hline $1969-05-28$ & $1969-05-28$ & Lei n. ${ }^{\circ} 49033$, Renda fixas do FFH \\
\hline 1970-11-24 & $1970-11-24$ & Decreto-Lei n. ${ }^{\circ} 576 / 70$, Dos solos \\
\hline $1974-05-27$ & 1974-05-27 & Decreto-Lei n. ${ }^{\circ} 217 / 74$ \\
\hline 1974-09-12 & 1974-09-12 & Decreto-Lei n. ${ }^{\circ} 445 / 74$, Lei de Rendas \\
\hline $1975-03-25$ & $1975-03-25$ & Decreto-Lei $n \cdot{ }^{\circ} 155 / 75$ \\
\hline 1975-04-14 & 1975-04-14 & Decreto-Lei n. ${ }^{\circ} 198$-A/75 \\
\hline $1976-07-22$ & $1976-07-22$ & Decreto-Lei n. ${ }^{\circ} 583 / 76$ \\
\hline $1977-06-25$ & $1977-06-25$ & Portaria $n .^{\circ} 386 / 77$ \\
\hline $1977-07-20$ & 1977-07-20 & Decreto-Lei n. ${ }^{\circ} 293 / 77$ \\
\hline 1981-06-04 & 1981-04-06 & Decreto-Lei n. ${ }^{\circ} 148 / 81$, Renda regime habitação diploma \\
\hline 1983-03-17 & 1983-03-17 & Portaria n. $.^{\circ} 288 / 83$ \\
\hline $1985-09-20$ & 1985-09-20 & Lei n. ${ }^{\circ} 46 / 85$, Regimes de renda livre, condicionada e apoiada nos contratos de arrendamento para habitação \\
\hline 1990-10-15 & 1992-01-01 & Decreto-Lei $n .{ }^{\circ} 321-\mathrm{B} / 90$, Regime do arrendamento urbano \\
\hline 1993-05-07 & 1993-05-07 & Decreto-Lei n. ${ }^{\circ} 166 / 93$ \\
\hline 2006-02-27 & 2006-06-27 & Lei n. ${ }^{\circ}$ 6/2006, Novo Regime do arrendamento urbano \\
\hline 2012-08-14 & 2012-08-14 & Lei n. ${ }^{\circ} 31 / 2012$ \\
\hline \multicolumn{3}{|r|}{ Russian Federation (RU) } \\
\hline 1916-08-27 & 1916-09-09 & Высочайше утверждённое положение Совета министров "О воспрещении повышать цены на жилые помещения" \\
\hline 1917-08-05 & 1917-08-18 & Постановление Временного правительства "Об установлении предельных цен на квартиры и другие помещения" \\
\hline $1917-10-28$ & 1917-10-28 & Постановление НКВД "О жилищном моратории" \\
\hline 1917-10-30 & 1917-10-30 & Постановление НКВД О правах городских самоуправлений в деле регулирования жилищного вопроса \\
\hline 1917-11-08 & 1917-11-08 & Декрет ВЦиК «О земле» \\
\hline $1917-12-14$ & 1917-12-18 & Декрет СНК О запрещении сделок с недвижимостью \\
\hline 1918-08-20 & 1918-08-20 & Декрет ВЦИК «Об отмене права частной собственности на недвижимости в городах» \\
\hline $1920-05-25$ & 1920-05-25 & Декрет СНК РСФСР «О мерах правильного распределения жилищ среди трудящегося населения» \\
\hline 1921-01-27 & 1921-01-27 & $\begin{array}{l}\text { Декрет СНК "Об отмене взимания платы за жилые помещения с рабочих и служащих и за пользование водопрово- } \\
\text { дом, канализацией и очисткой, газом и электричеством и общественными банями - с государственных учреждений } \\
\text { и предприятий и их рабочих и служащих и о распространении указанных льгот на инвалидов труда и войны и лиц, } \\
\text { находящихся на их иждивении" }\end{array}$ \\
\hline 1922-04-20 & 1922-04-20 & О плате за пользование жилыми помещениями \\
\hline $1922-04-27$ & 1922-04-27 & Декрет СНК РСФСР "О невыселении в административном порядке граждан из занимаемых ими жилищ" \\
\hline 1922-11-11 & 1922-11-11 & Постановление "О введении в действие Гражданского кодекса РСФСР"(ст. 152-179) \\
\hline 1923-06-13 & 1923-06-13 & Постановление ВЦИК и СНК РСФСР "Об оплате жилых помещений в поселениях городского типа" \\
\hline 1923-06-21 & 1923-06-21 & $\begin{array}{l}\text { Инструкция НКВД по применению постановления ВЦИК и СНК О плате за пользование жилыми помещениями от } 13 \\
\text { июня } 1923 \text { года }\end{array}$ \\
\hline 1924-01-09 & 1924-01-09 & Декрет ВЦИК и СНК РСФСР "О выселении граждан из занимаемых ими помещений" \\
\hline 1924-07-21 & 1924-07-21 & Положение ВЦИК и СНК "Об оплате жилых помещений в поселениях городского типа" \\
\hline 1924-08-21 & 1924-08-21 & $\begin{array}{l}\text { Инструкция НКВД по применению положения ВЦИК и СНК Об оплате жилых помещений в поселениях городского } \\
\text { типа от } 21 \text { июня } 1924 \text { года }\end{array}$ \\
\hline 1924-09-29 & 1924-09-29 & Декрет ВЦИК и СНК РСФСР О праве пользования дополнительной жилой площадью \\
\hline
\end{tabular}




\section{Table 7: List of legal acts (continued)}

\begin{tabular}{|c|c|c|}
\hline $\begin{array}{l}\text { Date of legal } \\
\text { act (yyyy- } \\
\text { mm-dd) }\end{array}$ & $\begin{array}{l}\text { Enactment } \\
\text { or publica- } \\
\text { tion date } \\
\text { (yyyy-mm- } \\
\text { dd) }\end{array}$ & Title of legal act \\
\hline 1925-03-30 & 1925-03-30 & Декрет ВЦИК и СНК РСФСР Об изменении и дополнении ст. 182 Гражданского кодекса РСФСР \\
\hline 1925-06-01 & 1925-06-01 & Декрет ВЦИК и СНК РСФСР "Об оплате жилых помещений в городских поселениях". \\
\hline 1925-11-09 & 1925-11-09 & $\begin{array}{l}\text { Декрет ВЦИК и СНК РСФСР "Об изменении постановления ВЦИК и СНК РСФСР от } 1 \text { июня } 1925 \text { года "Об оплате } \\
\text { жилых помещений в городских поселениях }\end{array}$ \\
\hline 1926-06-04 & 1926-06-04 & $\begin{array}{l}\text { Постановление ЦИК и СНК СССР "О квартирной плате и мерах к урегулированию пользования жилищами в город- } \\
\text { ских поселениях" }\end{array}$ \\
\hline 1926-06-14 & 1926-06-14 & $\begin{array}{l}\text { Декрет ВЦИК и СНК РСФСР Об условиях и порядке административного выселения граждан из занимаемых ими } \\
\text { помещений }\end{array}$ \\
\hline 1926-08-02 & 1926-08-02 & Декрет ВЦИК и СНК РСФСР Об изменении статьи 171-а Гражданского кодекса РСФСР \\
\hline 1926-08-16 & 1926-08-16 & Декрет ВЦИК и СНК РСФСР Об ограничении принудительных уплотнений и переселений в квартирах \\
\hline 1926-08-26 & 1926-08-26 & Декрет ВЦИК и СНК РСФСР Об оплате жилых помещений в городах и рабочих посёлках \\
\hline 1926-09-13 & 1926-09-13 & $\begin{array}{l}\text { Декрет ВЦИК и СНК РСФСР Об изменении и дополнении декрета от } 14 \text { июня } 1926 \text { года об условиях и порядке } \\
\text { административного выселения граждан из занимаемых ими помещений }\end{array}$ \\
\hline 1926-10-11 & 1926-10-11 & $\begin{array}{l}\text { Декрет ВЦИК и СНК РСФСР О порядке выселения лиц, осужденных за покупку жилой площади, из занимаемых ими } \\
\text { помещений }\end{array}$ \\
\hline 1926-10-18 & 1926-10-18 & Декрет ВЦИК и СНК РСФСР Об урегулировании взноса квартирной платы и о выселении неплательщиков \\
\hline 1926-12-08 & 1926-12-08 & Декрет СНК РСФСР Об условиях и сроках хранения права на жилую площадь за временно отъезжающими \\
\hline $1927-02-28$ & $1927-02-28$ & $\begin{array}{l}\text { Постановление ЦИК и СНК СССР "О дополнении примечанием статьи } 10 \text { Декрета от } 23 \text { августа } 1926 \text { года "Об оплате } \\
\text { жилых помещений в городах и рабочих посёлках }\end{array}$ \\
\hline $1927-08-22$ & 1927-08-22 & $\begin{array}{l}\text { Постановление ВЦИК и СНК РСФСР О мероприятиях по освобождению фабрично-заводских жилых помещений и } \\
\text { жилых помещений в домах, закрепленных за учреждениями и предприятиями, от лиц, потерявших связь с этими } \\
\text { учреждениями и предприятиями, и по облегчению размещения рабочих и служащих государственных промышленных } \\
\text { предприятий при перемене ими места работы }\end{array}$ \\
\hline $1927-11-15$ & 1927-11-15 & Постановление СНК РСФСР О мероприятиях по жилищному хозяйству в городских поселениях \\
\hline 1928-01-04 & 1928-01-04 & Постановление ЦИК и СНК СССР "О жилищной политике" \\
\hline 1928-05-14 & 1928-05-14 & Постановление ВЦИК и СНК РСФСР "Об оплате жилых помещений в городах и рабочих посёлках" \\
\hline 1928-06-23 & 1928-06-23 & Инструкция НКВД "Об оплате жилых помещений в городах и рабочих посёлках" \\
\hline 1937-10-17 & 1937-10-17 & Постановление ЦИК и СНК СССР О сохранении жилищного фонда и улучшении жилищного хозяйства в городах \\
\hline 1953-09-10 & 1953-09-10 & $\begin{array}{l}\text { Указ президиума Верховного совета СССР Об отмене административного выселения из домов государственных пред- } \\
\text { приятий, учреждений и организаций рабочих и служащих, прекративших трудовые отношения }\end{array}$ \\
\hline $1961-12-08$ & $1961-12-08$ & Закон СССР Об утверждении Основ гражданского законодательства Союза ССР и союзных республик \\
\hline 1964-06-11 & 1964-06-11 & Гражданский кодекс РСФСР \\
\hline 1981-06-24 & 1981-06-24 & Основы жилищного законодательства СССР и союзных республик \\
\hline 1983-06-24 & 1983-06-24 & Жилищный кодекс РСФСР \\
\hline 1991-07-04 & 1991-07-04 & О приватизации жилищного фонда в Российской федерации \\
\hline 1996-01-26 & 1996-01-26 & "Гражданский кодекс Российской Федерации (часть вторая)"N 14-Ф3 \\
\hline 1996-06-15 & 1996-06-15 & Федеральный закон "О товариществах собственников жилья" \\
\hline 2004-12-29 & 2004-12-29 & "Жилищный кодекс Российской Федерации"N 188-Ф3 \\
\hline \multicolumn{3}{|r|}{ San Marino (SM) } \\
\hline 1921-01-25 & 1921-01-25 & Legge 25 Gennaio 1921 N.3 sulla requisizione di case ad uso di abitazione \\
\hline 1922-03-14 & 1922-03-14 & Decreto consigliare 14 Marzo 1922 che sostituisce alla commissione di requisizione un commissario per gli alloggi \\
\hline 1939-09-16 & 1939-09-16 & Decreto che istituisce Commissioni speciali per regolare la pubblica annona e i fitti di vani ed appartamenti \\
\hline 1942-07-10 & 1942-07-10 & Decreto Reggenziale N. 23 che, in via temporanea, regola gli sfratti da vani od appartamenti ad uso abitazione \\
\hline 1943-11-01 & 1943-11-01 & Decreto N. 50 che rende obbligatoria la denuncia dei locali affittati \\
\hline 1943-11-15 & 1943-11-15 & Decreto che fissa l'obbligatorietà dei contratti di locazione per gli sfollati e il canone d'affitto \\
\hline $1944-02-28$ & 1944-02-28 & $\begin{array}{l}\text { Decreto che istituisce Commissioni speciali per la Pubblica Annona e le locazioni dei vani ed appartamenti a relativi canoni } \\
\text { e che stabilisce norme per l'accertamento di materiali, prodotti, merci e generi di qualsiasi specie introdotti nel territorio } \\
\text { della Repubblica nonchè le eventuali requisizioni }\end{array}$ \\
\hline 1945-03-01 & 1945-03-01 & Legge che regola le locazioni di vani e appartamenti ad uso civile abitazione \\
\hline 1950-05-23 & 1950-05-28 & Legge 23 maggio 1950 n. 18 sugli affitti, subaffitti, e sfratti e sulla proroga dei contratti di locazione \\
\hline 1974-03-20 & 1974-03-20 & Legge sulle locazioni di immobili adibiti ad uso di civile abitazione, sugli sfratti e sull'equo canone \\
\hline $1991-02-20$ & 1991-06-01 & Legge 20 febbraio $1991 \mathrm{n} .26$ Testo Unico in materia di locazione di immobili \\
\hline $1995-02-21$ & $1995-02-27$ & $\begin{array}{l}\text { Legge } 21 \text { febbraio } 1995 \text { n.27 (pubblicata il } 27 \text { febbraio 1995) "Disposizioni circa la locazione di immobili destinati ad } \\
\text { abitazione" }\end{array}$ \\
\hline
\end{tabular}




\section{Table 7: List of legal acts (continued)}

\begin{tabular}{|c|c|c|}
\hline $\begin{array}{l}\text { Date of legal } \\
\text { act (yyyy- } \\
\text { mm-dd) }\end{array}$ & $\begin{array}{l}\text { Enactment } \\
\text { or publica- } \\
\text { tion date } \\
\text { (yyyy-mm- } \\
\text { dd) }\end{array}$ & Title of legal act \\
\hline \multicolumn{3}{|r|}{ Singapore (SG) } \\
\hline 1939-10-16 & 1939-10-30 & Ordinance no. 35 of 1939 to restrict the increase of rent and to provide for matters incidental thereto \\
\hline $1947-07-24$ & 1947-08-01 & Ordinance no. 25 of 1947 Control of Rent Ordinance \\
\hline \multirow[t]{2}{*}{ 1953-06-16 } & 1953-06-27 & Rent Ordinance No. 22 of 1953 \\
\hline & 1987-03-30 & Control of Rent Act (Chapter 58) of 1985 \\
\hline 2001-03-26 & 2001-01-04 & Control of Rent (Abolition) Act 2001 \\
\hline \multicolumn{3}{|r|}{ Slovakia (SK) } \\
\hline \multicolumn{3}{|r|}{ (for legal acts between 1917 and 1992 see Czechia) } \\
\hline 1996-01-20 & 1996-04-01 & Zákon Národnej rady Slovenskej republiky o cenách \\
\hline $2003-12-22$ & 2004-01-10 & $\begin{array}{l}\text { Výnos Ministerstva výstavby a regionálneho rozvoja Slovenskej republiky z 22. decembra } 2003 \text { č. V-1/2003 o regulácii cien } \\
\text { nájmu bytov }\end{array}$ \\
\hline 2008-05-01 & 2008-05-01 & Opatrenie Ministerstva financií Slovenskej republiky z 23. apríla 2008 č. 01/R/2008 o regulácii cien nájmu bytov \\
\hline \multicolumn{3}{|r|}{ Spain (ES) } \\
\hline 1911-06-12 & 1911-06-12 & Ley de casas baratas \\
\hline $1920-06-21$ & $1920-06-21$ & Real decreto relativo a contratos de arrendamiento de fincas urbanas y alquileres de las mismas [Decreto Bugallal] \\
\hline 1921-10-19 & 1921-10-19 & $\begin{array}{l}\text { Real decreto prorrogando la vigencia del de } 21 \text { de Junio de } 1920 \text {, relativo a contratos de arrendamientos de fincas urbanas y } \\
\text { alquileres de las mismas hasta el } 31 \text { de Diciembre de } 1922\end{array}$ \\
\hline $1921-12-10$ & $1921-12-10$ & Ley de casas baratas \\
\hline $1922-12-02$ & $1922-12-02$ & $\begin{array}{l}\text { Real decreto prorrogando hasta el } 31 \text { de Diciembre de } 1923 \text { el relativo a contratos de arrendamiento de fincas urbanas y } \\
\text { alquileres de las mismas }\end{array}$ \\
\hline $1923-12-13$ & $1923-12-13$ & $\begin{array}{l}\text { Real decreto disponiendo que el de } 21 \text { de Junio de } 1920 \text {, relativo a los contratos de arrendamientos de fincas urbanas, regirá } \\
\text { en todas las poblaciones de más de } 6.000 \text { almas, desde } 1^{\circ} \text {. de Enero a } 30 \text { de Junio de } 1924 \text {, con las modificaciones contenidas } \\
\text { en los artículos que se insertan }\end{array}$ \\
\hline 1924-06-20 & 1924-06-20 & $\begin{array}{l}\text { Real decreto disponiendo que el Decreto de } 21 \text { de Junio de } 1920 \text {, relativo a los contratos de arrendamientos urbanos, con las } \\
\text { modificaciones introducidas por el de } 13 \text { de Diciembre último, así como las disposiciones aclaratorias y complementarias de } \\
\text { las mismas, continúen en vigor hasta el } 31 \text { de Diciembre del corriente año }\end{array}$ \\
\hline 1924-12-17 & 1925-01-01 & Real decreto relativo a contratos de arrendamiento de fincas urbanas \\
\hline $1925-12-21$ & $1925-12-21$ & $\begin{array}{l}\text { Real decreto estableciendo normas especiales, hasta } 30 \text { de Junio de } 1926 \text {, relativas a los contratos de arrendamiento de fincas } \\
\text { urbanas }\end{array}$ \\
\hline $1926-05-24$ & 1926-05-24 & $\begin{array}{l}\text { Real decreto prorrogando hasta el } 31 \text { de Diciembre del año actual la vigencia del de } 21 \text { de Diciembre de } 1925 \text {, regulador de } \\
\text { los contratos de arrendamiento de fincas urbanas }\end{array}$ \\
\hline $1927-12-14$ & $1927-12-14$ & $\begin{array}{l}\text { Real decreto-ley prorrogando la vigencia del de } 21 \text { de Diciembre de } 1925 \text {, sin más modificaciones de su texto que las que se } \\
\text { insertan }\end{array}$ \\
\hline $1928-12-24$ & $1928-12-24$ & $\begin{array}{l}\text { Real decreto-ley prorrogando hasta el } 31 \text { de Diciembre de } 1929 \text { la vigencia del Real decreto de } 21 \text { de Diciembre de } 1925 \text {, } \\
\text { reglamentando los arrendamientos de fincas urbanas }\end{array}$ \\
\hline $1930-12-26$ & $1930-12-26$ & $\begin{array}{l}\text { Real decreto (rectificado) prorrogando hasta el } 31 \text { de Diciembre } 1931 \text { la vigencia del de } 21 \text { de Diciembre de } 1925 \text {, reglamen- } \\
\text { tando los arrendamientos de fincas urbanas con las modificaciones que se indican }\end{array}$ \\
\hline $1931-12-29$ & $1931-12-29$ & Decreto relativo a contratos de arrendamiento de fincas urbanas \\
\hline $1935-06-25$ & $1935-06-25$ & Ley de 25 de junio de 1935 dictando normas para remediar el paro obrero \\
\hline $1936-07-25$ & 1936-07-25 & Decreto relativo a los alquileres de fincas urbanas \\
\hline 1939-04-19 & 1939-04-19 & $\begin{array}{l}\text { Ley estableciendo un regimen de protección a la vivienda de renta reducida y creando un Instituto Nacional de la Vivienda } \\
\text { encargado de su aplicación }\end{array}$ \\
\hline 1941-08-07 & 1941-08-07 & $\begin{array}{l}\text { Ley de } 7 \text { de agosto de } 1941 \text { por la que se establecen normas para el justiprecio e inscripción en el Registro de la Propiedad } \\
\text { de los inmuebles destinados a la construcción de viviendas protegidas, que sean objeto de expropiación forzosa }\end{array}$ \\
\hline 1942-05-07 & 1942-05-07 & $\begin{array}{l}\text { Ley por la que se regulan las rentas o alquileres de arrendamientos de casas, con excepción de las dedicadas a la explotación } \\
\text { de industrias o establecimientos mercantiles }\end{array}$ \\
\hline 1944-01-24 & 1944-01-24 & Decreto-ley por el que se prorroga por seis meses la tramitación de juicios y ejecución de sentencias firmes de desahucios \\
\hline 1944-07-07 & 1944-07-07 & $\begin{array}{l}\text { Decreto-ley por el que se prorrogan hasta la publicación en el Boletín Oficial del Estado de la nueva Ley sobre Arrendamientos } \\
\text { Urbanos, los plazos señalados en el Decreto-Ley de } 24 \text { de enero último, referentes a la suspensión para ejecutar y tramitir } \\
\text { las sentencias y juicios de desahucio, con las excepsiones en aquél establecidas }\end{array}$ \\
\hline 1944-11-25 & 1944-11-25 & Ley sobre reducción de contribuciones e impuestos en la construcción de casas de renta para la denominada "clase media" \\
\hline $1946-12-31$ & 1947-01-01 & La Ley de Bases de Arrendamientos Urbanos \\
\hline 1948-11-19 & 1948-11-19 & Decreto-ley de 19 de noviembre de 1948 por el que se modifica la Ley de 25 de noviembre de 1944 sobre viviendas bonificadas \\
\hline 1953-11-27 & 1953-11-27 & $\begin{array}{l}\text { Decreto-ley de } 27 \text { de noviembre de } 1953 \text { por el que se restablece la vigencia del de } 19 \text { de noviembre de } 1948 \text {, sobre viviendas } \\
\text { bonificables }\end{array}$ \\
\hline
\end{tabular}




\section{Table 7: List of legal acts (continued)}

\begin{tabular}{|c|c|c|}
\hline $\begin{array}{l}\text { Date of legal } \\
\text { act (yyyy- } \\
\text { mm-dd) }\end{array}$ & $\begin{array}{l}\text { Enactment } \\
\text { or publica- } \\
\text { tion date } \\
\text { (yyyy-mm- } \\
\text { dd) }\end{array}$ & Title of legal act \\
\hline 1954-05-14 & 1954-05-14 & $\begin{array}{l}\text { Decreto-ley de } 14 \text { de mayo de } 1954 \text { por el que se encarga al Instituto Nacional de la Vivienda la ordenación de un plan de } \\
\text { viviendas de "tipo social" }\end{array}$ \\
\hline 1954-07-15 & 1954-07-15 & Ley de 15 de julio de 1954 sobre protección de "viviendas de renta limitada" \\
\hline $1955-06-24$ & 1955-06-24 & $\begin{array}{l}\text { Decreto de } 24 \text { de junio de } 1955 \text { por el que se aprueba el Reglamento para la aplicación de la Ley de } 15 \text { de julio de } 1954 \text { sobre } \\
\text { protección de "viviendas de renta limitada" }\end{array}$ \\
\hline 1956-04-03 & 1956-04-03 & $\begin{array}{l}\text { Decreto-ley de } 3 \text { de abril de } 1956 \text { por el que se adapta el de } 14 \text { de mayo de } 1954 \text { a la legislación de viviendas de "renta } \\
\text { limitada" y se mejoran las características constructivas de las de "tipo social" }\end{array}$ \\
\hline 1956-04-13 & 1956-04-13 & Decreto de 13 de abril de 1956 por el que se aprueba el texto articulado de la Ley de Arrendamientos Urbanos \\
\hline 1963-07-24 & $1963-07-24$ & $\begin{array}{l}\text { Decreto } 2131 / 1963 \text {, de } 24 \text { de julio, por el que se aprueba el texto refundido de la legislación sobre viviendas de protección } \\
\text { estatal }\end{array}$ \\
\hline 1964-12-19 & 1964-12-19 & Ley $40 / 1964$, de 11 de junio, de Reforma de la de Arrendamientos Urbanos \\
\hline $1968-07-24$ & $1968-07-24$ & $\begin{array}{l}\text { Decreto } 2114 / 1968 \text {, de } 24 \text { de julio, por el que se aprueba el Reglamento para la aplicación de la Ley sobre Viviendas de } \\
\text { Protección Oficial, texto refundido aprobado por Decretos } 2131 / 1963 \text {, de } 24 \text { de julio, y } 3964 / 1964 \text {, de } 3 \text { de diciembre }\end{array}$ \\
\hline 1976-07-30 & 1976-07-30 & Real Decreto-ley 12/1976, de 30 de julio, sobre inversión en vivienda \\
\hline $1976-11-12$ & 1976-11-12 & $\begin{array}{l}\text { Real Decreto 2960/1976, de } 12 \text { de noviembre, por el que se aprueba el texto refundido de la Legislación de Viviendas de } \\
\text { Protección Oficial }\end{array}$ \\
\hline $1978-10-31$ & $1978-10-31$ & Real Decreto-ley 31/1978, de 31 de octubre, sobre política de viviendas de protección oficial \\
\hline 1985-04-30 & $1985-04-30$ & Real Decreto-ley 2/1985 sobre Medidas de Política Económica [Decreto Boyer] \\
\hline $1994-11-24$ & 1995-01-01 & Ley $29 / 1994$, de 24 de noviembre, de Arrendamientos Urbanos \\
\hline 2013-06-04 & 2013-06-04 & Ley $4 / 2013$, de 4 de junio, de medidas de flexibilización y fomento del mercado del alquiler de viviendas \\
\hline \multicolumn{3}{|r|}{ Switzerland $(\mathrm{CH})$} \\
\hline 1911-03-30 & 1911-03-30 & Obligationenrecht \\
\hline 1914-08-26 & 1914-08-27 & Bundesratsbeschluss vom 26. August 1914 betreffend die Ausweisung von Mietern \\
\hline 1917-06-18 & 1917-06-20 & Bundesratsbeschluss vom 18. Juni 1917 betreffend Schutz der Mieter gegen Mietzinserhöhungen und Kündigungen \\
\hline 1918-08-05 & 1918-08-05 & Bundesratsbeschluss vom 5. August 1918 zur Ausdehnung des Bundesratsbeschlusses vom 18. Juni 1917 \\
\hline 1918-10-29 & 1918-11-01 & $\begin{array}{l}\text { Bundesratsbeschluss vom 29. Oktober } 1918 \text { betreffend die Bekämpfung der Wohnungsnot durch Beschränkung der } \\
\text { Freizügigkeit }\end{array}$ \\
\hline 1918-11-08 & 1918-11-15 & Bundesratsbeschluss vom 8. November 1918 betreffend in Inanspruchnahme unbenutzter Wohnungen \\
\hline $1919-07-15$ & $1919-07-15$ & Bundesratbeschluss \\
\hline 1920-02-09 & 1920-02-09 & Bundesratbeschluss betreffend Milderung der Wohnungsnot durch Förderung der Hochbautätigkei \\
\hline 1920-04-09 & $1920-04-15$ & Bundesratsbeschluss vom 9. April 1920 betreffend Bekämpfung der Miet- und Wohnungsnot \\
\hline $1920-05-11$ & $1920-05-11$ & Bundesratbeschluss betreffend Milderung der Wohnungsnot durch Förderung der Hochbautätigkei \\
\hline 1921-02-19 & 1921-02-19 & Bundesratbeschluss \\
\hline $1922-07-28$ & 1922-09-01 & $\begin{array}{l}\text { Bundesratsbeschluss vom 28. Juli } 1922 \text { betreffend teilweise Aufhebung des Bundesratsbeschlusses vom } 9 \text {. April } 1920 \text { betref- } \\
\text { fend Bekämpfung der Miet- und Wohnungsnot }\end{array}$ \\
\hline $1925-05-20$ & 1926-11-01 & Bundesratsbeschluss vom 20. Mai 1925 betreffend die Aufhebung der Vorschriften zur Bekämpfung der Mietund Wohnungsnot \\
\hline $1936-09-27$ & 1936-09-27 & Bundesratsbeschluss vom 27. September 1936 über ausserordentliche Massnahmen betreffend die Kosten der Lebenshaltung \\
\hline 1939-05-24 & 1939-05-24 & Verfügung XVI des EVD betreffend ausserordentliche Massnahmen über die Kosten der Lebenshaltung \\
\hline 1939-09-01 & 1939-09-01 & $\begin{array}{l}\text { Bundesratsbeschluss vom 1. September } 1939 \text { betreffend die Kosten der Lebenshaltung und den Schutz der regulären Mark- } \\
\text { tordnung }\end{array}$ \\
\hline 1939-09-26 & 1939-09-26 & Bundesratsbeschluss vom 26. September 1939 betreffend Verlängerung der Ausweisungsfristen bei Miete \\
\hline $1941-10-15$ & 1941-10-20 & Bundesratsbeschluss vom 15. Oktober 1941 betreffend Massnahmen gegen die Wohnungsnot \\
\hline 1942-03-16 & 1942-03-16 & BRB vom 16. März 1942 betreffend Massnahmen zur Milderung der Wohnungsnot durch Förderung der Bautätigkeit \\
\hline 1946-02-08 & $1946-02-08$ & Bundesratsbeschluss vom 8. Februar 1946 betreffend Lockerung des Bundesratsbeschlusses von 1941 \\
\hline 1950-08-30 & 1950-10-01 & $\begin{array}{l}\text { Verfügung der eidgenössischen Preiskontrolle vom 30. August } 1950 \text { betreffend Erlaubnis, bei Immobilien, die seit dem } 31 \text {. } \\
\text { Dezember } 1943 \text { keine Erhöhung erfahren hatten, die Mietzinse um } 10 \% \text { anzuheben }\end{array}$ \\
\hline 1950-09-07 & 1950-09-12 & $\begin{array}{l}\text { Verfügung der eidgenössischen Preiskontrolle vom } 7 \text {. September } 1950 \text { betreffend behördliche Festsetzung der Mietzinse für } \\
\text { möblierte Einzelzimmer und möblierte Ferienwohnungen }\end{array}$ \\
\hline 1953-06-10 & 1954-01-01 & Bundesbeschluss vom 10. Juni 1953 über die Durchführung einer beschränkten Preiskontrolle \\
\hline $1953-12-30$ & 1954-01-01 & Verordnung über die Mietzinskontrolle und die Beschränkung des Kündigungsrechts vom 30. Dezember 1953 \\
\hline 1954-06-01 & 1954-06-05 & Bundesratsbeschluss vom 1. Juni 1954 über Mietzinse von Immobilien \\
\hline $1956-12-28$ & 1957-01-01 & Verordnung vom 28. Dezember 1956 über die Mietzinskontrolle und die Beschränkung des Kündigungsrechts \\
\hline $1957-11-26$ & $1957-12-01$ & Bundesratsbeschluss vom 26. November 1957 über Mietzinse von Immobilien \\
\hline $1960-12-21$ & 1961-01-01 & $\begin{array}{l}\text { Bundesbeschluss über Mietzinse für Immobilien und die Preisausgleichskasse für Milch und Milchprodukte vom 21. Dezember } \\
1960\end{array}$ \\
\hline
\end{tabular}




\section{Table 7: List of legal acts (continued)}

\begin{tabular}{|c|c|c|}
\hline $\begin{array}{l}\text { Date of legal } \\
\text { act (yyyy- } \\
\text { mm-dd) }\end{array}$ & $\begin{array}{l}\text { Enactment } \\
\text { or publica- } \\
\text { tion date } \\
\text { (yyyy-mm- } \\
\text { dd) }\end{array}$ & Title of legal act \\
\hline 1961-04-11 & 1961-04-15 & Verordnung über die Mietzinsen und Kündigungsbeschränkung vom 11. April 1961 \\
\hline 1969-12-19 & 1970-12-18 & Bundesbeschluss vom 19. Dezember 1969 betreffend die Aufhebung der Mietpreisüberwachung und der Ausnahmevorschriften \\
\hline 1972-06-30 & 1972-06-30 & Bundesbeschluss über Massnahmen gegen Missbräuche im Mietwesen \\
\hline 1972-07-10 & 1972-07-14 & Verordnung über Massnahmen gegen Missbräuche im Mietwesen \\
\hline 1972-07-10 & 1972-07-14 & $\begin{array}{l}\text { Bundesratsbeschluss vom 10. Juli } 1972 \text { über die Unterstellung von Gemeinden unter den Bundesbeschluss über Massnahmen } \\
\text { gegen Missbräuche im Mietwesen }\end{array}$ \\
\hline 1987-10-01 & 1987-10-01 & Volksabstimmung vom 7. Dezember 1986 \\
\hline 1989-12-15 & 1990-07-01 & Bundesgesetz vom 15. Dezember 1989 über die Änderung des OR (Miete und Pacht) \\
\hline 1990-05-09 & 1990-05-09 & VO über Miete und Pacht von Wohn- und Geschäftsräumen vom 9. Mai 1990 \\
\hline $1995-06-23$ & 1996-03-01 & Bundesgesetz über Rahmenmietverträge und deren Allgemeinverbindlicherklärung \\
\hline 2007-11-28 & 2007-11-28 & VO vom 28. November 2007 \\
\hline & & Togo (TG) \\
\hline 1926-04-01 & 1929-04-13 & Loi réglant, à partir du ler avril 1926, les rapports des bailleurs et des locataires de locaux d'habitation \\
\hline 1929-03-30 & 1929-04-13 & Prorogation au Togo et à la Réunion de l'application des dispositions de la loi du ler avril 1926 \\
\hline 1929-04-23 & 1929-05-01 & $\begin{array}{l}\text { Décret du } 30 \text { mars } 1929 \text { rendant applicables au Togo et à la Réunion des dispositions de la loi du } 28 \text { mars } 1929 \text { prorogeant } \\
\text { jusqu'au ler juillet } 1929 \text { l'application des dispositions de l'article } 11 \text { de la loi du ler avril } 1926 \text { réglant les rapports des } \\
\text { bailleurs et des locataires de locaux d'habitation (Arrêté de promulgation No. } 183 \text { du 23/04/1929) }\end{array}$ \\
\hline 1938-05-08 & 1938-05-12 & Décret du 8 mai 1938 portant réglementation des loyers des locaux d'habitation en Afrique occidentale française \\
\hline 1940-10-03 & 1940-10-07 & Décret du 3 octobre 1940, réglementation des loyers des locaux d'habitation en Afrique occidentale française \\
\hline $1941-06-23$ & 1942-07-01 & $\begin{array}{l}\text { Décret du } 23 \text { juin } 1941 \text { modifiant et completant le décret du } 8 \text { mai 1938, modifié par le décret du } 3 \text { octobre } 1940 \text { portant } \\
\text { réglementation des loyers des locaux d'habitation en Afrique occidentale française }\end{array}$ \\
\hline 1942-02-09 & 1942-02-12 & Décret No. 396 du 9 février 1942 relatif à la réglementation des loyers d'habitation en Afrique occidentale française \\
\hline 1942-06-19 & 1942-07-01 & Arrêté de promulgation No. 346 du 19 juin 1942 promulgant au Togo le décret du 13 mai 1942 \\
\hline 1943-07-19 & 1943-09-01 & $\begin{array}{l}\text { Décret du } 19 \text { juillet } 1943 \text { sur la réglementation des loyers des locaux d'habitation en A.O.F. et au Togo (Arrêté de promul- } \\
\text { gation No. } 445 \mathrm{Cab} \text {. du } 20 \text { août 1943) }\end{array}$ \\
\hline 1944-01-29 & 1944-03-16 & $\begin{array}{l}\text { Décret portant prorogation de jouissance des loyers en AOF et au Togo (Arrêté de promulgation No. } 112 \text { Cab. du } 1 \mathrm{er} \text { mars } \\
\text { 1944) }\end{array}$ \\
\hline 1944-09-14 & 1944-10-01 & Décret (Arrêté de promulgation No. 469 du 14 septembre 1944) \\
\hline $1945-02-16$ & 1945-03-01 & Décret du 11 janvier 1945 (Arrêté de promulgation No. 87 Cab. du 16 février 1945) \\
\hline 1952-06-30 & 1952-07-03 & Décret No. $52-764$ du 30 juin 1952 portant réglementation des loyers des locaux d'habitation en Afrique occidentale française \\
\hline $1961-12-22$ & $1962-01-16$ & Décret No. 61-121 du 22 décembre 1961 portant règlementation des loyers des locaux d'habitation \\
\hline \multicolumn{3}{|r|}{ Tunisia $(\mathrm{TN})$} \\
\hline 1941-03-13 & 1941-03-13 & Décret du 13 mars 1941 réprimant le refus de louer à un père de famille un local à usage d'habitation ou professionnel \\
\hline 1941-09-29 & 1941-09-29 & Décret du 29 septembre 1941 sur la déclaration des locaux vacants \\
\hline 1943-07-22 & 1943-07-22 & $\begin{array}{l}\text { Décret du } 22 \text { juillet } 1943 \text { suspendant temporairement en faveur des réfugiés et sinistrés les clauses des baux de location à } \\
\text { usage d'habitation qui interdisent la sous-location, la cession de bail ou le prêt d'appartement }\end{array}$ \\
\hline 1944-05-01 & 1944-05-01 & Décret du 1er mai 1944 \\
\hline 1946-09-26 & 1946-09-26 & Décret du 26 septembre 1946 modifiant l'article 17 du décret du 1er mai 1944 \\
\hline 1946-12-31 & 1946-12-31 & $\begin{array}{l}\text { Décret du } 31 \text { décembre } 1946 \text { prorogeant le décret du 1er mai } 1944 \text { et interdisant la transformation des locaux à usage } \\
\text { d'habitation }\end{array}$ \\
\hline $1947-05-29$ & 1947-05-29 & Décret du 29 mai 1947 \\
\hline 1948-07-01 & 1948-07-01 & Décret du 1er juillet 1948 \\
\hline $1948-10-28$ & 1948-10-30 & $\begin{array}{l}\text { Décret du } 28 \text { octobre } 1948 \text { (25 hadja } 1367) \text { rélatif aux rapports entre bailleurs et locataires ou occupants de locaux } \\
\text { d'habitation ou à usage professionnel et édictant certaines dispositions financières en matière d'immeubles bâtis }\end{array}$ \\
\hline $1956-08-23$ & $1956-08-24$ & $\begin{array}{l}\text { Décret du } 23 \text { août } 1956 \text { (16 moharem 1376), abrogeant l'article } 28 \text { du décret du } 28 \text { octobre } 1948 \text { (25 doul hidja 1367) rélatif } \\
\text { aux rapports entre bailleurs et locataires ou occupants de locaux d'habitation ou à usage professionnel et édictant certaines } \\
\text { dispositions financières en matière d'immeubles bâtis }\end{array}$ \\
\hline $1958-08-23$ & 1958-04-01 & $\begin{array}{l}\text { Loi No. 58-44 du } 31 \text { mars } 1958 \text { (10 ramadan 1377), portant modification du décret du } 28 \text { octobre } 1948 \text { (25 doul hidja } 1367 \text { ) } \\
\text { rélatif aux rapports entre bailleurs et locataires ou occupants de locaux d'habitation ou à usage professionnel et édictant } \\
\text { certaines dispositions financières en matière d'immeubles bâtis }\end{array}$ \\
\hline $1962-05-24$ & 1962-05-25 & $\begin{array}{l}\text { Loi No. 62-23 du } 24 \text { mai } 1962 \text { (20 doul hidja 1381), portant modification du décret du } 28 \text { octobre } 1948 \text { (25 doul hidja } 1367 \text { ) } \\
\text { rélatif aux rapports entre bailleurs et locataires ou occupants de locaux d'habitation ou à usage professionnel et édictant } \\
\text { certaines dispositions financières en matière d'immeubles bâtis }\end{array}$ \\
\hline 1970-02-03 & 1970-02-03 & Loi No. $70-6$ du 3 février 1970, portant réduction du loyer de certains locaux d'habitation \\
\hline
\end{tabular}




\section{Table 7: List of legal acts (continued)}

\begin{tabular}{|c|c|c|}
\hline $\begin{array}{l}\text { Date of legal } \\
\text { act (yyyy- } \\
\text { mm-dd) }\end{array}$ & $\begin{array}{l}\text { Enactment } \\
\text { or publica- } \\
\text { tion date } \\
\text { (yyyy-mm- } \\
\text { dd) }\end{array}$ & Title of legal act \\
\hline 1972-06-26 & 1972-06-27 & $\begin{array}{l}\text { Loi No. } 72-47 \text { du } 26 \text { juin 1972, portant mantien dans les lieux et fixation du taux maximum des loyers des locaux à usage } \\
\text { d'habitation }\end{array}$ \\
\hline 1976-02-18 & $1976-02-20$ & $\begin{array}{l}\text { Loi No. } 76-35 \text { du } 18 \text { février } 1976 \text { rélative aux rapports entre propriétaires et locataires de locaux à usage d'habitation, de } \\
\text { profession ou d'administration publique }\end{array}$ \\
\hline 1981-09-01 & 1981-09-04 & Décret-loi n81-13 accordant le maintien dans les lieux aux locataires \\
\hline 1983-06-27 & 1983-07-01 & $\begin{array}{l}\text { Loi nº3-61 du } 27 \text { juin 1983, rélatvie aux immeubles appartenant à des étrangers et construits ou acquis avant } 1956 \text { le } \\
\text { maintien dans les lieux (Décret 1981) à tout occupant et interdisant notamment aux Français de gérer leurs biens, de les } \\
\text { vendre sans autorisation, de conserver un pied à terre en Tunisie, etc. }\end{array}$ \\
\hline $1993-12-27$ & 1994-01-01 & $\begin{array}{l}\text { Loi n } 93-122 \text { du } 27 \text { décembre } 1993 \text { portant modification de la loi No. } 76-35 \text { du } 18 \text { février } 1976 \text { rélative aux rapports entre } \\
\text { propriétaires et locataires de locaux à usage d'habitation, de profession ou d'administration publique }\end{array}$ \\
\hline & & United Kingdom of Great Britain and Northern Ireland (UK) \\
\hline 1915-11-25 & 1915-11-25 & Increase of rent and Mortgage Interest (War Restrictions) Act \\
\hline $1917-07-10$ & $1917-07-10$ & Courts (Emergency restrictions) Act \\
\hline 1918-05-02 & 1918-05-02 & Increase of rent and Mortgage Interest (Amendments) Act \\
\hline 1919-04-02 & 1919-04-02 & Increase of rent and mortgage interest (restrictions) act \\
\hline 1920-07-02 & 1920-07-02 & Increase of rent and mortgage interest (restrictions) act \\
\hline 1923-04-01 & $1923-04-01$ & Chamberlain's Housing Act \\
\hline 1923-06-24 & 1923-06-24 & Rent and mortgage interest restrictions act \\
\hline 1924-08-07 & 1924-08-07 & Wheatley Housing Act \\
\hline $1926-06-24$ & 1926-06-24 & Expiring Laws Continuance Act \\
\hline $1933-12-25$ & $1933-12-25$ & Rent and Mortgage Interest Restrictions (Amendment) Act 1933 \\
\hline $1938-11-25$ & $1938-11-25$ & Rent and Mortgage Interest Restrictions (Amendment) Act 1938 \\
\hline $1939-09-03$ & $1939-09-03$ & Rent and Mortgage Interest Restrictions Act 1939 \\
\hline $1944-10-01$ & $1944-10-01$ & Housing (Temporary Accommodation) Act \\
\hline $1946-03-26$ & $1946-03-26$ & Furnished Houses (Rent Control) Act 1946 \\
\hline 1949-01-01 & 1949-01-01 & Landlord and Tenant (Rent Control) Act 1949 \\
\hline 1951-07-17 & 1951-07-17 & Reserve and Auxiliary Forces (Protection of Civil Interests) Act 1951 \\
\hline 1952-10-23 & $1952-10-23$ & Crown Lessees Act 1952 \\
\hline $1954-06-30$ & $1954-06-30$ & House Repairs and Rents Act \\
\hline $1954-10-01$ & $1954-10-01$ & Landlord and Tenant Act \\
\hline $1957-07-06$ & $1957-07-06$ & Rent Act 1957 \\
\hline $1965-12-18$ & $1965-12-18$ & Rent Act 1965 \\
\hline $1974-07-31$ & $1974-07-31$ & Rent Act 1974 \\
\hline 1977-07-29 & 1977-07-29 & Rent Act 1977 \\
\hline 1980-08-08 & 1980-08-08 & Housing Act 1980 \\
\hline 1988-11-15 & 1988-11-15 & Housing Act 1988 \\
\hline $1988-11-15$ & $1988-11-15$ & Housing (Scotland) Act 1988 \\
\hline \multicolumn{3}{|r|}{ Uruguay (UY) } \\
\hline $1927-12-16$ & $1927-12-22$ & Ley $\mathrm{N}^{\circ} 8.153$, de 16. de diciembre de 1927 \\
\hline $1931-10-21$ & $1931-10-21$ & Ley número 8.789 de 21 de Octubre de 1931 \\
\hline $1943-12-13$ & $1943-12-16$ & Ley $\mathrm{n}^{\circ} 10.460$ Alquileres - se dispone una rebaja en los de inmuebles para habitacion \\
\hline $1948-10-01$ & 1948-10-01 & Ley $\mathrm{N}^{\circ} 11.129$ Alquileres — se acuerda un nuevo regimen \\
\hline 1950-06-20 & 1950-06-20 & Ley $\mathrm{N}^{\circ} 11.451$ Arrendamientos y desalojos — se modifican disposiciones tratandose de bienes urbanos \\
\hline 1953-03-24 & $1953-03-24$ & $\begin{array}{l}\text { Ley } \mathrm{N}^{\circ} 11.921 \text { alquileres }- \text { se fijan procedimientos para regular los precios de arrendamiento de los inmuebles destinados a } \\
\text { casa-habitacion o comercio, y se clausuran juicios de desalojos }\end{array}$ \\
\hline 1958-01-09 & 1958-01-09 & $\begin{array}{l}\text { Ley } N^{\circ} 12.492 \text { Alquileres - se clausuran los procedimientos en los juicios de desalojo pendientes de ejecucion contra inquilinos } \\
\text { buenos pagadores y se modifican y amplian normas que regulan la fijacion del precio de los alquileres }\end{array}$ \\
\hline 1964-10-19 & 1964-10-19 & $\begin{array}{l}\text { Ley } \mathrm{N}^{\circ} 13.292 \text { Alquileres - se establece un nuevo regimen de arrendamientos, desalojos y lanzamientos urbanos y se derogan } \\
\text { todas las leyes promulgadas con posterioridad a la vigencia de la } \mathrm{n}^{\circ} 8.153 \text { de } 16 \text { de diciembre de } 1927\end{array}$ \\
\hline 1968-06-06 & 1968-06-06 & $\begin{array}{l}\text { Ley } \mathrm{N}^{\circ} 13.659 \text { - se establece un nuevo regimen de alquileres, desalojos y lanzamientos y se organiza la asesoria tecnica de } \\
\text { arrendamientos }\end{array}$ \\
\hline $1970-07-17$ & $1970-07-17$ & Ley 13.870 Alquileres y desalojos - se modifican y amplian las disposiciones de la ley 13.659 \\
\hline 1974-07-04 & 1974-07-04 & $\begin{array}{l}\text { Ley } N^{\circ} 14.219 \text { Alquileres - se modifica el regimen vigente en materia de arrendamientos y se dan nuevas normas sobre } \\
\text { desalojos y lanzamientos }\end{array}$ \\
\hline
\end{tabular}


Table 7: List of legal acts (continued)

\begin{tabular}{|c|c|c|}
\hline $\begin{array}{l}\text { Date of legal } \\
\text { act (yyyy- } \\
\text { mm-dd) }\end{array}$ & $\begin{array}{l}\text { Enactment } \\
\text { or publica- } \\
\text { tion date } \\
\text { (yyyy-mm- } \\
\text { dd) }\end{array}$ & Title of legal act \\
\hline 1980-09-22 & 1980-09-22 & Ley $\mathrm{N}^{\circ} 15.056$ Alquileres — se modifica el regimen vigente de arrendamientos, desalojos y lanzamientos \\
\hline 1981-07-14 & 1981-07-14 & Decreto Ley $\mathrm{N}^{\circ} 15.154$ Ley de arrendamientos urbanos y suburbanos \\
\hline $1985-12-17$ & 1985-12-17 & Ley $\mathrm{N}^{\circ} 15.799$ Arrendamientos urbanos — se aprueba ley de emergencia \\
\hline $1985-12-17$ & 1986-01-01 & Ley $\mathrm{N}^{\circ} 15.799$ Arrendamientos urbanos — se aprueba ley de emergencia \\
\hline 1994-01-11 & 1994-01-18 & Ley $N^{\circ} 16.462$ Rendicion de cuentas y balance de ejecucion presupuestal. Ejercicio 1992 \\
\hline 2011-08-10 & 2011-08-10 & Ley $\mathrm{N}^{\circ} 18.795$ Acceso a la vivienda de interés social - se declara de interés nacional \\
\hline
\end{tabular}

\section{Table 8: Composition of clusters}

\begin{tabular}{l|l}
\hline Cluster & Countries \\
\hline $\mathrm{A}$ & Angola, Argentina, Australia, Bolivia, Brazil, Canada (Alberta, Ontario, \\
& Quebec), Colombia, Cyprus, Iceland, Liechtenstein, Mali, Macao, Mexico \\
& (Distrito Federal), Nicaragua, Peru, Philippines, Singapore, San Marino, \\
& Salvador, Togo, Tunisia, UK, Uruguay \\
\hline B & Austria, Belgium, Switzerland, Chile, Czech Republic, Germany, Spain, \\
& France, Greece, Ireland, Italy, Luxembourg, Morocco, Monaco, Madagascar, \\
& Norway, New Zealand, Panama, Poland, Portugal, Russia, Slovakia \\
\hline
\end{tabular}

Table 9: Correlation between our and alternative indices

\begin{tabular}{|c|c|c|c|c|}
\hline Index & Rent_laws & Tenure_security & Rationing & $\overline{\mathrm{RMRI}}$ \\
\hline Malpezzi_Ball_1991 & -0.463 & 0.302 & 0.329 & -0.174 \\
\hline MB_1991_pval & 0.040 & 0.196 & 0.156 & 0.462 \\
\hline MB_1991_N & \multicolumn{4}{|c|}{20} \\
\hline Formalism_2000 & 0.156 & 0.217 & 0.165 & 0.249 \\
\hline Formalism_pval & 0.371 & 0.211 & 0.344 & 0.149 \\
\hline Formalism_N & \multicolumn{4}{|c|}{35} \\
\hline OECD_2009 & 0.145 & 0.102 & 0.376 & 0.157 \\
\hline OECD_pval & 0.566 & 0.686 & 0.124 & 0.533 \\
\hline $\mathrm{OECD \_ N}$ & \multicolumn{4}{|c|}{18} \\
\hline GPG_2017 & -0.337 & -0.145 & -0.192 & -0.297 \\
\hline GPG_pval & 0.051 & 0.415 & 0.276 & 0.088 \\
\hline GPG_N & \multicolumn{4}{|c|}{36} \\
\hline
\end{tabular}


Figure 1: Existence of rent control

\section{Existed or exists}

yes no

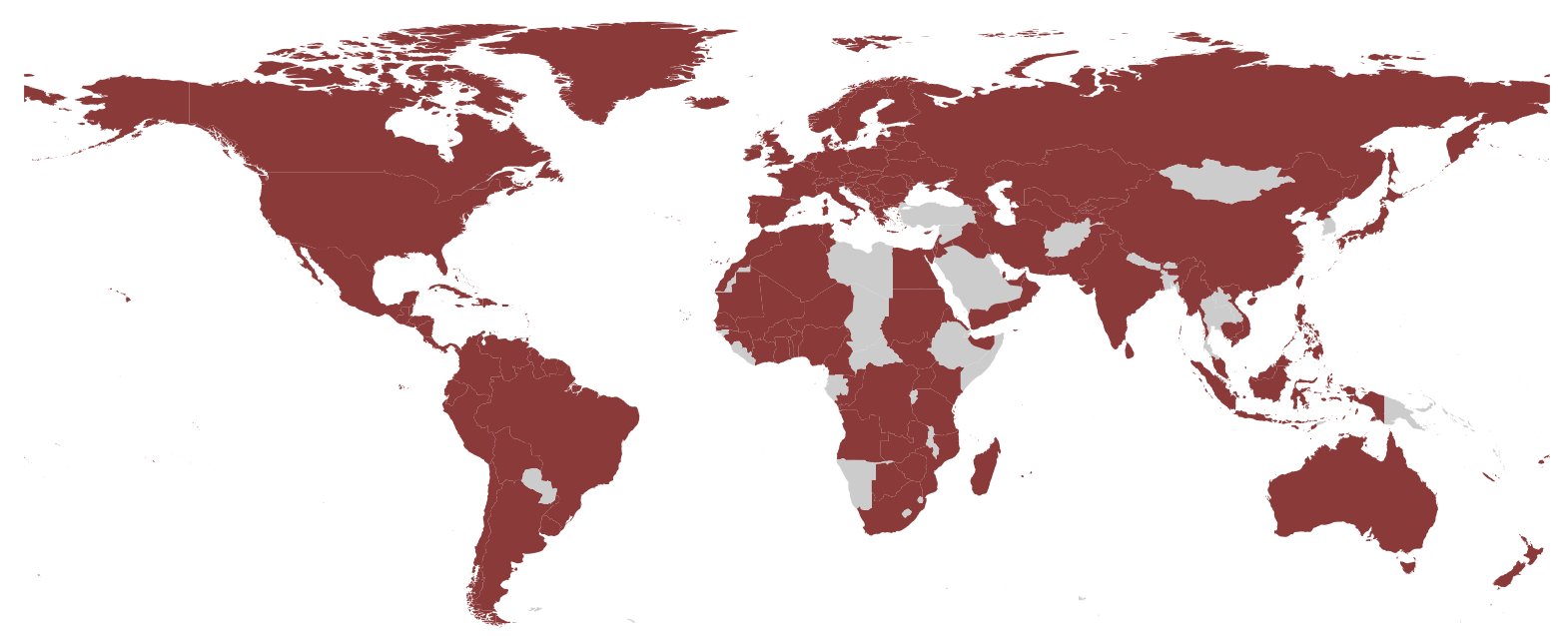


Figure 2: Housing policy tools

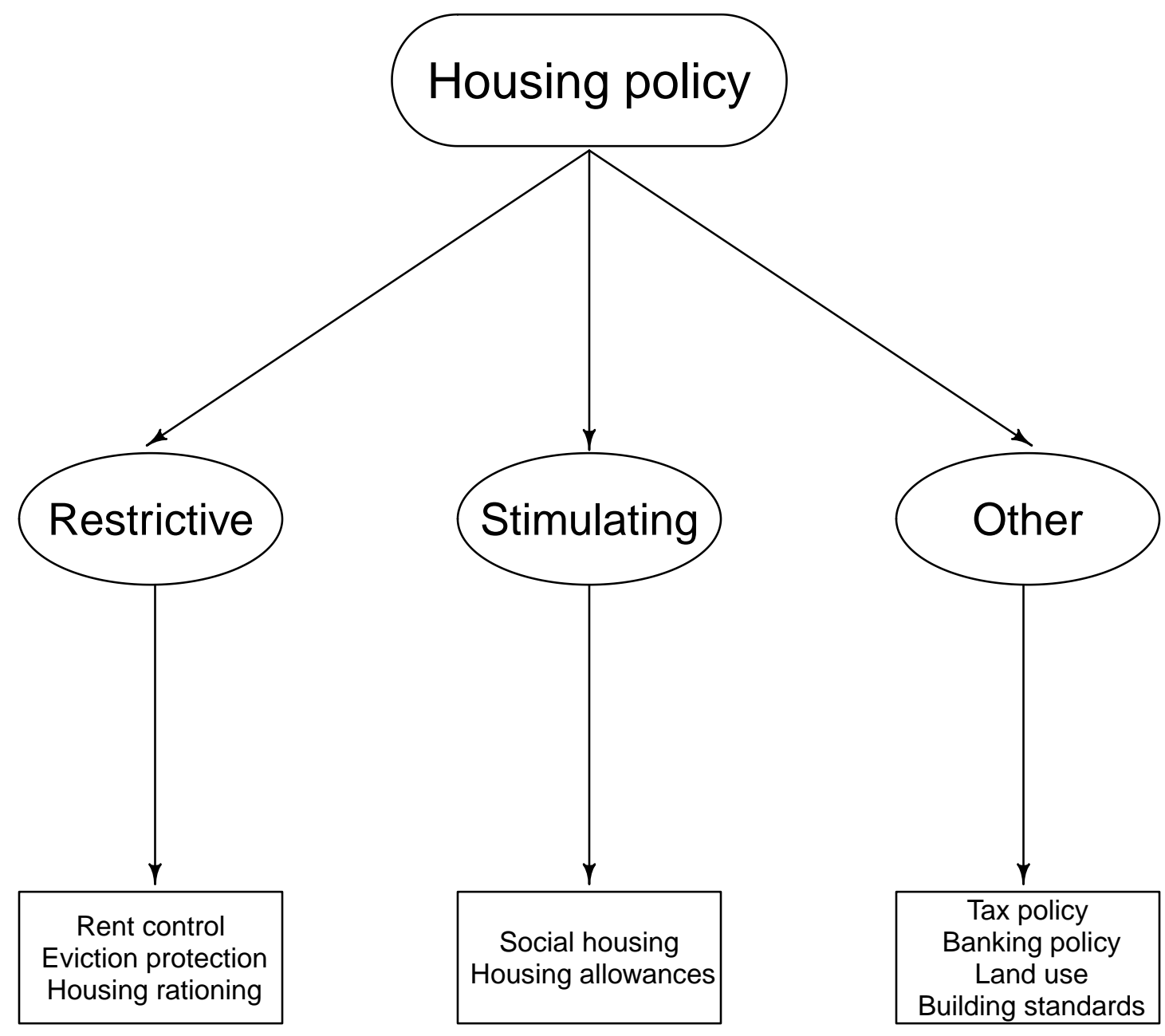


Figure 3: Number of legal acts regulating housing market by country

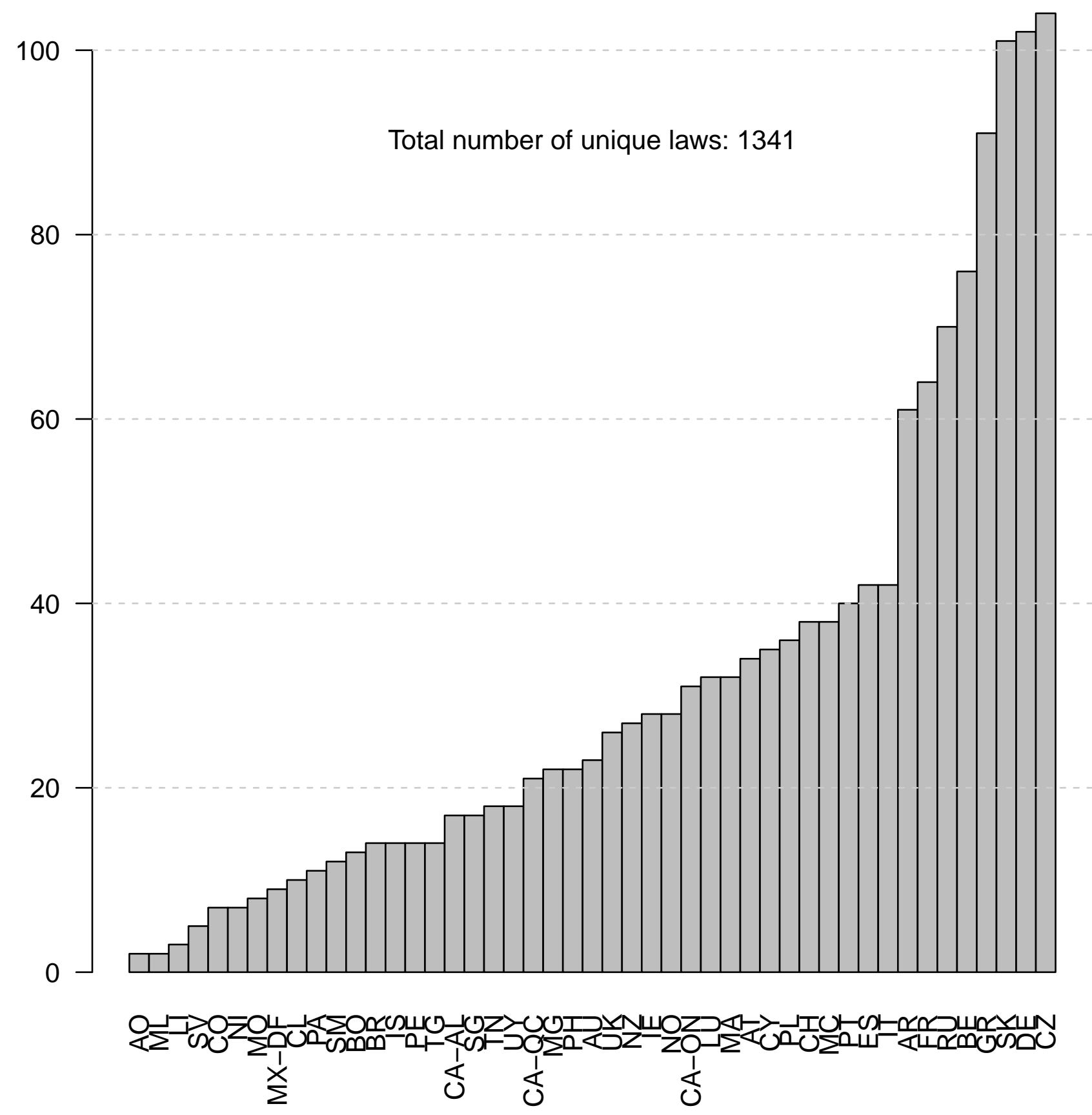


Figure 4: Countries covered by this study
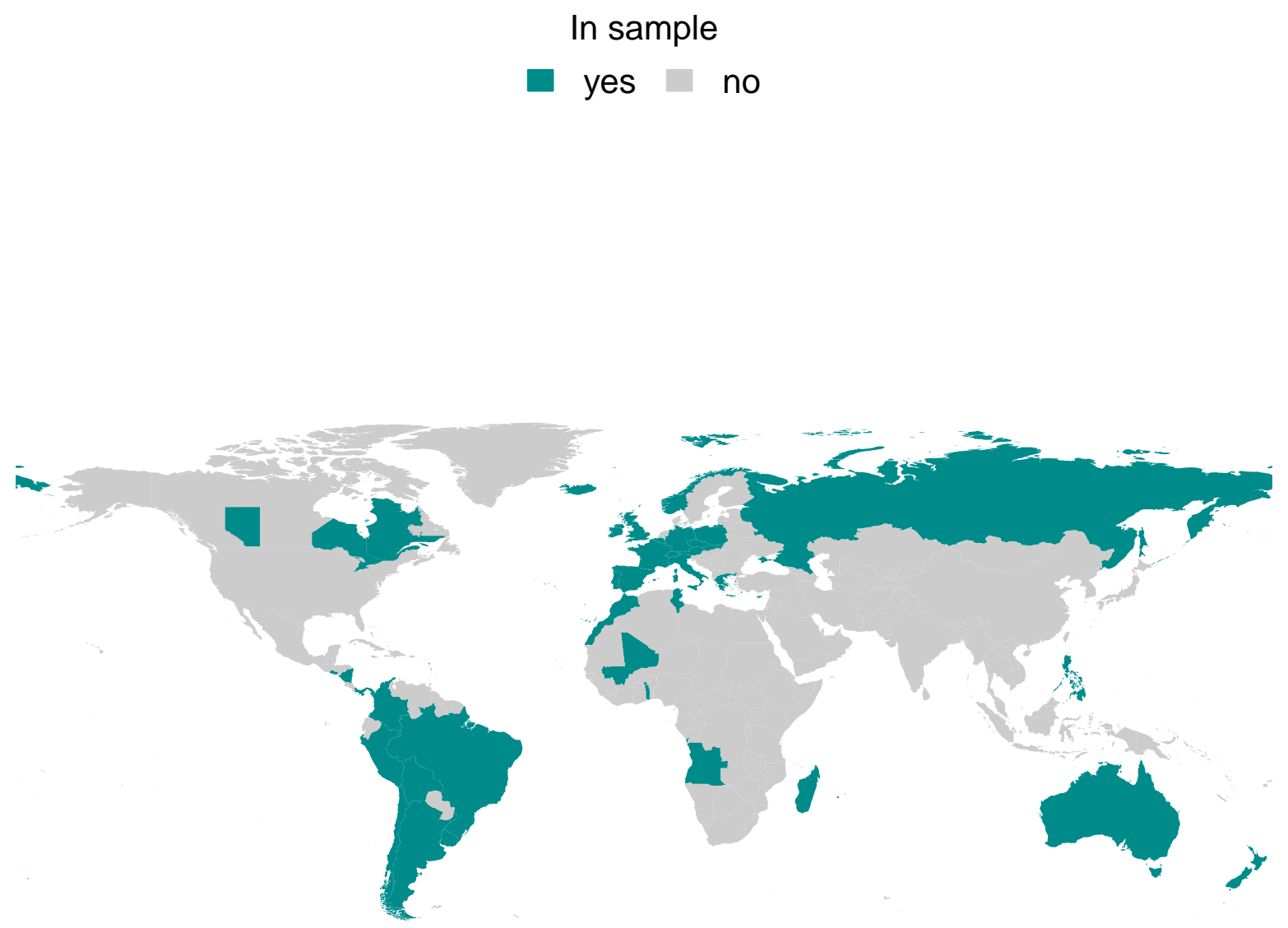
Figure 5: Evolution of distribution of the housing regulations intensity
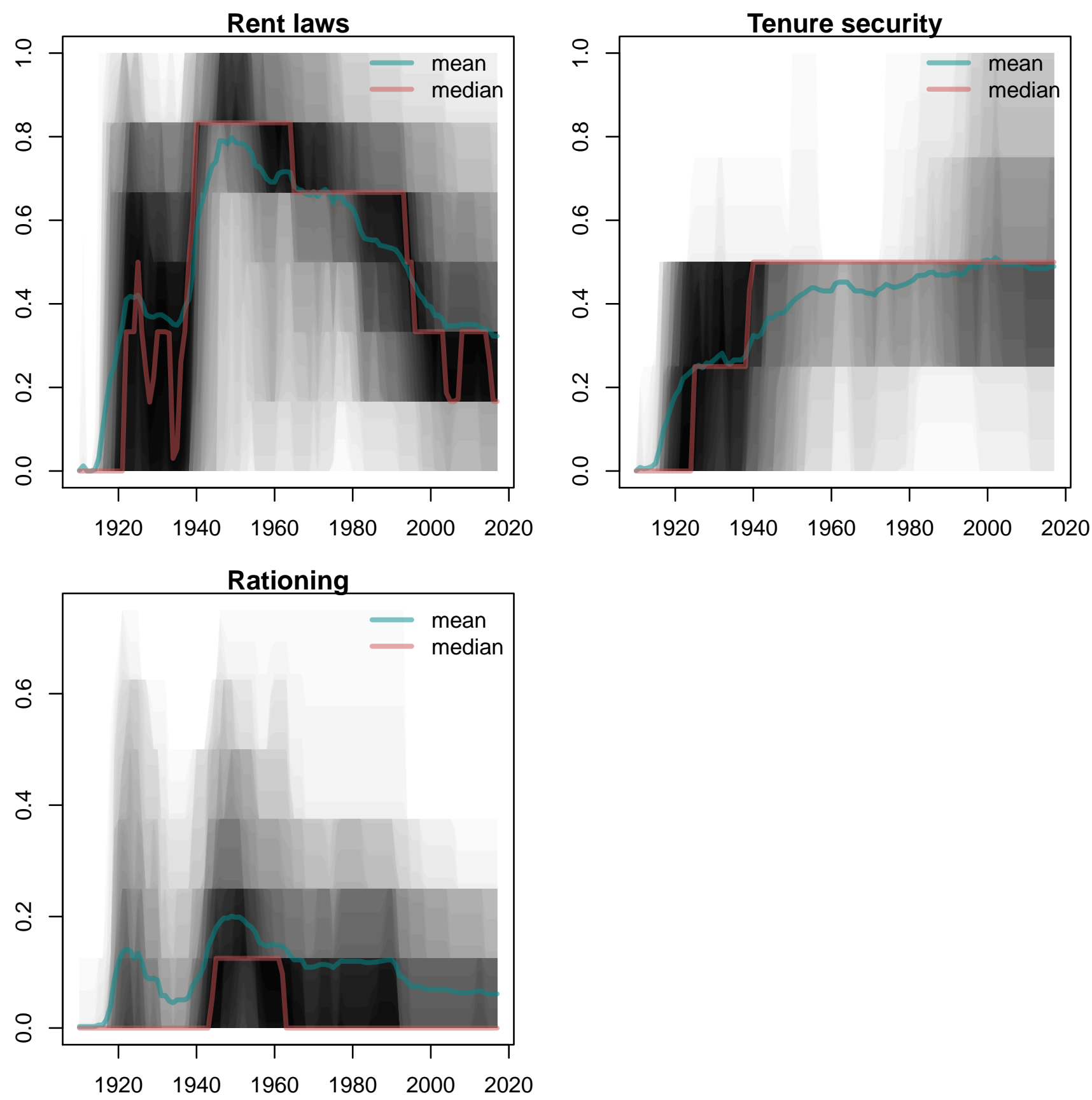
Figure 6: Rent control intensity by continents
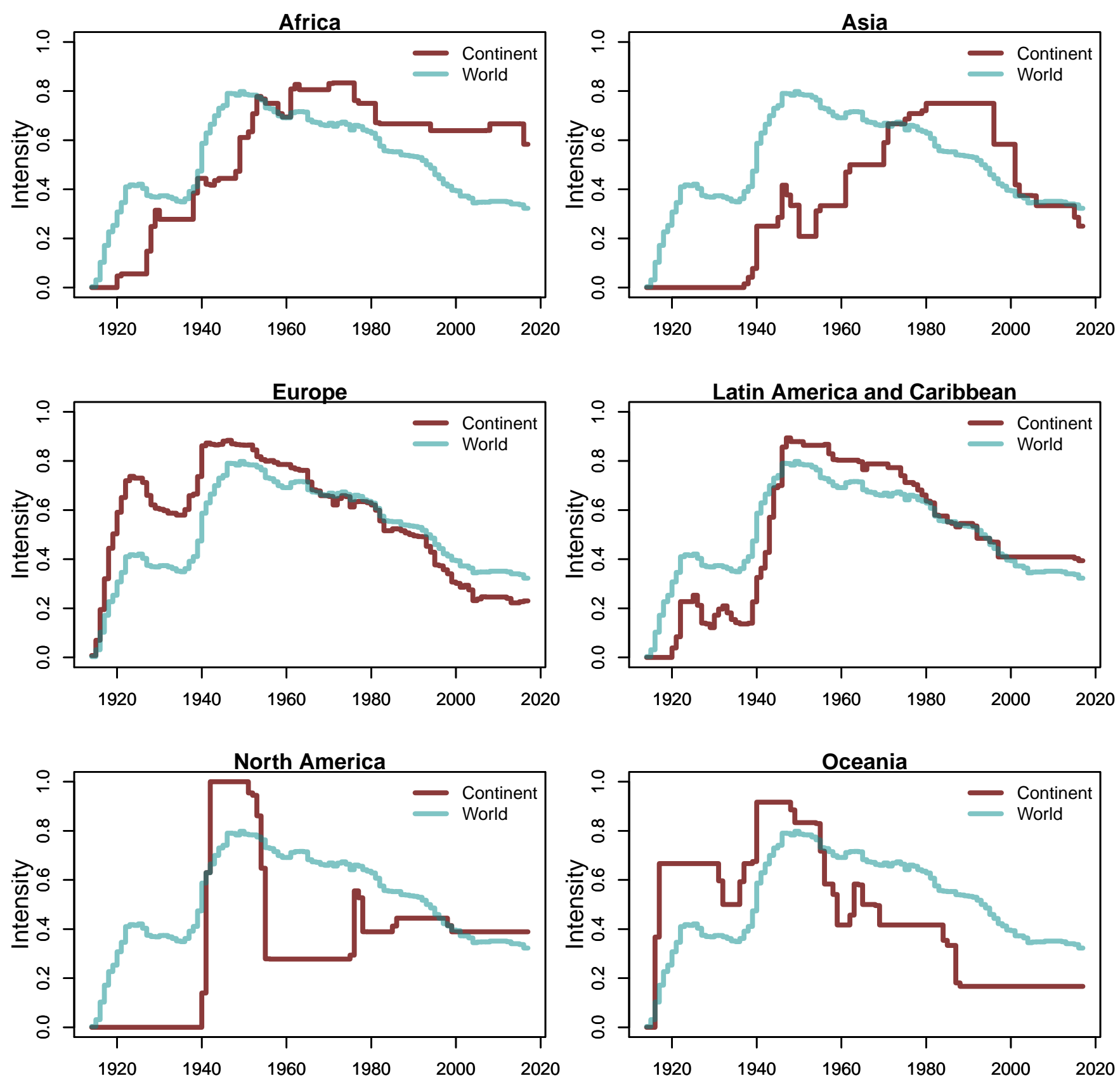
Figure 7: Generations of rent control by continent
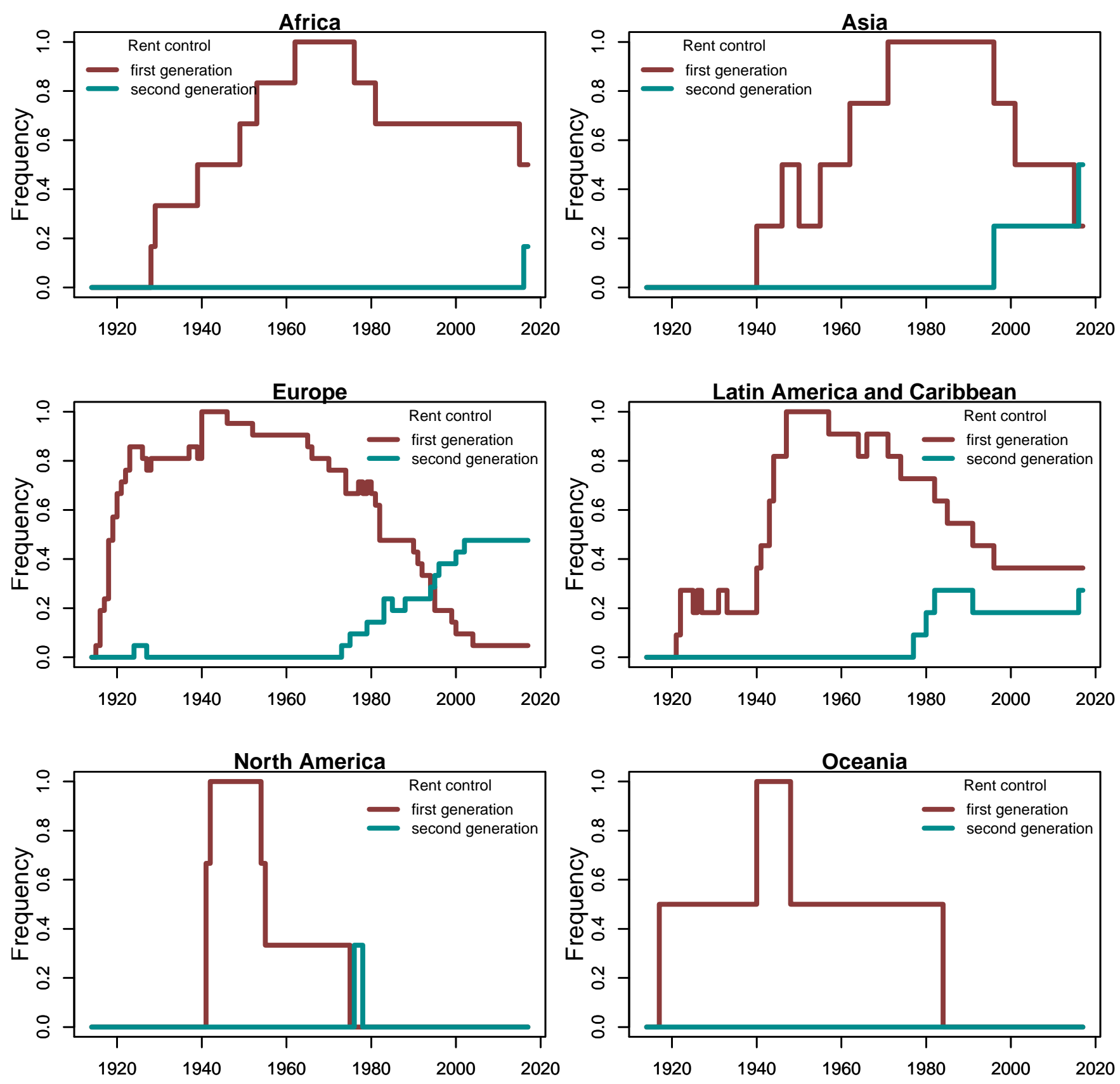
Figure 8: Tenure security intensity by continents
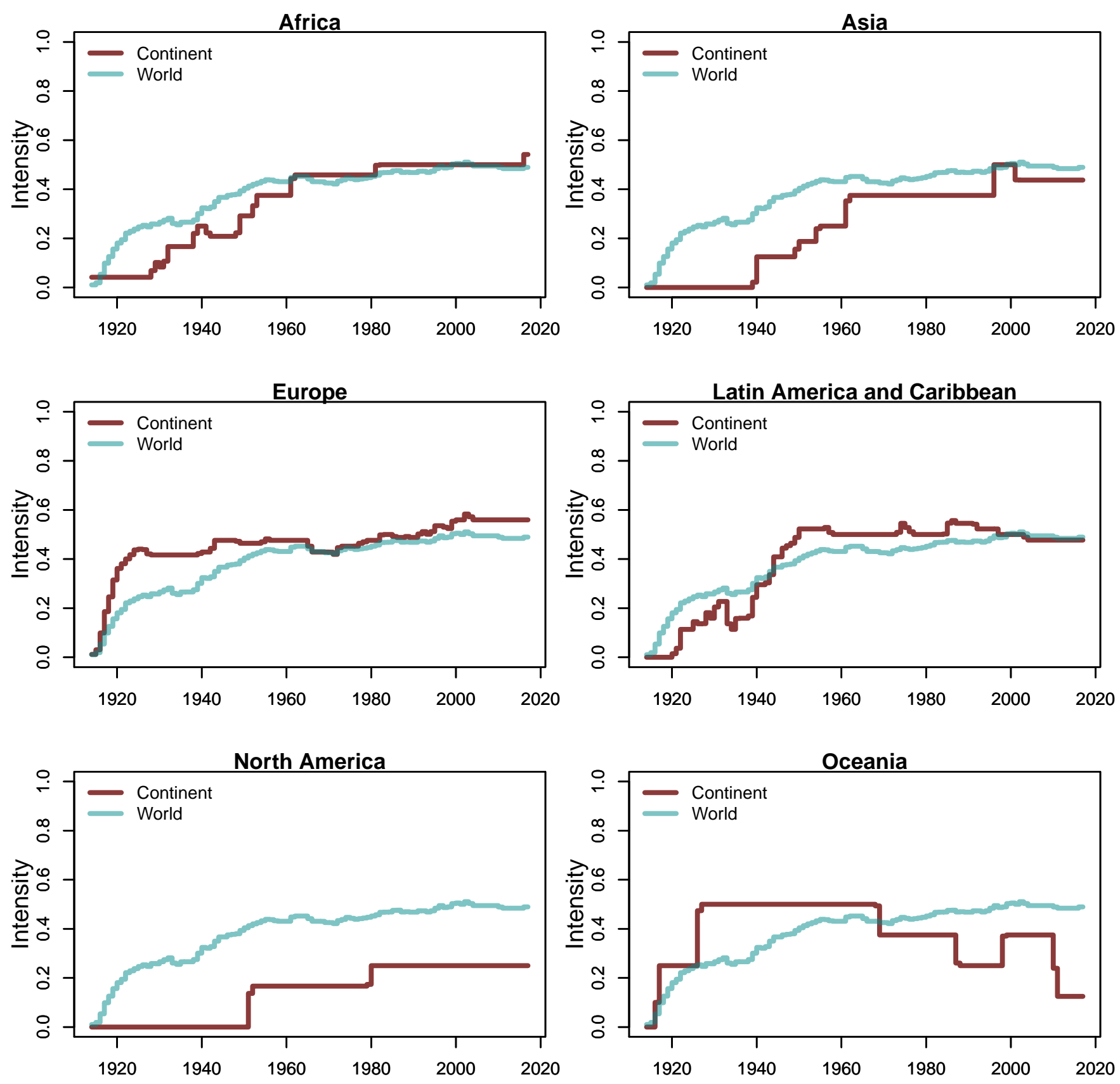
Figure 9: Housing rationing intensity by continents
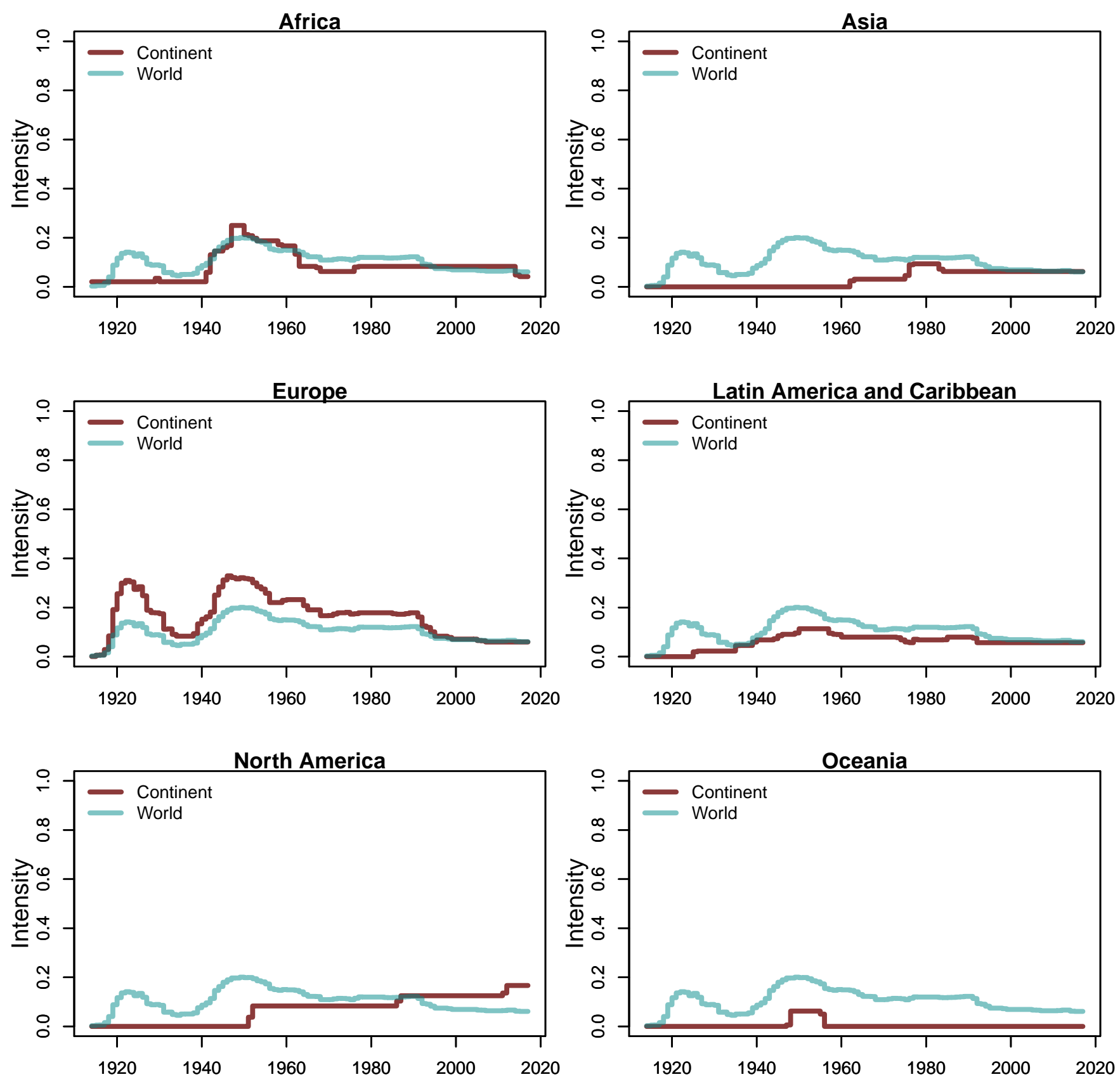
Figure 10: Cluster-based trajectories of housing regulation intensity
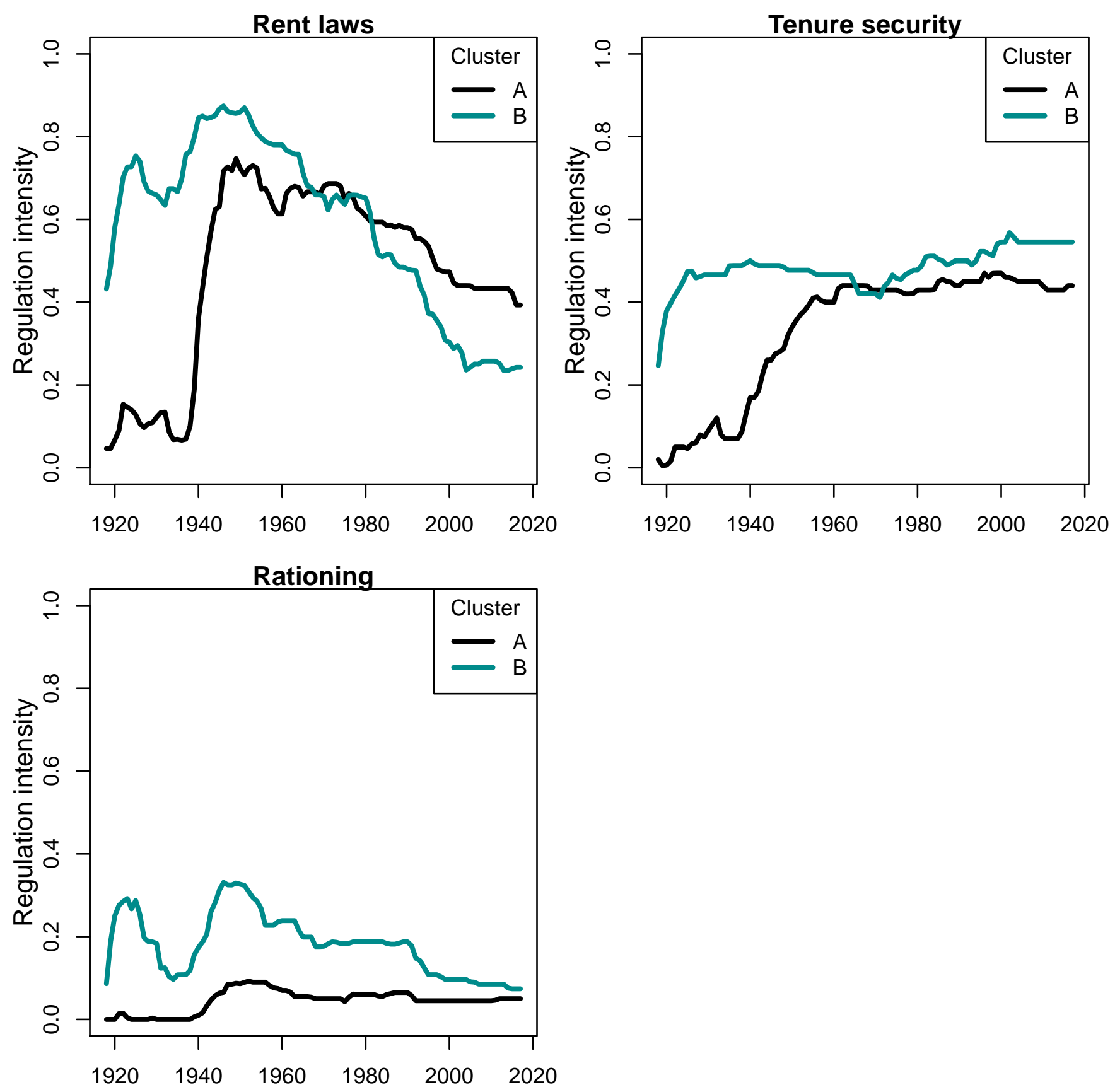

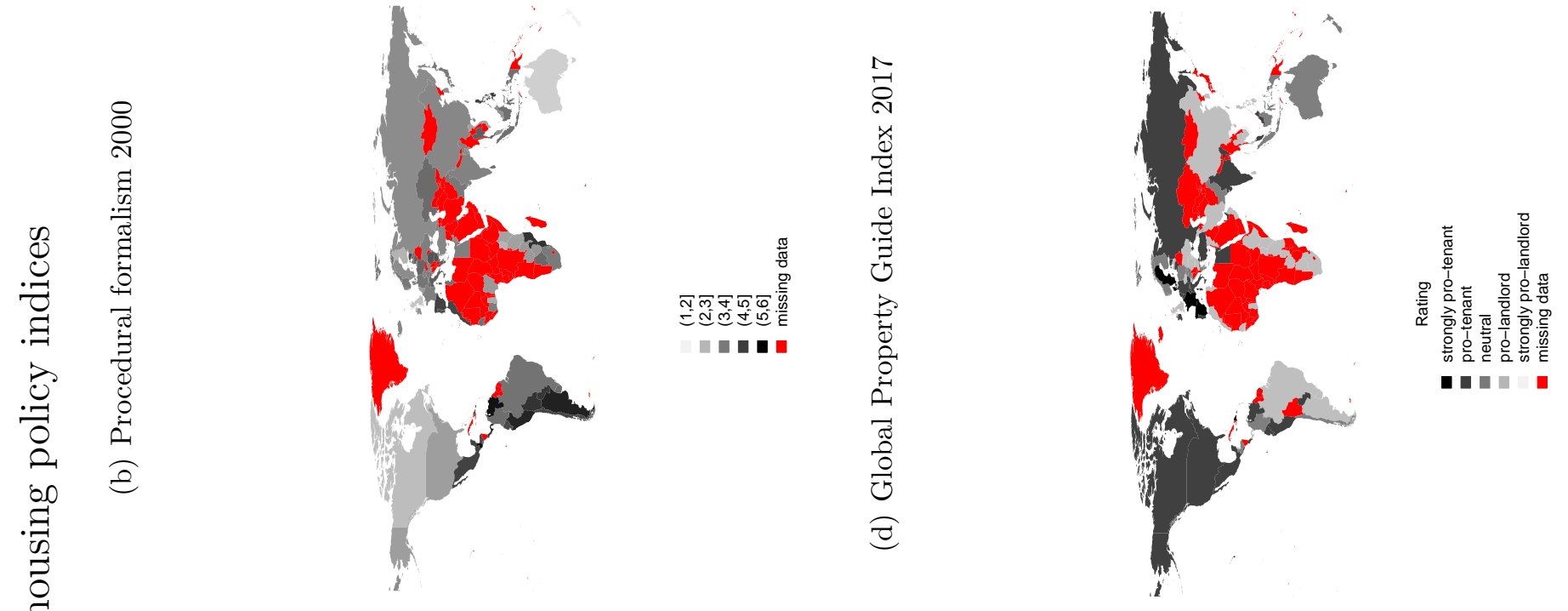

葛

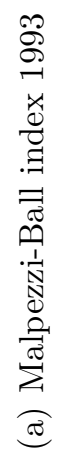
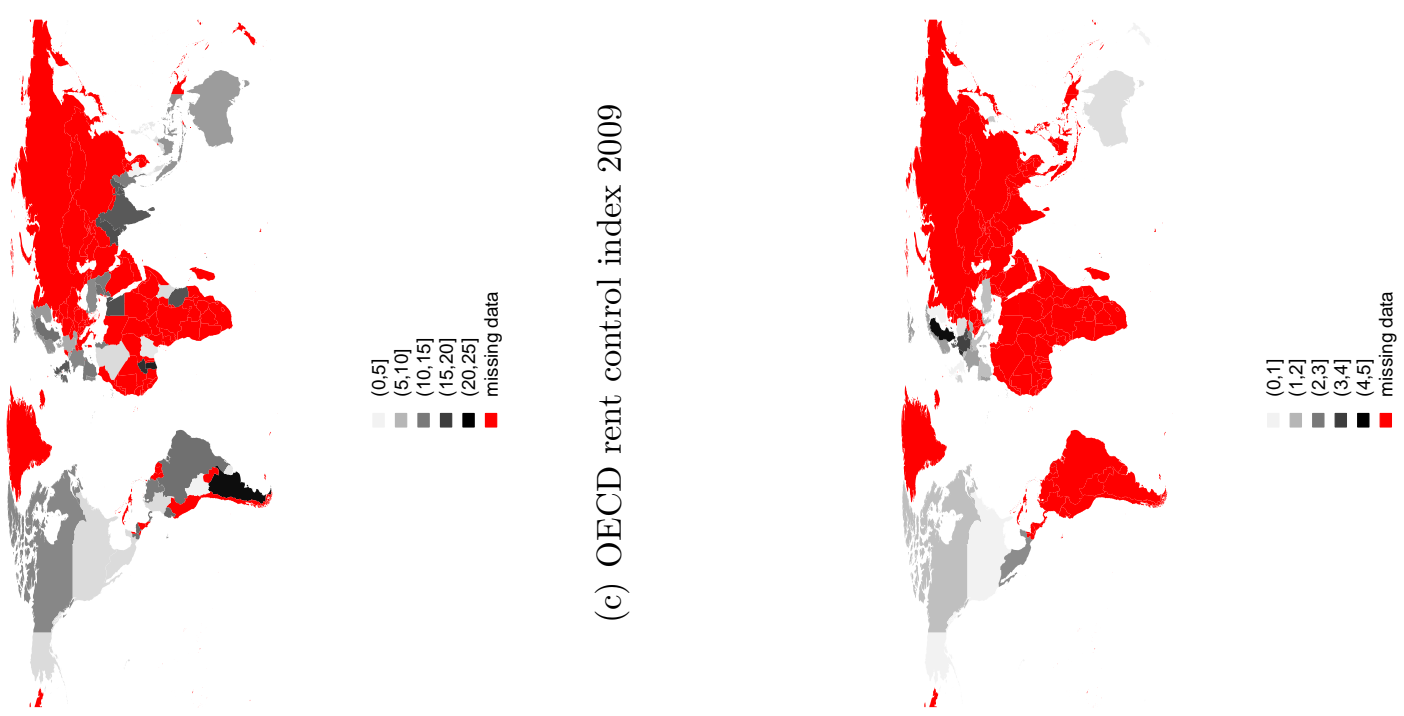